UNIVERSIDADE DE BRASÍLIA

FACULDADE DE TECNOLOGIA DEPARTAMENTO DE ENGENHARIA MECÂNICA

\title{
ESTUDO DA INFLUÊNCIA DO TEMPO DA MOAGEM NA OBTENÇÃO DA LIGA Cu-13Al-4Ni VIA METALURGIA DO PÓ
}

\section{LARA JARDIM GROSSI}

ORIENTADORA: PALLOMA VIEIRA MUTERLLE

DISSERTAÇÃO DE MESTRADO EM CIÊNCIAS MECÂNICAS

PUBLICAÇÃO: ENM.DM- 247/2016 BRASÍLIA/DF: OUTUBRO/2016 


\section{UNIVERSIDADE DE BRASÍLIA}

FACULDADE DE TECNOLOGIA

DEPARTAMENTO DE ENGENHARIA MECÂNICA

\section{ESTUDO DA INFLUÊNCIA DO TEMPO DA MOAGEM NA OBTENÇÃO DA LIGA Cu-13Al-4Ni VIA METALURGIA DO PÓ}

\section{LARA JARDIM GROSSI}

DISSERTAÇÃO DE MESTRADO SUBMETIDA AO DEPARTAMENTO DE ENGENHARIA MECÂNICA DA FACULDADE DE TECNOLOGIA DA UNIVERSIDADE DE BRASÍLIA, COMO PARTE DOS REQUISITOS NECESSÁRIOS PARA A OBTENÇÃO DO GRAU DE MESTRE EM CIÊNCIAS MECÂNICAS.

APROVADA POR:

Prof. Dr ${ }^{\mathrm{a}}$. Palloma Vieira Muterlle (Orientador)

Prof. Dr .Cosme Roberto Moreira da Silva (Examinador Interno)

Prof. Dr. Edson Paulo Silva

(Examinador Externo) 


\section{FICHA CATALOGRÁFICA}

\section{LARA JARDIM GROSSI}

Estudo da influência do tempo de moagem na obtenção da liga $\mathrm{Cu}-13 \mathrm{Al}-4 \mathrm{Ni}$ via metalurgia do pó. [Distrito Federal] 2016.

xv, 90p. 210 x 297 mm (ENC/FT/UnB, Mestre, Ciências Mecânicas, 2016).

Dissertação de Mestrado - Universidade de Brasília.

Faculdade de Tecnologia

Departamento de Engenharia Mecânica
1. Metalurgia do pó
2. Moagem de alta energia
3. Liga CuAlNi
4. Tempo de moagem
I. ENC/FT/UnB
II. Título (série)

\section{REFERÊNCIA BIBLIOGRÁFICA}

GROSSI, J. L. (2016). Estudo da influência do tempo de moagem na obtenção da liga Cu-13Al-4Ni via metalurgia do pó. Dissertação de Mestrado em Ciências Mecânicas. Publicação ENM.DM- 247/2016 Departamento de Engenharia Mecânica. Universidade de Brasília. Brasília DF, 90p.

\section{CESSÃO DE DIREITOS}

AUTOR: Lara Jardim Grossi

TÍTULO: Estudo da influência do tempo de moagem na obtenção da liga Cu-13Al-4Ni via metalurgia do pó

\section{GRAU: Mestre ANO: 2016}

É concedida à Universidade de Brasília permissão para reproduzir cópias desta dissertação de mestrado e para emprestar ou vender tais cópias somente para propósitos acadêmicos e científicos. O autor reserva outros direitos de publicação e nenhuma parte desta dissertação de mestrado pode ser reproduzida sem a autorização por escrito do autor.

Lara Jardim Grossi

E-mail: larajgrossi@yahoo.com.br 


\section{DEDICATÓRIA}

Dedico este trabalho ao meu pai Miguel e à minha mãe Italia, pois com amor, dedicação e carinho me fizeram vencer mais esta etapa.

Aos meus irmãos pelo cuidado e incentivo. 


\section{AGRADECIMENTOS}

Agradeço primeiramente a Deus por sempre guiar minha vida me dando força para enfrentar os desafios.

Ao meu pai e minha mãe pelo apoio, amor e incentivo nesta caminhada e em todos os momentos da minha vida. Nenhuma conquista seria possível sem eles.

Aos meus irmãos Bruno e Breno pelo carinho, ajuda e apoio.

Ao Renan pelo amor, incentivo e companheirismo.

À Luiza pela amizade, ajuda e bons momentos que passamos juntas em Brasília.

Agradeço a Professora Palloma Vieira Muterlle pela orientação durante o desenvolvimento do meu trabalho.

Aos Professores Cosme Roberto Moreira da Silva, Jorge Luiz de Almeida Ferreira, Daniel Rosa e Rodrigo Arbey Muñoz Meneses pelos conhecimentos transmitidos e incentivos durante a realização do meu trabalho.

Aos professores e alunos do Instituto de Física da UnB, em especial ao Professor José Antônio Coaquira e ao aluno de doutorado Marco Antonio Martinez pela disponibilidade na utilização de equipamentos fundamentais no meu trabalho.

À CAPES pela concessão da bolsa de mestrado.

Aos técnicos e funcionários do SG9

A todos meus amigos, em especial à Kátia Bianchi, Annalycia Teixeira, Andressa Alves, Lara Souza, Clícia Naldoni, Karl Acerbi, Bruno Ferreira, Edson Almeida e Luiz Otávio Peçanha que mesmo longe me apoiaram durante toda esta trajetória.

Aos amigos do mestrado que levarei para toda a vida Bruno Cavalcante, Flávia Barcelos Gustavo Reinke, Karen Fabara, Naya Damasceno, Nilo Brandão, Paola Cajas, Raquel Araújo, Tadeu Castro e Thiago Miranda. Obrigada pelo agradável convívio e ajudas fundamentais para a conclusão deste trabalho. 


\section{RESUMO}

O presente trabalho estuda a influência do tempo da moagem de alta energia nas características, como dureza e densidade, da liga $\mathrm{Cu}-13 \mathrm{Al}-4 \mathrm{Ni}$ obtida pelo processo de metalurgia do pó. O estudo desta liga vem tendo grande crescimento uma vez que, esta possui alta aplicabilidade na indústria e é passível do efeito memória de forma. Inicialmente, os pós elementares de cobre, alumínio e níquel foram caracterizados em relação à morfologia e a pureza, além da determinação da temperatura de fusão de cada um de forma individual. Observou-se que todos os pós caracterizados apresentaram pureza acima de 99,5\% sendo adequados para a utilização na técnica de metalurgia do pó. Os componentes da liga, nas proporções adequadas, forma inseridos em um moinho de bolas planetário e submetidos à moagem por tempos de 2, 4, 8 e 16 horas ao vácuo obedecendo aos mesmos procedimentos e parâmetros evitando que variações na moagem interferissem no resultado final. As densidades aparentes dos pós já moídos foram calculadas e observou-se que o aumento do tempo de moagem diminui o valor desta densidade devido à deformação plástica dos elementos envolvidos. Os pós moídos foram compactados uniaxialmente a frio, utilizando a pressão específica de cada amostra que, foi determinada através da construção de curvas de compressibilidade. As densidades a verde foram calculadas e os resultados obtidos indicaram que o aumento do tempo de moagem provoca a diminuição do seu valor. Os compactados foram sinterizados a $1000^{\circ} \mathrm{C}$ por uma hora e meia em atmosfera de argônio. As densidades e, consequentemente, as porosidades das amostras sinterizadas foram calculadas. As melhores densificações, em relação à densidade teórica, foram obtidas para os tempos de moagem de 4 e 8 horas, que apresentaram, respectivamente, a porcentagem de porosidade de $21,419 \%$ e $21,628 \%$. Estudos de calorimetria diferencial de varredura confirmaram que nenhuma das ligas em estudo apresentou o efeito memória de forma sugerindo que são necessárias outras etapas para possibilitar o aparecimento desta característica. Os resultados de DRX confirmaram a presença das fases $\gamma_{2}, \alpha$ e AlNi formadas após a sinterização. Além disso, o aumento do tempo de moagem favoreceu o surgimento das fases $\gamma_{2}$ e AlNi. O valor mais elevado de microdureza, 237,080 HV/10 gf, foi obtido para as amostras que sofreram moagem de 4 horas. Desta forma, 4 horas de moagem foi o tempo ideal, em relação à densificação e microdureza, para a obtenção da liga CuAlNi considerando os parâmetros utilizados neste trabalho. 


\section{ABSTRACT}

This work studies the influence of the high energy milling time in the manufacture of $\mathrm{Cu}-13 \mathrm{Al}-4 \mathrm{Ni}$ alloy by powder metallurgy process, as well as, the finals characteristics of the products. The study of this alloy has had growth since it has high applicability in the industry and is liable of shape memory. Firstly, the elementary powders of copper, aluminum and nickel were characterized in regarding of the morphology, purity and melting temperature of each individual element. All powders that were analyzed have showed purity over than 99,5\%, suitable for the powder metallurgy technic. The components of alloy, in the correct proportions, were inserted in a Planetary Balls Mill and have been submitted to milling for 2, 4, 8 and 16 hours following the same procedures and parameters to prevent that variations interfere in the final result. The apparent densities of the milled powders were calculated and, the results have showed that the increasing the milling time decreases the value of this density, because of the plastic deformation in the involved elements. The milled powders were uniaxially cold compressed, using specific pressure for each sample which, were determined through the construction of compressibility curves for the four different milling times. The green densities were calculated and, the results have showed that the milling time increase causes the decrease of this density. The compressed were sintered at $1000{ }^{\circ} \mathrm{C}$ for 90 minutes in argon atmosphere. The densities, and consequently, the porosity were determined. The best densifications, in relation to theoretical density, were obtained for the milling time of 4 and 8 hours, which have showed, respectively, the percentage of porosity of $21,419 \%$ and $21,628 \%$. Studies of Differential Scanning Calorimetry have confirmed that the alloys didn't show the shape memory effect, suggesting that are necessary others steps to possibility the appearance of this characteristic. The DRX results have confirmed the presence of $\gamma_{2}, \alpha$ e AlN i phases formed after the slow cooling at an oven. Furthermore, the increasing of the milling time has favored the appearance of $\gamma_{2}$ and AlNi phases. The higher value of microhardness, 237,080 HV/10 gf, was obtained for the samples which have been milled for 4 hours. Thus, 4 hours was the ideal milling time, in relation to densification and microhardness for obtain the $\mathrm{CuAlNi}$ alloy considering the parameters used in this work. 


\section{SUMÁRIO}

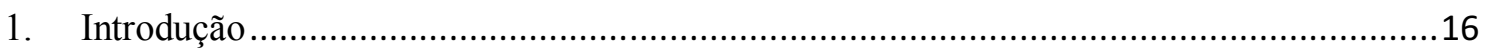

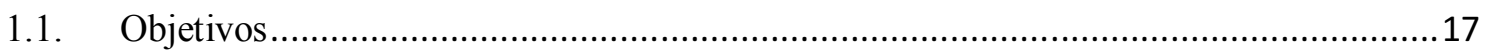

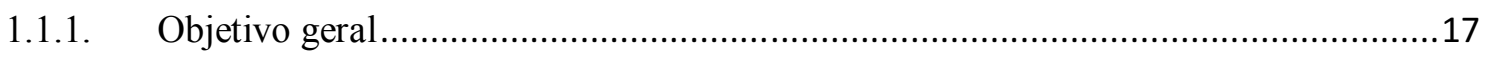

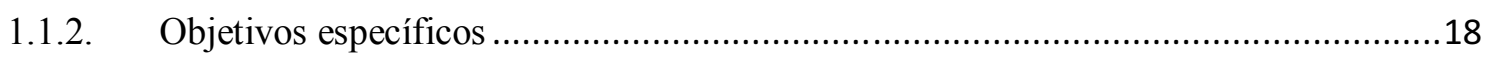

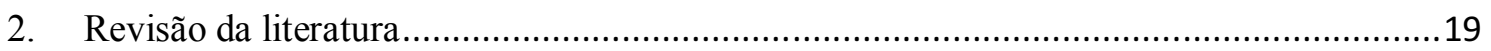

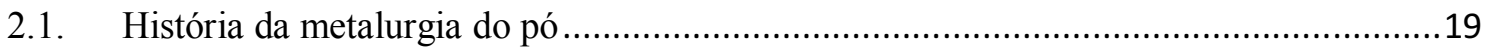

2.2. Aplicações da técnica de metalurgia do pó ....................................................................20

2.3. Vantagens e desvantagens da metalurgia do pó ...........................................................20

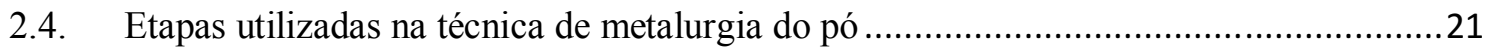

2.4.1. Caracterização dos pós utilizados como matéria-prima ...............................................21

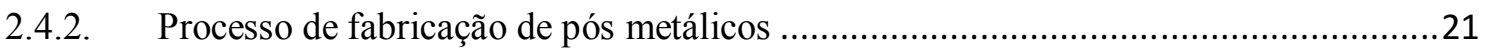

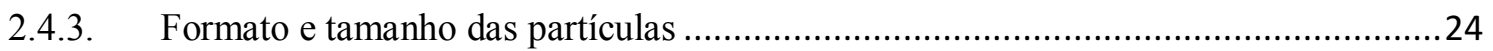

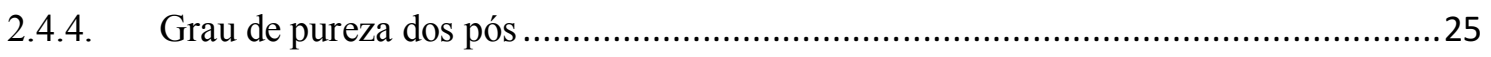

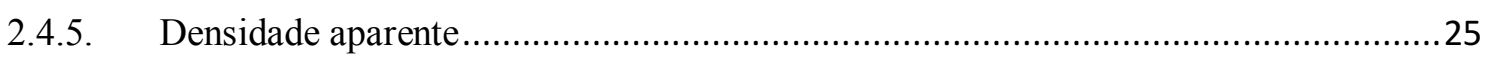

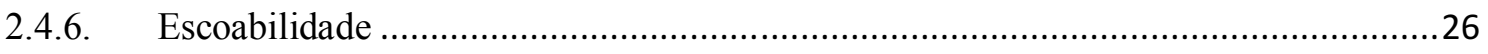

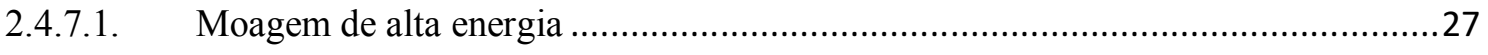

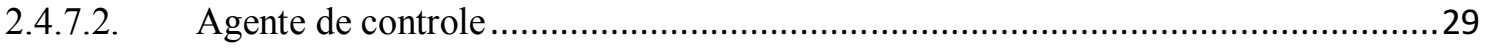

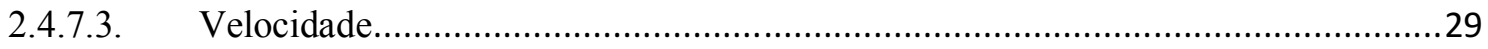

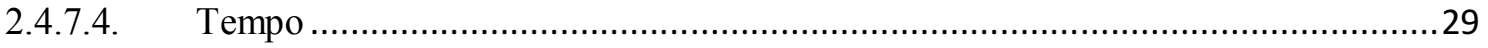

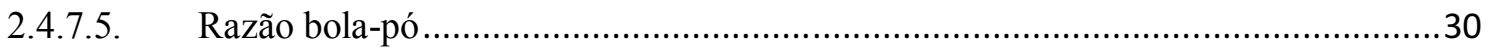

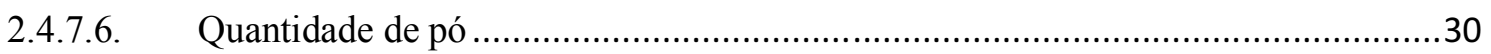

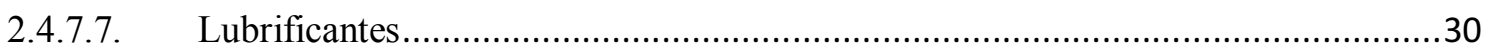

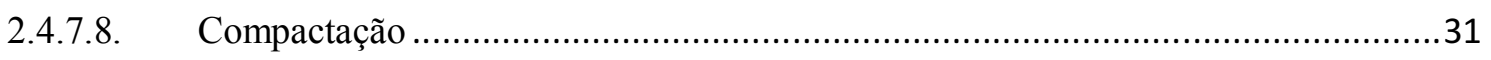

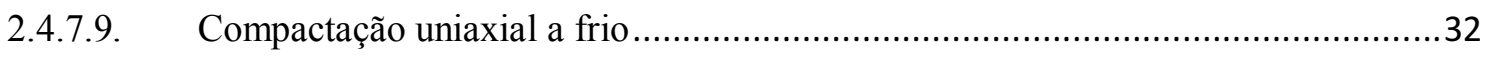

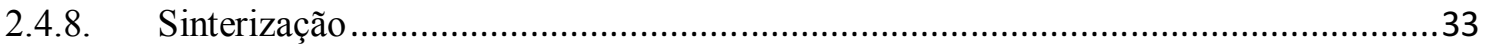

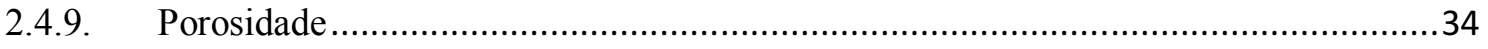

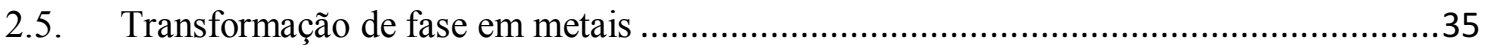

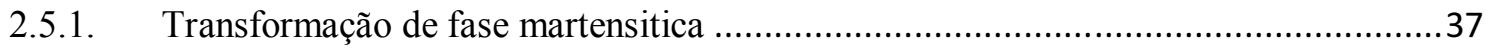

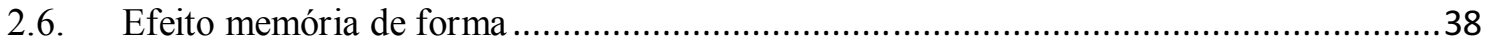

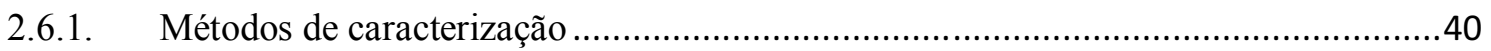

2.6.2. Aplicação das ligas com efeito memória de forma .....................................................41

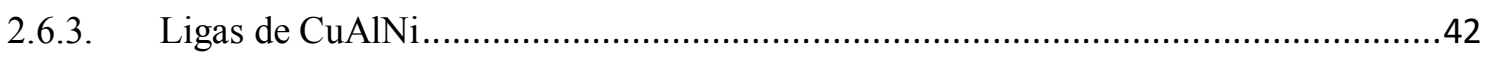

2.6.4. Ligas CuAlNi fabricadas pelo processo de metalurgia do pó ....................................45 


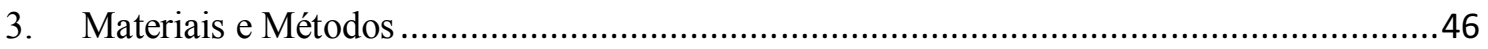

3.1. Caracterização dos pós elementares ……................................................................... 47

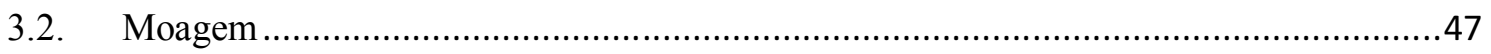

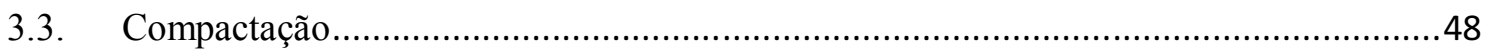

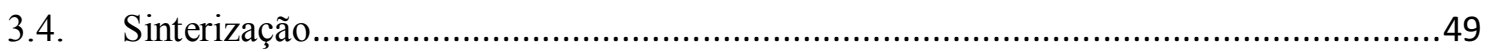

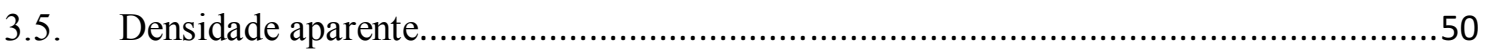

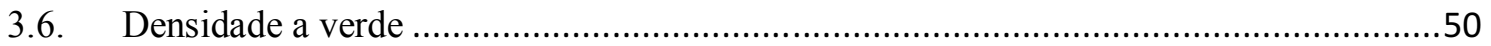

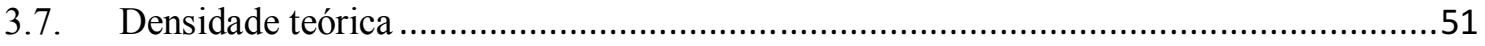

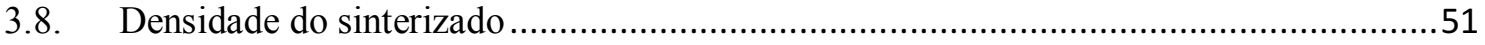

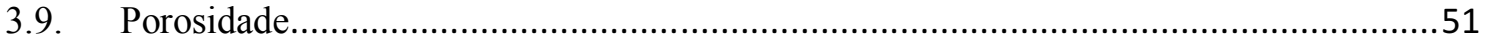

3.10. Análise DSC das peças sinterizadas .....................................................................52

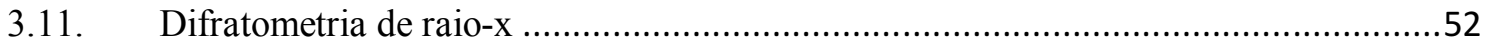

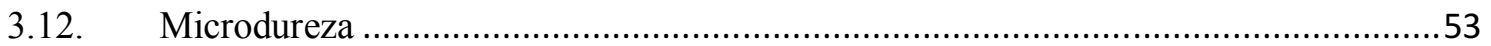

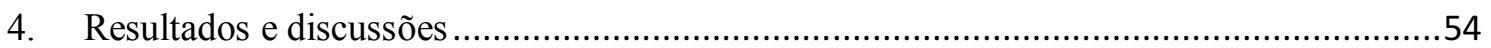

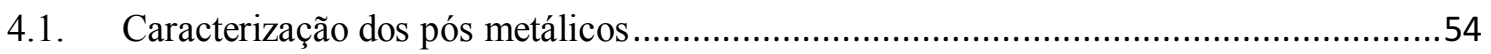

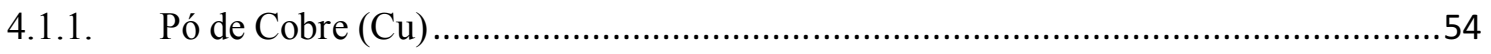

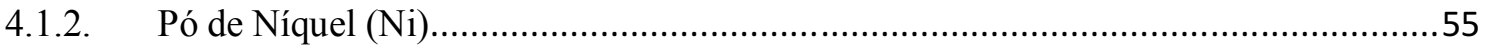

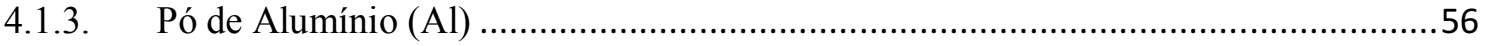

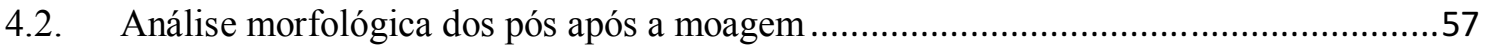

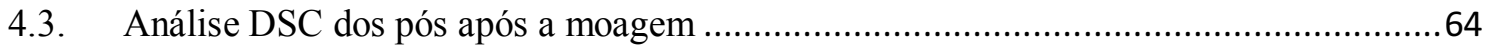

4.4. Cálculo da densidade aparente dos pós após a moagem..............................................64

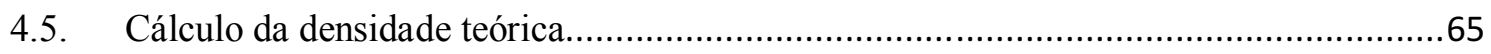

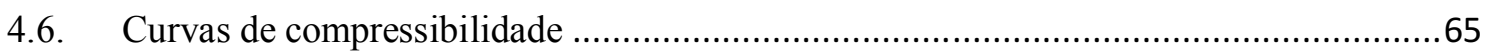

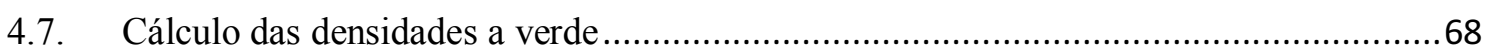

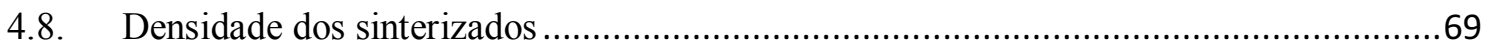

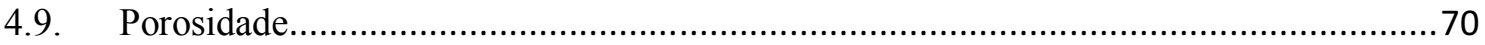

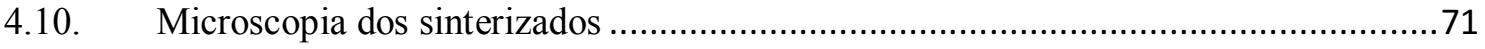

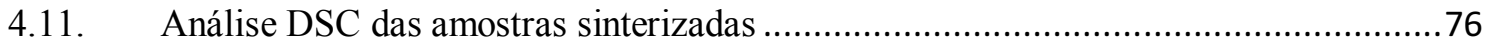

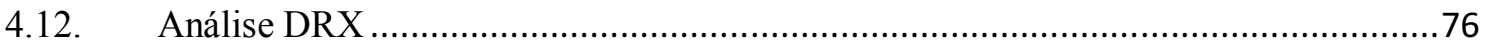

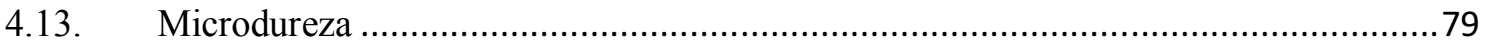

5. Conclusões e sugestões para trabalhos futuros ........................................................... 80

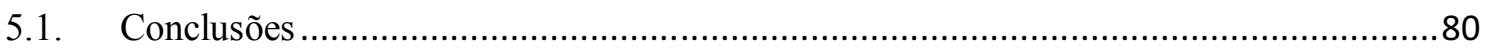

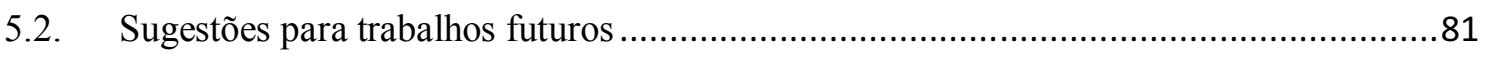

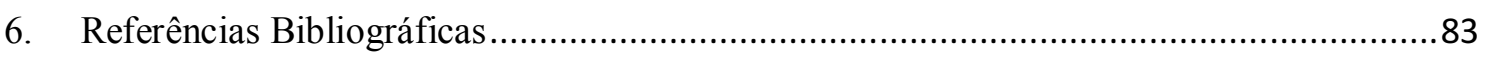


ANEXO I

ANEXO II ... 
$\begin{array}{ll}\text { Figura 2.1: Processo de atomização } & 23\end{array}$

Figura 2.2: Método de deposição eletrolítica para a obtenção de pós de ferro 24

$\begin{array}{ll}\text { Figura 2.3: Morfologia das partículas metálicas } & 25\end{array}$

Figura 2.4: Desenho esquemático do Funil de Hall. Utilizado para medição de 26 escoabilidade e densidade aparente

Figura 2.5: Eventos que ocorrem em materiais dúcteis durante a moagem de alta 28 energia

$\begin{array}{ll}\text { Figura 2.6: Esquema de um moinho agitador } & 29\end{array}$

Figura 2.7: Compactação uniaxial a frio $\quad 32$

Figura 2.8: Principais estágios da sinterização 34

Figura 2.9: Evolução da região de contato e da variação da porosidade no decorrer da 35 sinterização

Figura 2.10: Modelo simplificado da transformação martensitica 37

Figura 2.11: Variação da energia em relação à temperatura 38

Figura 2.12: Curva característica da transformação martensítica termoelástica 39

Figura 2.13: Fase mastensítica e austenítica para liga Ni-Ti 39

Figura 2.14: Curva típica de tensão-deformação para diferentes temperaturas relativas 41 de transformações

Figura 2.15: Influência da quantidade de Al na temperatura de mudança de fase 43

Figura 2.16: : Diagramas de fases da liga CuAlNi seção de 3\% de Ni em peso 44

Figura 2.17: Diagramas de fases ternário da liga CuAlNi 44

Figura 3.1: Fluxograma das etapas do trabalho 46

$\begin{array}{ll}\text { Figura 3.2: Procedimento de moagem. } & 48\end{array}$

Figura 3.3: Desenho esquemático da matriz de compactação 48

$\begin{array}{ll}\text { Figura 3.4: Etapas da sinterização } & 49\end{array}$

$\begin{array}{ll}\text { Figura 4.1: Pó de Cobre } & 54\end{array}$

Figura 4.2: Resultado da EDS para o pó de Cobre 55

Figura 4.3: Pó de Níquel

Figura 4.4: Resultado da EDS para o pó de Níquel 56 
Figura 4.5: Pó de Alumínio

Figura 4.6: Resultado da EDS para o pó de Alumínio 57

Figura 4.7: Pós metálicos após diferentes tempos de moagem 58

Figura 4.8: Pós metálicos sem sofrerem moagem de alta energia 59

$\begin{array}{ll}\text { Figura 4.9: Pós metálicos após moagem de } 2 \mathrm{~h} & 60\end{array}$

$\begin{array}{ll}\text { Figura 4.10: Pós metálicos após moagem de 4h } & 61\end{array}$

$\begin{array}{ll}\text { Figura 4.11: Pós metálicos após moagem de } 8 \mathrm{~h} & 62\end{array}$

Figura 4.12: Pós metálicos após moagem de 16h 62

Figura 4.13: Pós metálicos após diferentes tempos de moagem 63

Figura 4.14: Gráfico de barras da densidade aparente em relação ao tempo de moagem 65

Figura 4.15: Curva de compressibilidade para os pós moídos por 2 horas 66

Figura 4.16: Curva de compressibilidade para os pós moídos por 4 horas 66

Figura 4.17: Curva de compressibilidade para os pós moídos por 8 horas 67

Figura 4.18: Curva de compressibilidade para os pós moídos por 16 horas 67

Figura 4.19: Evolução da densidade a verde com o tempo de moagem 68

Figura 4.20: Gráfico de barras da densidade do sinterizado em relação ao tempo de 70 moagem

$\begin{array}{ll}\text { Figura 4.21: Imagens dos sinterizados em diferentes tempos moagem } & 72\end{array}$

Figura 4.22: Imagens dos sinterizados com moagem de 2h 73

$\begin{array}{ll}\text { Figura 4.23: Imagens dos sinterizados com moagem de 4h } & 73\end{array}$

$\begin{array}{ll}\text { Figura 4.24: Imagens dos sinterizados com moagem de 8h } & 74\end{array}$

$\begin{array}{ll}\text { Figura 4.25: Imagens dos sinterizados com moagem de 16h } & 74\end{array}$

Figura 4.26: Mapa de raio-x da amostra sinterizada com moagem de 4 horas 75

Figura 4.27: DRX para os sinterizados com moagem de 2 horas 76

$\begin{array}{ll}\text { Figura 4.28: DRX para os sinterizados com moagem de } 4 \text { horas } & 77\end{array}$

$\begin{array}{ll}\text { Figura 4.29: DRX para os sinterizados com moagem de } 8 \text { horas. } & 77\end{array}$

$\begin{array}{ll}\text { Figura 4.30: DRX para os sinterizados com moagem de } 16 \text { horas. } & 78\end{array}$ 
Tabela 1: Valores para as densidades aparentes dos pós após a moagem 64

Tabela 2: Valores para os cálculos das densidades a verde das misturas 68

Tabela 3: Densidade dos sinterizados 69

Tabela 4: Porosidade dos sinterizados 71

Tabela 5: Valores obtidos para microdureza Vickers (10 gf) 


\section{LISTA DE SÍMBOLOS}

$\mathrm{A}_{\mathrm{s}}$

$\mathrm{M}_{\mathrm{s}}$

$\Delta \mathrm{H}$

$\Delta \mathrm{Q}$

$\rho_{\mathrm{t}}$

$\mathrm{w}_{\mathrm{Cu}}$

$\mathrm{w}_{\mathrm{Al}}$

$\mathrm{w}_{\mathrm{Ni}}$

$\mathrm{w}_{\text {est }}$

$\rho_{\mathrm{Cu}}$

$\rho_{\mathrm{Al}}$

$\rho_{\mathrm{Ni}}$

$\rho_{\text {est }}$

$\varphi$

$\mathrm{Cu}$

Al

$\mathrm{Ni}$
Austenite start

Martensite start

Variação de entalpia

Efeito calorífico

Densidade teórica da mistura

Percentual em peso do cobre

Percentual em peso do alumínio

Percentual em peso de níquel

Percentual em peso do estearato de zinco

Densidade teórica do cobre

Densidade teórica do alumínio

Densidade teórica do níquel

Densidade teórica do estearato de zinco

Porosidade

Cobre

Alumínio

Níquel 


\section{LISTA DE ABREVIATURAS}

SMA

DRX

DSC

TM

RPM

MEV

EDS

BSE

TGA

HV
Shape Memory Alloys

Difratometria de Raio-x

Differential Scanning Calorimetry

Transformação de fase martensítica

Rotações por minuto

Microscópio Eletrônico de Varredura

Espectroscopia de Energia Dispersiva

Backscattering electrons

Análise Termogravimétrica

Dureza Vickers 


\section{Introdução}

A liga CuAlNi pertence ao conjunto de ligas denominadas ligas memória de forma (SMA, do inglês Shape Memory Alloys). Estes materiais vêm sendo amplamente pesquisados por possuírem características específicas como o efeito memória de forma e a pseudoelasticidade, que são utilizadas na área médica, em controle de vibrações, no setor automotivo, dentre outros. Atualmente, as ligas $\mathrm{SMA}_{s}$ mais estudadas e utilizadas são as de NiTi, CuAlNi, CuZnNi, CuAlBe e CuAlMn. As NiTi são as que apresentam melhores propriedades termoelásticas, porém possuem elevado custo, encarecendo, ou, em muitas vezes inviabilizando seu uso. Neste contexto, surge o interesse em utilizar a liga $\mathrm{CuAlNi}$ por possuir baixo custo, facilidade de obtenção e altas temperaturas de transformações (WEE et al. 2015) (CALUÊTE, 2012).

$\mathrm{O}$ efeito memória de forma na liga CuAlNi assim como seu comportamento na transformação de fase é influenciado pela quantidade de alumínio e níquel na composição final da liga. Reduzindo a parcela de Al (abaixo de 12\%) melhoram-se as suas propriedades mecânicas, porém, afeta diretamente as transformações martensiticas. $\mathrm{A}$ introdução de $\mathrm{Ni}$ no sistema binário $\mathrm{CuAl}$ favorece a difusão do $\mathrm{Cu}$ e do $\mathrm{Al}$, contribuindo para que, durante o resfriamento, haja somente uma fase estável, a fase $\beta$. Entretanto, aumentando-se a quantidade de $\mathrm{Ni}$ a liga torna-se mais frágil. Assim, a composição química ótima e mais comercialmente utilizada para a liga CuAlNi é de aproximadamente $13 \%$ em peso de $\mathrm{Al}$ e $3-4,5 \%$ em peso de Ni e a base de cobre (OTSUKA; WAYMAN,1998).

A escolha do processo de fabricação de um material é de suma importância para obter as características finais desejadas no produto. Existem diversos métodos de fabricação da liga $\mathrm{CuAlNi}$, desde os mais tradicionais como a fundição até os estudados de forma mais recente como o processo de fusão à plasma. De forma geral, este último método vem apresentando ligas com melhores propriedades físicas e mecânicas. Outra vantagem é que processo de fusão a plasma é especialmente vantajosas quando elementos químicos reativos com atmosfera comum estão envolvidos na fabricação da liga. Porém, as ligas obtidas por este método além de possuírem custo de fabricação mais elevado, possuem, de acordo com estudos, menor densidade se comparadas com as processadas por fundição. Em ambos os casos, as ligas apresentaram o efeito memória de forma, mas com pequenas diferenças nas temperaturas de mudanças de fases. (SILVA et al., 2007). 
Outra forma de obtenção da liga CuAINi é através da técnica de metalurgia do pó, que possui vantagens em relação a outros métodos quando se trata de acabamento superficial, fabricação de grandes volumes de peças, tolerância dimensional, dentre outras. Esta técnica possui diversos parâmetros e etapas as quais devem ser monitoradas e estudadas para que as características desejadas do produto sejam alcançadas. Fatores como o tempo e tipo de moagem, adição de lubrificante, técnica de compactação, temperatura e tempo de sinterização devem ser analisados, e determinados, de acordo com os procedimentos utilizados, e com as características finais desejas para a liga. Neste contexto Tang et.al, 2007 propôs a fabricação da liga CuAlNi por metalurgia do pó utilizando moagem de alta energia, porém, com baixa rotação (100 rpm) e maiores tempos de moagem (40h) e sinterização (20h). Outros pesquisadores, como Sharma M. et al., 2011, propuseram a fabricação da liga em estudo utilizando a compactação a frio seguido de laminação a quente dentro da técnica de metalurgia do pó. Já Ibarra et al., 2005 utilizou pós de $\mathrm{Cu}, \mathrm{Al}$ e $\mathrm{Ni}$ pré ligados através do processo de atomização e compactação isostática a quente.

Este trabalho tem como objetivo obter e caracterizar a liga $\mathrm{Cu}-13 \mathrm{Al}-4 \mathrm{Ni}$ através da técnica de metalurgia do pó, utilizando como meio de mistura e homogeneização a moagem de alta energia. A proposta apresentada é um estudo de como o tempo de moagem interfere nas características da liga $\mathrm{CuAlNi}$, sendo assim, não visa obter o efeito memória de forma. É um estudo preliminar, para servir de base em posteriores pesquisas, que visam estudar os procedimentos e tratamentos térmicos adequados para a obtenção do efeito memória de forma nesta liga fabricada por metalurgia do pó pelos procedimentos apresentados neste trabalho.

Para avaliar a influência do tempo de moagem na liga obtida, realizou-se a moagem dos pós elementares durante 2, 4, 8 e 16 horas, com velocidade de $250 \mathrm{rpm}$, seguido de compactação uniaxial a frio e sinterização a $1000^{\circ} \mathrm{C}$ por uma hora e meia.

\subsection{Objetivos}

\subsubsection{Objetivo geral}

Obter e caracterizar a liga $\mathrm{Cu}-13 \mathrm{Al}-4 \mathrm{Ni}$ via metalurgia do pó, utilizando moagem de alta energia. 


\subsubsection{Objetivos específicos}

1.1.2.1. Avaliar a influência do tempo de moagem, de $2,4,8$ e 16 horas, nas características finais da liga obtidas pelo processo de metalurgia do pó;

1.1.2.2. Identificar as fases presentes no material após a sinterização através de análises de difração de raio-x;

1.1.2.3. Avaliar o comportamento da liga sinterizada em função da temperatura. 


\section{Revisão da literatura}

Para a compreensão do processo de metalurgia do pó, assim como do comportamento e da importância da ligas Cu-13Al-4Ni é necessário o estudo de cada etapa do processo de forma individual, assim como das características específicas da liga em estudo.

\subsection{História da metalurgia do pó}

A técnica da metalurgia do pó, sob o ponto de vista da indústria é recente. Porém, existem relatos da existência de peças com cerca de 6000 anos, como por exemplo, de ferro, confeccionadas a partir do pó deste metal. A utilização desta técnica para a fabricação de peças, utilizando metais com alto ponto de fusão, surgiu no início do século XIX, uma vez que, naquela época não existiam equipamentos que possibilitavam alcançar elevadas temperaturas, e assim, fundir o material. O químico Willian Wollaston, em 1829, foi o principal responsável por tornar público e produzir platina compactada a partir de pós esponjosos deste metal, assim, Wollaston é considerado o precursor da metalurgia do pó (CHIAVERINI, 2001).

Outros cientistas como Spring e Hallock, criaram diferentes misturas utilizando pós metálicos, e esta técnica ficou cada vez mais conhecida. Porém, somente no final do século passado, é que a metalurgia do pó começou a ser utilizada em larga escala. Inicialmente, esta técnica foi aplicada em metais com alto ponto de fusão como o tungstênio e molibdênio, já que nesta época não existiam equipamentos que conseguissem atingir temperaturas tão elevadas.

A partir de 1920 a técnica da metalurgia do pó começou a ter um grande crescimento, devido ao avanço da tecnologia da sinterização a vácuo. A partir daí novos produtos utilizados na indústria mecânica, em materiais de contato elétrico, dentre outros foram surgindo e alavancando a metalurgia do pó atual (CREMONEZI et al., 2009). Ao longo dos anos a metalurgia do pó foi se desenvolvendo, sendo que, após a Segunda Guerra Mundial, esta se expandiu devido à criação de novas técnicas. Então, a partir de 1960 a metalurgia do pó passou a ser utilizado na obtenção de diversas peças, utilizando várias ligas e também as superligas (CREMONEZI et al., 2009). 


\subsection{Aplicações da técnica de metalurgia do pó}

Quando se deseja fabricar um produto as escolhas da técnica e dos materiais que serão utilizados são de grande importância para a obtenção de um produto de qualidade e economicamente viável. A decisão de qual metodologia a ser utilizada deve obedecer algumas condições. Para a utilização da metalurgia do pó, estudam-se inicialmente duas condições importantes. A primeira está relacionada com o material, por exemplo, metalduro, cerâmicas, contatos elétricos, filamentos de lâmpadas, alguns tipos de filtros, imãs e pastilhas de freios, possuem fabricações economicamente viáveis somente se forem realizadas com a técnica da metalurgia do pó. Na segunda condição na qual existem outros tipos de técnicas viáveis de fabricação, se deve observar fatores como: formato e tamanho da peça, tolerâncias geométricas, composição do material, aplicação e ambiente de trabalho, propriedades mecânicas exigidas e tamanho do lote a ser fabricado. Assim, o processo de fabricação viável do material será definido de acordo com as condições existentes. (CREMONEZI et al., 2009).

Como foi dito anteriormente, alguns materiais só podem ser fabricados através da metalurgia do pó. Além disso, com esta técnica é possível realizar o controle microestrutural possibilitando uma versatilidade nas características do material produzido (MUTERLLE, 2016).

\subsection{Vantagens e desvantagens da metalurgia do pó}

Diversos fatores contribuem para que a haja um crescimento na utilização da técnica da metalurgia do pó. Ambientalmente ela é vantajosa, uma vez, que apresenta um aproveitamento da matéria prima acima de 95\%, é um processo não poluente e que exige baixa energia. Tudo isso também contribui para tornar o produto economicamente vantajoso se comparado aos obtidos por outros processos. Em relação à fabricação, a metalurgia do pó permite a obtenção de grandes volumes de peças, as quais podem apresentar formas complexas, além de possuir ótima tolerância dimensional e ótimo acabamento superficial.

As desvantagens da técnica da metalurgia do pó estão relacionadas com as dimensões e formatos da peça a ser produzida. Devido à necessidade de compactação, peças muito grandes e com cantos "vivos" se tornam inviáveis se fabricadas através da metalurgia do pó. (CHIAVERINI, 2001). 


\subsection{Etapas utilizadas na técnica de metalurgia do pó}

Para a fabricação de peças via metalurgia do pó é necessário seguir algumas etapas básicas desta técnica. Em cada etapa é preciso estabelecer parâmetros de trabalho, sendo que, estes são escolhidos de forma adequada para cada tipo de material a ser processado. A escolha desses parâmetros irá afetar de forma direta as características e qualidade do produto final.

\subsubsection{Caracterização dos pós utilizados como matéria-prima}

Para a obtenção de peças via metalurgia do pó, de forma especial as ligas metálicas, é necessário, inicialmente, caracterizar individualmente cada pó elementar que será utilizado, como matéria prima, na liga, com o intuito de entender o comportamento de cada elemento de forma individual. Diversas características e informações a respeito dos pós devem ser estudadas, analisadas e levadas em consideração antes do início do processo de fabricação do material.

Assim, os pós elementares são caracterizados em relação ao processo de fabricação, distribuição granulométrica, pureza, microestrutura e tamanho da partícula, dentre outras características que fazem parte da etapa de caracterização dos pós. Estas serão determinadas de acordo com o interesse específico de cada procedimento e material a ser produzido.

\subsubsection{Processo de fabricação de pós metálicos}

Existem diversos métodos para a obtenção dos pós-metálicos, cada um possui suas particularidades. A escolha do processo depende do tipo de material, sendo que, o mesmo pó pode ser obtido por mais de um método, que estão listados abaixo (CHIAVERINI, 2001).

- Reações químicas e decomposição;

- Atomização de metais fundidos;

- Deposição eletrolítica;

- Carbonila;

- Processamento mecânico de materiais sólidos.

Nos processos que utilizam as reações químicas e decomposição é possível que se faça o controle dos parâmetros que envolvem cada reação de forma particular, possibilitando assim, uma otimização das propriedades finais do pó obtido, como por 
exemplo, as dimensões e formas das partículas que foram geradas. Neste tipo de processo o método de redução dos óxidos metálicos, utilizando como agente redutor gás ou sólido é o mais empregado, sendo que, o ferro, cobre, tungstênio e molibdênio são os elementos mais comuns de utilização desse método na obtenção de seus pós. Para a produção do pó de cobre através de reações químicas e decomposição, utilizam-se partículas de óxidos de cobre, as quais são oxidadas ao ar com temperatura superior a $650^{\circ} \mathrm{C}$. Este óxido, por ser frágil, pode ser moído até uma granulometria de -100 mesh. Esta redução é levada através de uma correia transportadora de aço inoxidável, submetida a uma faixa de temperatura de 425 a $650^{\circ} \mathrm{C}$, e atmosfera de hidrogênio ou amônia. Este processo resultará em uma massa porosa que pode ser moída até o tamanho de interesse da partícula. Esta técnica é uma forma econômica de processamento, porém, tem como desvantagem a qualidade final do pó, que pode ser afetada por impurezas, que surgem durante o processo de redução. (CHIAVERINI, 2001) (FERREIRA, 2002).

O método denominado de atomização, apresentado na Figura 2.1, é um processo de fácil entendimento, e está sendo atualmente, amplamente utilizado. Neste método é possível obter pós de praticamente qualquer metal ou liga metálica, e seu princípio consiste na pulverização de um metal líquido, possibilitando a geração de partículas muito finas com dimensões inferiores a $150 \mu \mathrm{m}$. O processo de pulverização consiste em forçar a passagem do metal líquido em um pequeno orifício, sendo que, na saída a corrente do metal líquido é desintegrada por jatos de água, gás ou ar. Dependendo do agente de atomização, as partículas dos pós resultantes terão formatos particulares. $\mathrm{Ou}$ seja, quando se utiliza gás comprimido (argônio, hélio, ar, etc.) como agente de atomização, as partículas possuirão formatos esféricos. Neste processo é possível obter pós de ligas comuns a especiais. Já no processo que utiliza água como agente de atomização, os pós gerados possuem formatos irregulares, sendo que metais e ligas que sofrem oxidação excessiva pela água são inviáveis a sua utilização neste processo. Cobre, bronze, alumínio, estanho, magnésio, dentre outros são exemplos de metais que pode ser empregado a atomização em água. Existem outros tipos de atomização mais sofisticados, porém, não serão abordados (CHIAVERINI, 2001) (FERREIRA, 2002). 


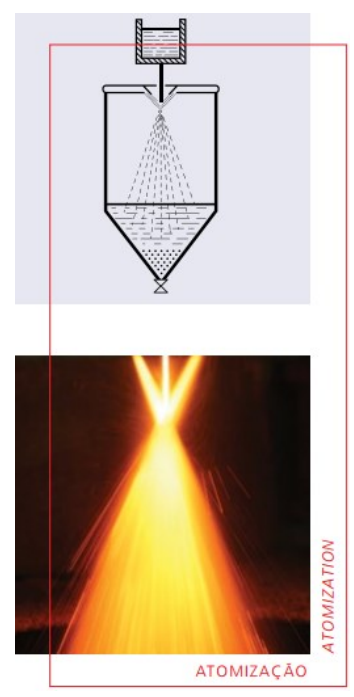

Figura 2.1: Processo de atomização (METALPÓ, 2016).

No método de deposição eletrolítica se faz a escolha da composição, concentração do eletrólito, condições de operações, dentre outros fatores. É um método bastante eficiente uma vez que, há a produção de pós metálicos de alta pureza, possuindo forma esponjosa ou dendrítica (que proporciona peças com alta densidade) e propriedades adequadas para a técnica de metalurgia do pó, como por exemplo, excelentes características de compactação. O processo inicia-se a partir de uma solução dos metais os quais serão produzidos os pós, juntamente com uma célula catódicas e outra como ânodo. Por exemplo, para o cobre, como eletrólito, utiliza-se sulfato de cobre operando com uma corrente de 500 a $1000 \mathrm{~A} / \mathrm{m}^{2}$, células de chumbo que vão atuar como cátodo, e de cobre atuando como ânodo. Após o processo de deposição ocorrer, será obtido um deposito quebradiço, que é removido por escovamento. Posteriormente, realiza-se a lavagem, filtragem e recozimento $\left(480^{\circ} \mathrm{C} \mathrm{e} 760^{\circ} \mathrm{C}\right)$ do mesmo. Para finalizar o processo, o material passa pela moagem seguida de peneiramento resultando em um pó com elevado grau de pureza (geralmente acima de 99,5\%). Este processo é mais utilizado para a produção de pós de ferro, cobre e metais preciosos (CHIAVERINI, 2001). A Figura 2.2 apresenta de forma esquemática o método de deposição eletrolítica para pós de ferro. 


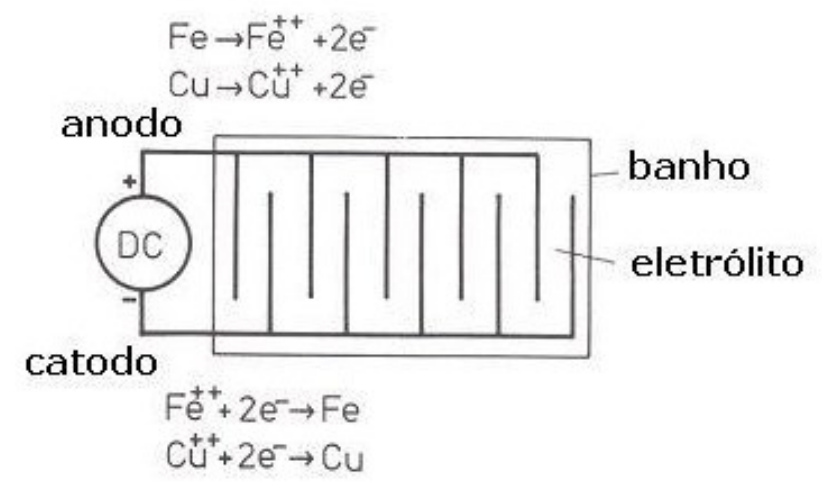

Figura 2.2: Método de deposição eletrolítica para a obtenção de pós de ferro (RODRIGUES, 2004).

O método Carbonila de produção de pós elementares é um processo de decomposição química de um composto metálico a temperaturas elevadas. Geralmente parte-se de compostos gasosos, resultando em partículas sólidas muito finas. Esta técnica é mais utilizada para a produção de pós de ferro e níquel (JESUS FILHO, 2006).

Em relação aos processos mecânicos, utiliza-se a pulverização mecânica para a obtenção dos pós metálicos. Esta técnica é aplicada em materiais frágeis e/ou em metais reativos. Esse método pode ser utilizado como um complemento aos outros citados anteriormente. O princípio é utilizar a moagem no processo, que tem como objetivo não somente a redução do tamanho das partículas, mas também, a modificação da forma da partícula, a aglomeração dos pós de natureza ou tamanhos distintos, a formação mecânica de ligas, modificações de propriedades, dentre outros efeitos que são gerados pela moagem do material (FERREIRA, 2002).

\subsubsection{Formato e tamanho das partículas}

Os formatos dos pós são determinados pelo processo de fabricação pelo qual o material passou. Com exceção do formato esférico, que é o mais ideal tendo como ponto de vista a compactação, todos os outros possuem formas irregulares. Porém, formatos irregulares proporcionam melhor sinterização, uma vez que, há a interação dos contornos das partículas. Ou seja, o formato das partículas afeta de forma significativa a densidade aparente dos pós, propriedades de compactação e sinterização (FERREIRA, 2002). Para determinar as morfologias dos pós elementares utilizam-se métodos de microscopia, como por exemplo, análises no Microscópio Eletrônico de Varredura. A Figura 2.3 apresenta algumas formas de partículas metálicas. 


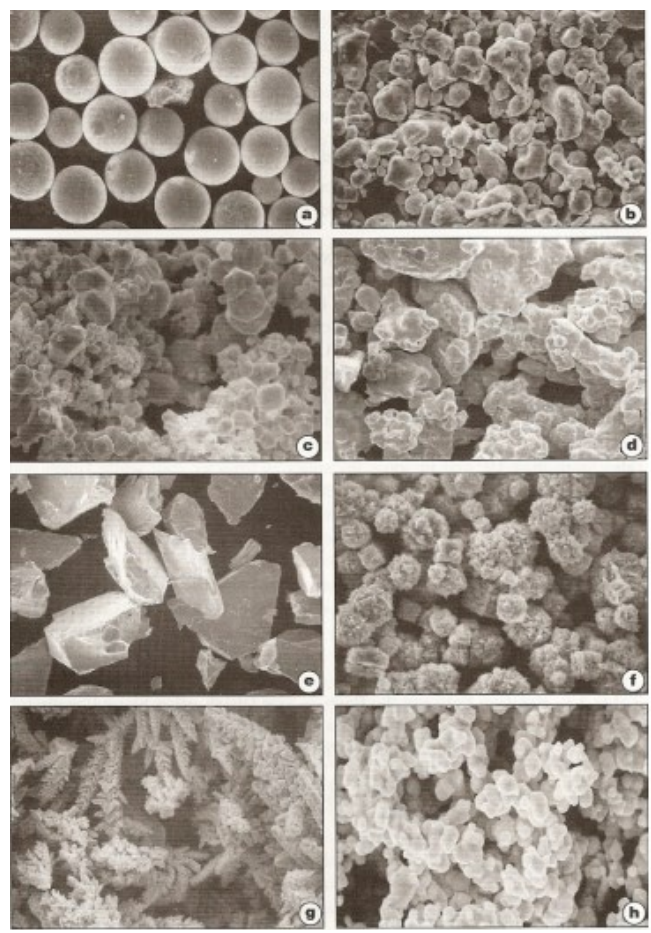

Figura 2.3: Morfologia das partículas metálicas. (a) esférica (b) arredondada

(c) aglomeradas (d) irregular (e) angular (f) com picos (g) dendrítica

(h) porosa (GERMAN, 1997).

\subsubsection{Grau de pureza dos pós}

Avaliar o grau de pureza dos pós metálicos é de grande importância para a qualidade do produto obtido após a aplicação das técnicas da metalurgia do pó, uma vez que, impurezas podem afetar as fases de compactação e de sinterização. O ideal é que o pó elementar apresente pureza acima 99,5\%. Outro problema relacionado com as impurezas, são as não metálicas, que após a compactação dos pós atuam como concentradores de tensões, afetando a deformação plástica do compactado (FERREIRA, 2002).

\subsubsection{Densidade aparente}

O estudo da densidade aparente do pó é importante pois, esta, influencia diretamente no preenchimento requerido da matriz com o pó, com o intuito de atingir a densidade do compactado. Vale ressaltar que, essa densidade pode ter seus valores influenciados pelos lubrificantes, e outros aditivos que são adicionados aos pós metálicos (CREMONEZI et al., 2009).

O valor da densidade aparente segundo Chiaverini (2001) é determinado como sendo o peso de uma unidade de volume do pó solto ou a relação do peso para o 
volume, em $\mathrm{g} / \mathrm{cm}^{3}$. E esta, vai depender do material, forma e área superficial da partícula, assim como a composição granulométrica que a amostra do pó possui. Em resumo, a densidade aparente vai diminuir à medida que as partículas forem se afastando do formato esférico.

\subsubsection{Escoabilidade}

A escoabilidade ou escoamento é uma propriedade mecânica muito importante para a caracterização dos pós metálicos, e vai interferir diretamente na compactação. $\mathrm{O}$ escoamento pode ser influenciado por agentes, que são o tipo e a quantidade de lubrificante utilizado durante a compactação dos pós, o formato geométrico da partícula, fatores ambientais, tipo de material e, por fim, a distribuição granulométrica dos pós que estão sendo utilizados. Para determinar a velocidade de escoamento da partícula, utiliza-se um equipamento denominado medido de vazão Hall, que está apresentado na Figura 2.4 (CHIAVERINI, 2001) (CREMONEZI et al., 2009).
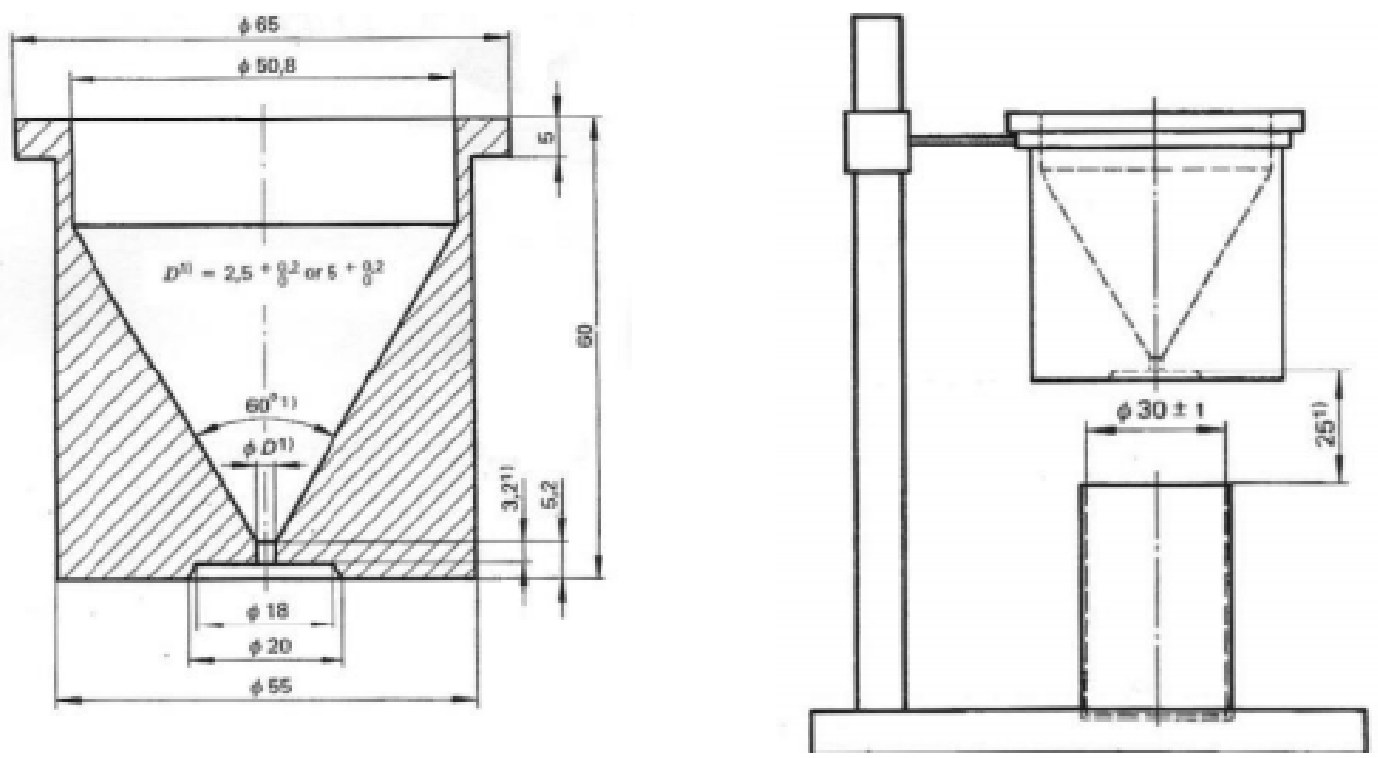

Figura 2.4: Desenho esquemático do Funil de Hall. Utilizado para medição de escoabilidade e densidade aparente (RODRIGUES, 2004).

\subsubsection{Moagem, mistura e homogeneização}

O processo de mistura ocorre com os pós metálicos, em misturadores, moinhos, ou rolos homogeneizadores. Os pós elementares são misturados nas proporções corretas da liga, e outras substâncias, como por exemplo, o lubrificante sólido. A eficácia do processo depende de diversos parâmetros como a granulometria dos pós envolvidos, o 
tempo e velocidade de mistura, o tipo de equipamento, relação de carga, etc. Geralmente, quanto maior for a uniformidade do tamanho das partículas que estão sendo misturadas, maior será a probabilidade dos resultados serem consistentes e adequados (CREMONEZI et al., 2009).

Problemas como a segregação dos pós metálicos, podem ser evitados controlando o tempo de mistura, observando a diferença de densidade entre os materiais envolvidos (maior a diferença, maior a chance de segregação) e o formato da partícula. Outra observação a ser feita, está relacionada com a mistura em moinhos. Nestes equipamentos, é necessário que se faça vácuo, ou uma atmosfera inerte, como por exemplo, de argônio, para que a oxidação dos pós metálicos não ocorra e inviabilize o processo de moagem (CREMONEZI et al., 2009).

Existem dois tipos de moagem, as denominadas moagem de baixa energia que são indicadas para materiais frágeis, e o segundo tipo, moagem de alta energia que é utilizada para a obtenção de pós e ligas de materiais dúcteis. Para cada técnica de moagem há diversos tipos de moinhos, cada um possuindo suas particularidades, e a escolha do tipo vai depender do objetivo e característica do material que se deseja moer (CHIAVERINI, 2001).

\subsubsection{Moagem de alta energia}

A mistura e homogeneização dos pós metálicos para a confecção da liga por metalurgia do pó, pode ser realizada de duas maneiras, através de misturadores ou através de moinhos, que são denominadas moagens de alta energia. Essa última técnica envolve altas rotações, frequências de impactos entre as bolas de moagem e as partículas dos pós envolvidos (reagentes). A mistura produzida apresentará alta dispersão.

A moagem de alta energia é realizada em moinhos os quais apresentam energia cinética relacionada às bolas (daí a denominação, moinho de bolas) que são utilizadas na moagem. Assim, as partículas sofrem choques mecânicos e deformações, absorvendo parte da energia. Durante o processo de moagem as partículas sofrem sucessivos ciclos de deformações, podendo levar a soldagem ou adesão entre as partículas e até a fratura.

No caso de materiais dúcteis a soldagem a frio é mais comum devido à deformação plástica que ocorre durante o processo. Para que haja uma diminuição desta deformação adicionam-se elementos conhecidos como agentes controladores do 
processo. A Figura 2.5 apresenta os eventos que ocorrem durante o processo de moagem de alta energia em materiais dúcteis (CASTAGNET, 2008).

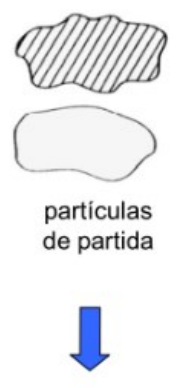

(I)

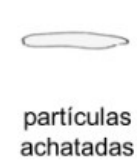

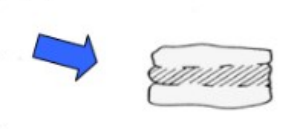

Soldagem a frio

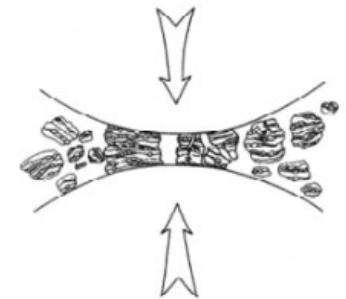

(II)
(IV)

Refinamento do agregado

\section{(III)}
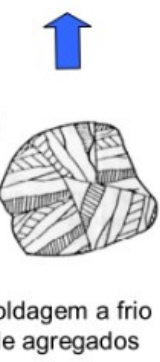

Agregado

Figura 2.5: Eventos que ocorrem em materiais dúcteis durante a moagem de alta energia (BENJAMIN; VOLIN, 1974 apud CASTAGNET, 2008).

Os moinhos mais conhecidos são os moinhos agitadores, planetários, atritores e os convencionais (jarra). A Figura 2.6 apresenta como é o comportamento da moagem em cada tipo de moinho.

(A)

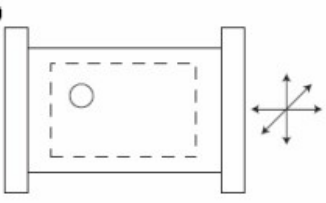

(C)

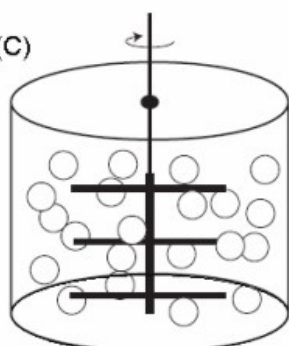

(B)

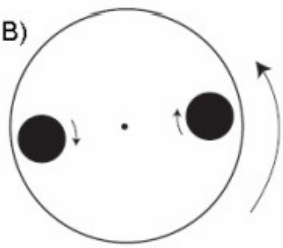

(D)

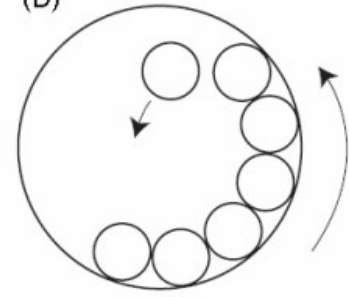

Figura 2.6: Esquema de um moinho agitador (A), planetário (B), atritor (C) e convencional (D) (CASTAGNET, 2008).

Segundo Tang et al. (1997) no processo de moagem de alta energia os pós elementares são pré ligados, modificando as características dos mesmos. Desta forma, a 
temperatura de sinterização para a fabricação da liga sofre uma redução, facilitando o processo de obtenção do material sinterizado.

\subsubsection{Agente de controle}

Quando se efetua a moagem principalmente em materiais muito dúcteis ocorre o fenômeno de soldagem a frio entre as partículas dos pós metálicos. Este é importante para a eficácia da moagem, entretanto, pode prejudicar todo o processo se não ocorrer de forma adequada.

Para garantir essa eficácia utilizam-se agentes de controle como, por exemplo, lubrificantes, hexano, ácido esteárico, metanol, etanol, dentre outros. Esses materiais são adicionados na quantidade entre 1 a $5 \%$ em peso do total da mistura, e a escolha adequada é de suma importância, pois o tipo, bem como a quantidade de agente lubrificante vai influenciar no tamanho e no formato das partículas (SALGADO, 2002).

\subsubsection{Velocidade}

A velocidade de moagem está relacionada com a energia cinética. Havendo contato entre os pós e as bolas, quanto maior a velocidade maior será a energia cinética aplicada e, portanto, precisará de menor tempo de moagem. Porém, dependendo do material, altas velocidades podem ser prejudiciais ao processo, devido à grande formação de soldagem a frio. Cada tipo de moinho vai alterar a velocidade de forma diferente, por isso, é necessário escolher o tipo certo de equipamento para a moagem.

Quando se tem um aumento de velocidade, ocorre também o aumento de temperatura do recipiente de moagem. Este aumento de temperatura deve ser controlado pois, pode ajudar ou prejudicar o resultado final do processo (CASTAGNET, 2008).

\subsubsection{Tempo}

A determinação do tempo de moagem vai depender do material, do tipo de moinho, da intensidade da moagem, da temperatura e da razão bola-pó. Este deve ser determinado conseguindo o equilíbrio entre a soldagem a frio e a fratura. A combinação de todas as variáveis do processo determina o tempo que o material ficará submetido à moagem (CASTAGNET, 2008).

O tempo também irá influenciar na formação de fases entre os elementos envolvidos. Longos tempos de moagem, em alguns casos, além de aumentar a 
contaminação, há a formação de fases indesejáveis do material moído. Assim, o estudo da influência do tempo é fundamental para atingir o objetivo do processo (SURYANARAYANA, 1995 apud SALGADO 2002).

\subsubsection{Razão bola-pó}

A razão bola-pó é a razão entre a massa das bolas (esferas) de moagem e a massa do pó que se deseja moer. Essa razão vai depender do tipo de moinho que se está utilizando, da quantidade de pó e volume do jarro do moinho. Geralmente utiliza-se a razão de 10:1 para moagens como pequenas quantidades de pó.

A definição desse parâmetro é de grande importância, pois, vai afetar o tempo total do processo de moer o material. Assim, quanto maior a razão bola-pó menor será o tempo de moagem, e essa razão varia de 1:1 até 220:1. Para cargas maiores, aplicam-se razões maiores (CASTAGNET, 2008).

\subsubsection{Quantidade de pó}

A quantidade de pó para a moagem vai depender do volume do recipiente utilizado para moer. Recomenda-se que se preencha com o pó e as bolas cerca de $50 \%$ do volume total do recipiente. É necessário deixar um volume desocupado para que haja a movimentação dos pós e das bolas e assim, tornar o processo eficiente ocorrendo impacto entre ambas (CASTAGNET, 2008).

\subsubsection{Lubrificantes}

Lubrificantes sólidos são inseridos na mistura com o objetivo de reduzir o atrito entre os componentes ferramentais, como por exemplo, a matriz de compactação e os pós, ajudando também na extração do material após a compactação. Os lubrificantes devem ser utilizados em quantidades adequadas, geralmente de $0,5 \%$ a $1,51 \%$ em peso do total da liga, evitando assim problemas na compressibilidade. Este será removido do compactado durante a etapa de sinterização (COSTA, 2014) (CHIAVERINI, 2001).

Os lubrificantes sólidos mais utilizados são o ácido esteárico, estearato de zinco, estearato de lítio e ceras sintéticas. Cada um vai se comportar de maneiras diferentes de acordo com o material que está sendo utilizadas, assim como, as condições de processamentos envolvidas. O conhecimento do seu comportamento na mistura é 
essencial para que a qualidade final da peça não seja afetada, como por exemplo, a formação indesejada de poros (CHIAVERINI, 2001).

\subsubsection{Compactação}

Na etapa de compactação a mistura dos pós tomará a forma do produto desejado, além de conferir a resistência mecânica necessária para a sua futura utilização, e a desinficação dos componentes, reduzindo a fração de vazios. Existem diversos tipos de compactação os mais utilizados são: compressão em matriz rígida, compressão isostática (a frio ou a quente), compactação por laminação de pós e a extrusão de pós metálicos (CHIAVERINI, 2001).

Os processos de compactação que são, atualmente, mais utilizados são a compactação em matriz rígida e a isostática, e segundo Chiaverini (2001), o comportamento dos pós quando submetidos à compressão pode ser dividido em três estágios. No primeiro as partículas de pó sofrem um processo de rearranjo, eliminando parcialmente a formação de vazios. O segundo estágio, está relacionado com a deformação plástica das partículas, uma vez que há uma relação entre a capacidade de deformação plástica dos pós e sua compressibilidade. Já no terceiro estágio, como as partículas ficaram frágeis devido ao encruamento dos estágios anteriores, estas quebram e formam fragmentos menores.

$\mathrm{Na}$ compactação unidirecional de matriz rígida as prensas empregadas são mecânicas ou hidráulicas, ou do tipo híbrido, a qual se associam os dois tipos de prensa em uma. Para escolher o tipo ideal de prensa deve-se ficar atento a sua capacidade em toneladas, e ao curso, que representa a profundidade de enchimento e curso de ejeção do compactado. Para cada tipo de pó que se deseja compactar existe um valor adequado de pressão para se aplicar, como também, a relação de compressão existente. Esses valores podem ser encontrados em curvas de compressibilidade específicas para cada material, nas quais a densidade é função da pressão aplicada. Outro fator importante é a determinação da profundidade de enchimento, esta é função da espessura da peça a ser produzida, da densidade a verde desejada e da relação de compressão do material utilizado (CHIAVERINI, 2001).

A retirada do da peça compactada, denominada de "peça verde", deve ser feita de forma criteriosa, pois a sua retirada de forma inadequada pode gerar trincas no material já compactado. A forma adequada da retirada da peça vai depender do tipo de prensa na qual foi realizada a compactação (CREMONEZI et al., 2009). 


\subsubsection{Compactação uniaxial a frio}

A compactação uniaxial a frio é uma das técnicas utilizadas em linhas de produção, sendo muito aplicada no setor automobilístico. Está técnica possui alta aplicabilidade uma vez que, possui baixo custo, elevada reprodutibilidade, possível de ser automatizada e poucas operações de acabamentos. É um processo simples que consiste no preenchimento da cavidade da matriz, seguida de compactação, descarregamento e retirada de pressão, e por fim, a extração do compactado (GERMAN, 1998 apud NEVES, 2005).

Durante este tipo de compactação ocorrem alguns mecanismos típicos do processo e, alguns que podem variar com o tipo de material, são eles: rearranjo e reorientação, deformação elástica, deformação plástica e fragmentação quando associado à materiais frágeis. Quando a pressão aplicada é baixa, o aumento da densidade a verde (densidade do compactado antes da sinterização) é resultado do rearranjo das partículas até um limite, no qual ocorre o empacotamento máximo dos pós, sendo que este limite dependerá do formato e tamanho das partículas. A Figura 2.7 exemplifica o processo de compactação uniaxial a frio (GERMAN, 1998 apud NEVES, 2005).
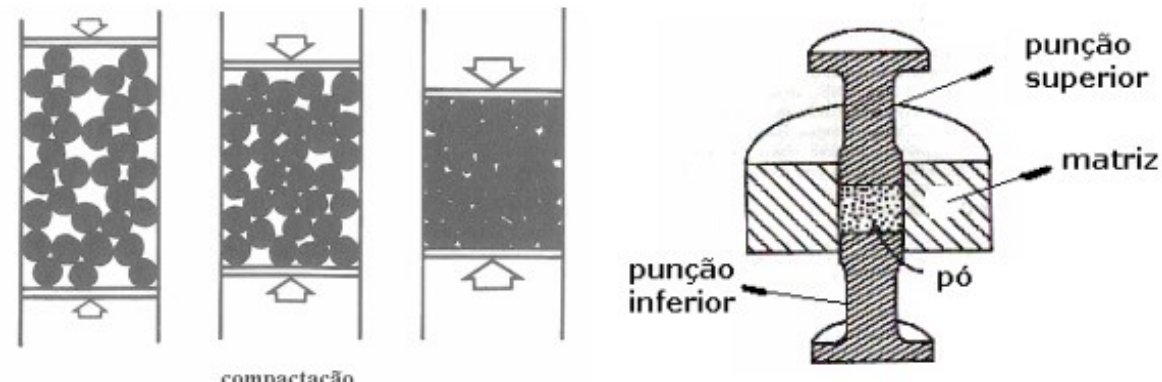

Figura 2.7: Compactação uniaxial a frio (RODRIGUES, 2004).

As características dos pós envolvidos na compactação influenciam diretamente o processo e o resultado final. Por exemplo, os comportamentos durante a compactação de pós elementares se diferem de misturas de pós com diferentes tamanhos de partículas e durezas. Além disso, a compressibilidade de um pó elementar ou de uma mistura pode ser afetada por fatores como forma de aplicação da pressão, geometria e tamanho das partículas e propriedade física do material particulado. Desta forma, a compressibilidade do material vai influenciar diretamente na porosidade, densidade a verde e recuperação elástica do produto final (NEVES, 2005). 


\subsubsection{Sinterização}

Após a etapa de compactação inicia-se o processo de sinterização. Este pode ser entendido como sendo um processo térmico onde ocorrerá forte união entre as partículas do compactado, que é transformado em corpos sólidos por mecanismo de transporte atômico difusional. A sinterização é realizada em fornos especiais nos quais se pode fazer o controle da atmosfera, temperatura e tempo do processo. Desta forma, os pós compactados irão adquirir resistência mecânica, dureza e densidade adequadas através do contato de formação entre as partículas.

Para a realização do processo de sinterização, é de grande importância que se tenha o conhecimento das temperaturas de fusão dos materiais que vão sofrer a sinterização, uma vez que, tal processo é realizado abaixo da temperatura de fusão do constituinte principal. Quando se tem elementos puros, determinar a temperatura de fusão é bem simples (dados tabelados, ou fornecido pelo fabricante). Porém, quando se trata de ligas, para determinar seu comportamento térmico, é necessário que se faça a análise, denominada, em inglês, de Differential Scanning Calorimetry (DSC), ou em português, Calorímetro Diferencial de Varredura, a qual pode determinar a temperatura de fusão da mistura e, consequentemente, a faixa de temperatura de trabalho do forno para a sinterização. Normalmente a temperatura da sinterização é da ordem $2 / 3$ a 2/4 da de fusão da liga que está sendo trabalhada (CREMONEZI et al., 2009).

O processo de sinterização pode ser dividido em três estágios principais, representados na Figura 2.8. São eles:

- Estágio inicial: Há a formação de ligação entre as partículas devido ao contato entre elas através de difusão atômica. Assim, a matéria se torna contínua na região dos contatos. Não são observadas movimentações significativas das partículas.

- Estágio intermediário: Aos poucos as partículas vão perdendo suas identidades. Neste estágio observa-se o crescimento dos grãos, sendo caracterizado pela densificação e consequente contração volumétrica e aumento das propriedades mecânicas.

- Estágio final: Ocorre o arredondamento e isolamento dos poros pequenos e no crescimento dos poros maiores, contribuindo para a redução da energia livre no sistema. 

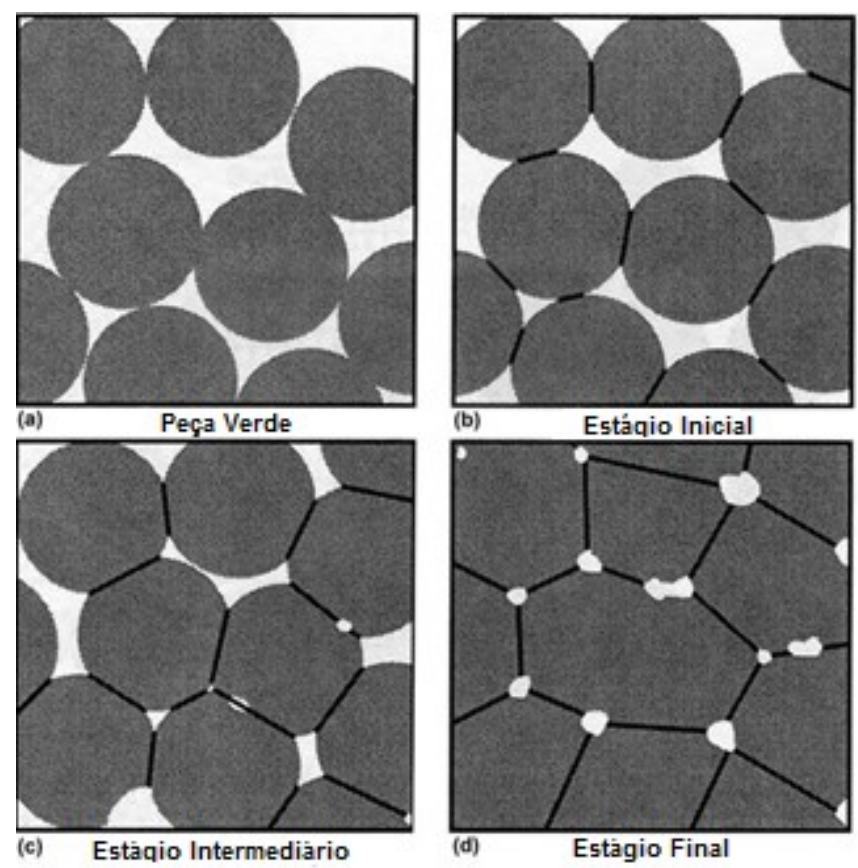

Figura 2.8: Principais estágios da sinterização (GERMAN, 1996) (modificado).

Durante o processo de sinterização ocorrem algumas mudanças nas características do sinterizado se comparado com a peça compactada. Em relação ao lubrificante adicionado no processo de moagem, este será eliminado durante a sinterização devido às altas temperaturas empregadas e, assim, haverá perda de massa. Mudanças no volume também podem ser observadas, devido às transformações de fases e reações químicas entre os elementos que constituem a liga, ou ainda, com os gases da atmosfera de sinterização (CREMONEZI et al., 2009).

Quando a sinterização é realizada de maneira incorreta a qualidade do material sinterizado pode ser afetada. De forma geral, os defeitos associados à sinterização ineficaz são baixa dureza, baixa resistência mecânica e dimensões diferentes da esperada. A sinterização inadequada geralmente é causada por diversos fatores como temperatura de sinterização baixa, agente redutor ineficiente, alta concentração de $\mathrm{O}_{2}$ na zona quente, densidade a verde incorreta, velocidade de aquecimento ou tempo incorretos na sinterização e o ponto de orvalho muito alta na zona quente. Todos esses fatores influenciam na eficácia da sinterização e, consequentemente, na qualidade do produto final (TAUBENBLAT, 1980).

\subsubsection{Porosidade}

A porosidade está presente em grande quantidade no compactado, e os poros podem ter tamanhos variados sendo que, de forma geral, estão interconectados. Na grande 
maioria dos casos, os poros são considerados como "defeitos", porém em outras situações estes são essenciais na aplicação do produto que está sendo fabricado. A porosidade em um material vai depender da forma pela qual os pós sofreram a compactação, e das características dos pós (SUN, et al, 1999 apud NEVES, 2005).

O processo de sinterização vai interferir na porosidade final de um material, pois a quantidade e o tamanho dos poros mudam no decorrer deste processo, como é apresentado na Figura 2.9. No início da sinterização (estágio inicial) ocorrerá a formação de ligação entre as partículas, e a redução da porosidade é pequena. No segundo estágio, vão ocorrer elevada contração e crescimento dos grãos. Já no último estágio, há uma lenta densificação ocorrendo elevado crescimento dos grãos e dos tamanhos médios dos poros (NEVES, 2005).

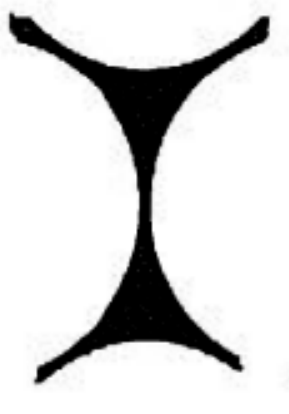

(a)

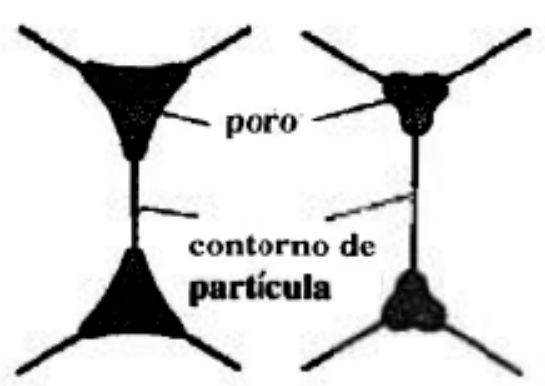

(b) (c)

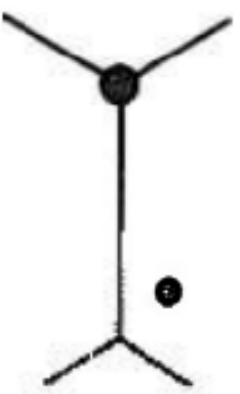

(d)

Figura 2.9: Evolução da região de contato e da variação da porosidade no decorrer da sinterização (a) ponto de contato inicial, (b) estágio inicial, (c) estágio intermediário e (d) estágio final da sinterização (GERMAN, 1996 apud NEVES, 2005).

No material o poro pode estar inserido no contorno de grão ou dentro do grão, este último provoca o aumento da energia do sistema, pois há a criação de novas interfaces em relação ao poro no contorno de grão. Já os poros localizados nos contornos de grão vão provocar maiores contrações em relação os poros fora do contorno. Assim, os poros dentro do grão aumentam a energia do sistema prejudicando a sinterização (NEVES, 2005).

\subsection{Transformação de fase em metais}

O estudo das transformações de fases é de grande importância para entender diversos comportamentos dos materiais já que, o desenvolvimento da microestrutura envolve algum tipo de transformação. A mistura de duas ou mais fases permite que 
estas se interajam entre si resultando em um material com propriedades diferentes das propriedades das fases individuais (VAN VLACK, 2003) (CALLISTER, 2002).

A grande maioria das transformações no estado sólido não ocorre de forma instantânea, devido à existência de obstáculos que impedem o curso da reação tornandoa dependente do tempo. Essas transformações podem ser de dois tipos, as difusionais, e as por deslocamento. Nas transformações difusionais a nova fase é formada através dos movimentos realizados de forma aleatórios dos átomos através de distâncias relativamente longas. Essas longas distâncias são necessárias, uma vez, que a nova fase possui composição química diferente da matriz da qual é formada. Neste tipo de transformação ocorre a redistribuição do soluto, sendo dependente do tempo e da temperatura (DIAS, 2005).

Nas transformações por deslocamento não serão necessários movimentos atômicos a longas distâncias como ocorre nas difusionais, já que não há mudança na composição química em relação à matriz, e assim, muitas vezes são independentes do tempo. As transformações por deslocamento são denominadas de atérmicas, pois a nova fase depende somente da temperatura e não do tempo em uma certa temperatura (DIAS, 2005).

Analisando de forma macroestrutural, a nucleação (formação dos núcleos da nova fase que são capazes de crescer) é o primeiro processo que acompanha a transformação de fase. Sítios com imperfeições, e em especial os contornos de grãos, são favoráveis aos crescimentos desses núcleos. A segunda fase é a etapa de crescimento dos núcleos anteriormente formados. Transformações em estado sólido que, pode ser verificado esses processos, são denominadas de transformações em estado sólido que exibem comportamento cinético (CALLISTER, 2002).

As transformações de fase em ligas metálicas podem ocorrer como consequência de alguns fenômenos como variação na composição, pressão externa e variações na temperatura. Esta última é a mais conveniente e pode ser aplicada através de tratamentos térmicos, os quais podem ser feitos de diversas maneiras, e a escolha vai depender das características finais desejadas (CALLISTER, 2002).

$\mathrm{Na}$ transformação de fases a liga vai se conduzir para um estado de equilíbrio sendo caracterizado por um diagrama de fases, o qual vai apresentar as fases produzidas em termos das suas composições e das quantidades relativas. Porém, o diagrama de fases não vai informar a velocidade para se atingir o equilíbrio que está sendo representado, 
não sendo possível determinar, através do diagrama, o tempo necessário para tal equilíbrio (CALLISTER, 2002).

\subsubsection{Transformação de fase martensitica}

A transformação de fase martesitica (TM) observada nos metais ocorre por nucleação e crescimento sem difusão. Ou seja, a transformação ocorre por deslocamento, em materiais no estado sólido como consequência da movimentação cooperativa entre os átomos das interfaces que separam a fase matriz da fase produto, e acontece quase que instantaneamente. Esta pode ocorrer pela diminuição da temperatura ou aplicação de tensão. Como ela ocorre de forma muito rápida, as taxas de transformações martensiticas serão independentes do tempo, porém, dependentes da temperatura. A Figura 2.10 representa de forma simplificada o modelo de transformação martensitica (GAMA, 2003) (CALLISTER, 2002).

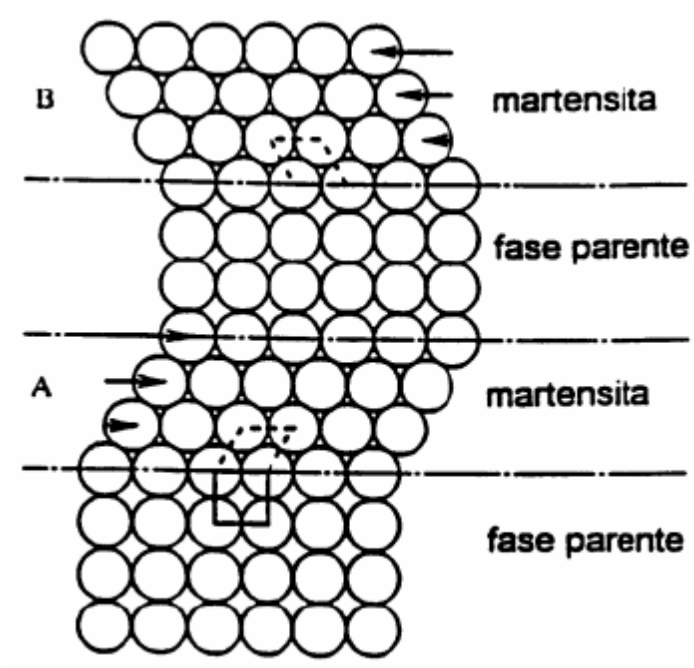

Figura 2.10: Modelo simplificado da transformação martensitica (OTSUKA; WAYMAN,1998) (modificado).

Quando um material que sofre TM é resfriado abaixo da temperatura crítica, iniciase a transformação realizada frequentemente pelo processo de cisalhamento. Na Figura 2.10, as martensitas da região A e B possuem estruturas cristalinas iguais, porém, com orientações diferentes.

A força motriz para a nucleação de uma fase é oriunda da variação de energia livre. Assim, a diminuição da energia livre, favorece a transformação de fase. No caso do resfriamento, a variação de energia livre para a formação da martensita é menor que da austenita. Utilizando o gráfico da energia livre de Gibbs em relação à temperatura 
representado na Figura 2.11, observa-se que a temperatura de estabilização da austenita é acima da $A_{s}$ (austenite start), e a temperatura para a formação da mertensita se encontra abaixo de $M_{S}$ (martensite start). Observa-se também que $T_{0}$ representa a temperatura de equilíbrio entre as duas fases, martensita e austenita. Assim, para temperaturas abaixo de $T_{0}$ a variação de energia livre vai favorecer a transformação martensitica, e para temperaturas acima de $T_{0}$ vai ocorrer transformações austenitica (GAMA, 2003).

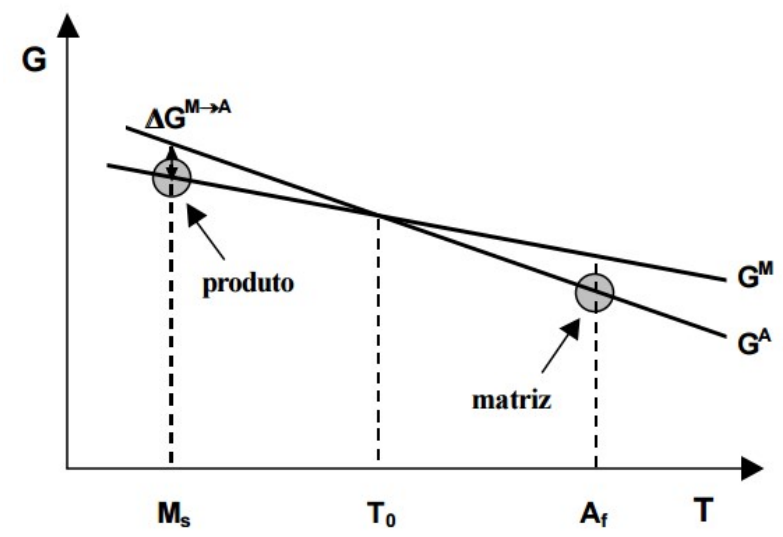

Figura 2.11: Variação da energia em relação à temperatura (OTSUKA; WAYMAN,1998) (modificado).

Ainda utilizando a Figura 2.11, a diferença entre $T_{0}$ e $M_{S}$ é denominada de superesfriamento favorecendo a formação de martensita. Outra e importante característica da transformação martensítica está relacionada com o efeito memória de forma, que é uma propriedade única de certas ligas que apresentam transformações martensíticas.

Assim, as TM são transformações de primeira ordem e, ocorrem por um processo de nucleação e crescimento, liberando calor na formação da fase martensítica e apresentam uma histerese associada com a transformação, e ainda, um intervalo de temperatura no qual há a coexistência da fase martensita com a austenita (OTSUKA; WAYMAN, 1998).

\subsection{Efeito memória de forma}

O efeito memória de forma vem sendo muito pesquisado devido a suas características e estão sendo aplicadas de forma crescente, principalmente na área da saúde. Nesse efeito, mesmo que a liga seja deformada em uma fase de baixa temperatura, ela pode retornar a forma original por transformação reversa (TR) através 
do aquecimento a uma temperatura crítica denominada de temperatura crítica de transformação reversa. Assim aumentando-se a temperatura, a martensita torna-se instável ocorrendo a TR e a martensita retorna a fase parente, representada na Figura 2.10 .

Ou seja, para as SMA, têm-se as chamadas temperaturas termoelásticas $\left(M_{s}, M_{f}, A_{s}, A_{f}\right)$ que são as temperaturas de início e final das fases matriz e produto, e que caracterizam esse tipo particular de liga, são elas:

- $M_{s}$ : Martensite start temperature;

- $M_{f}:$ Martensite finish temperature;

- $A_{s}:$ Reverse transformation start temperature;

- $A_{f}$ : Reverse transformation finish temperature.

Essas temperaturas de transformação podem ser determinadas medindo alguma propriedade física possível de se obter em função da temperatura (OTSUKA; WAYMAN,1998). A Figura 2.12 representa uma situação onde ocorre efeito memória de forma, que apresenta uma curva de transformação matersintica obtida durante um processo de aquecimento e resfriamento. Este efeito ocorre graças à reversibilidade cristalográfica da mastensítica formada. Essa reversibilidade pode ser observada na Figura 2.13 para uma liga Ni-Ti.

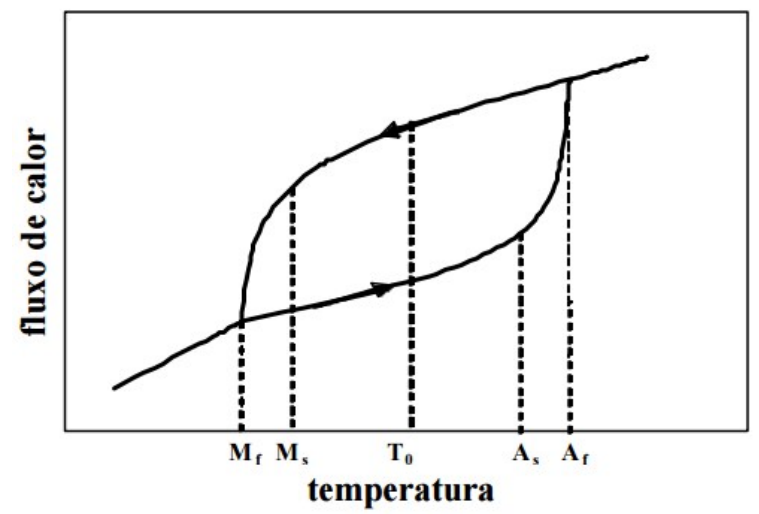

Figura 2.12: Curva característica da transformação martensítica termoelástica (GAMA, 2003).
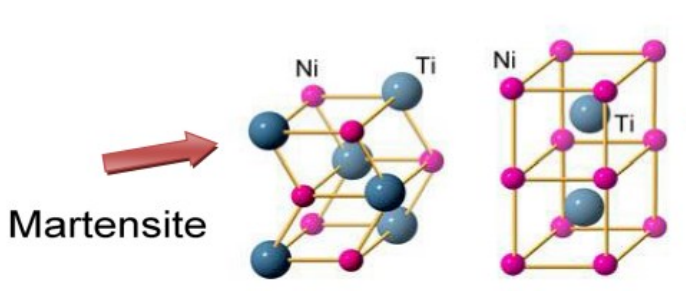

\section{Austenite}

Figura 2.13: Fase mastensítica e austenítica para liga Ni-Ti (ROCHA et al., 2012). 
Um caso particular que ocorre nas ligas com memória de forma é a superelasticidade (SE) no qual a temperatura final de transformação reversa é menor ou próxima à temperatura de deformação. Assim, a recuperação da forma se dá logo após a interrupção da deformação e retirada da carga, sem que haja necessidade de aquecimento (OTSUKA; WAYMAN,1998).

\subsubsection{Métodos de caracterização}

Para a caracterização das ligas com efeito memória de forma existem quatro métodos principais que são os mais utilizados. O método mais direto é o realizado através da análise DSC. Esta técnica mede o calor absorvido ou emitido de uma pequena amostra do material, através do seu aquecimento e resfriamento em uma determinada faixa de temperatura de transformação. São gerados picos endotérmicos e exotérmicos de acordo com a absorção ou emissão de energia das amostras, devido às suas transformações (HODGSON,1990).

O segundo método é utilizado para se determinar a resistividade da amostra no aquecimento e no resfriamento. Neste caso, as ligas apresentam alterações e picos em resistividades, até $20 \%$, através da faixa da temperatura de transformação. Entretanto, a correlação entre essas alterações com as mudanças de fase e/ou propriedades mecânicas não está sendo possível obter resultados satisfatórios (HODGSON,1990).

O método mais direto para caracterizar mecanicamente uma liga é, após o preparo adequado de uma amostra aplicar uma tensão constante na mesma, fazendo sua ciclagem através da transformação enquanto se mede a tensão que se ocorreu durante as transformações nas duas direções. A Figura 2.14 mostra uma curva típica gerada neste tipo de método de caracterização.

Os valores obtidos para os pontos de transformações, como $M_{s}$ e $A_{f}$ a partir deste método são um pouco mais alto dos obtidos pela análise DSC. Assim, este método é um indicativo da propriedade que se pode esperar de um dispositivo mecânico que possui memória de forma (HODGSON,1990).

Por último, para medir as propriedades de tensão-deformação pode-se realizar o ensaio padrão de tração utilizando valores de temperaturas além da faixa temperatura de transformação. A partir das mudanças de suas propriedades os valores para as temperaturas de transformação podem ser interpolados (HODGSON,1990). 


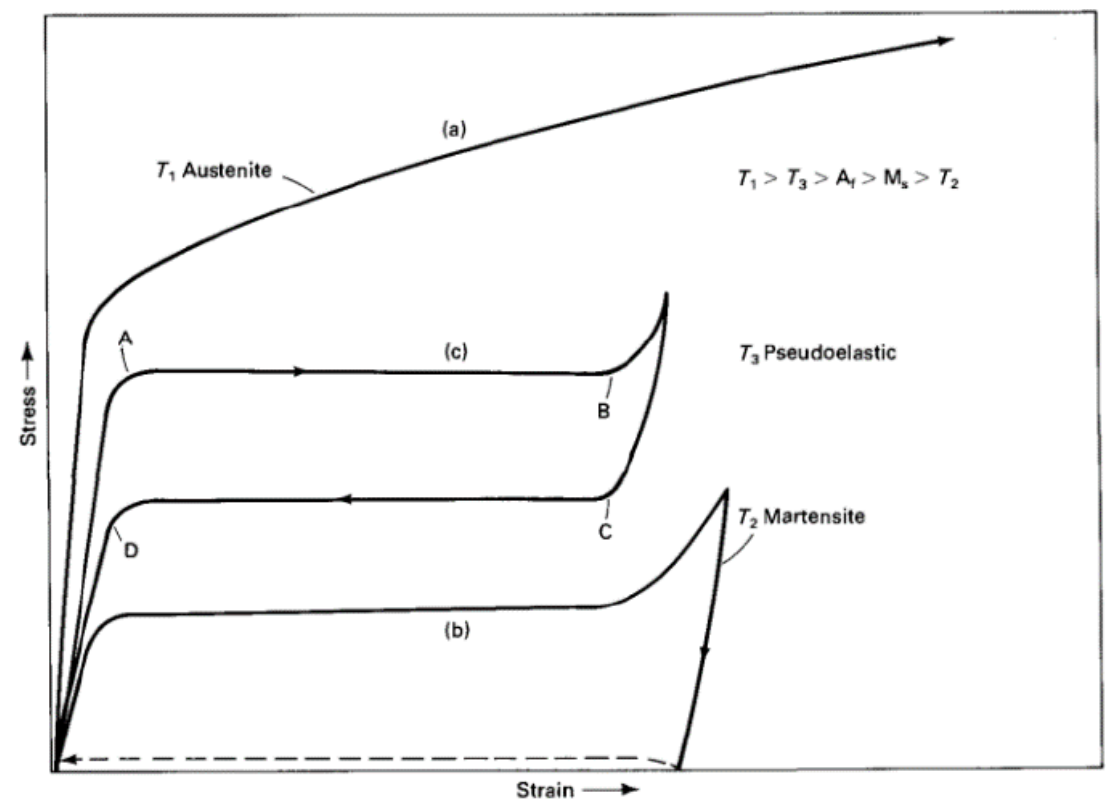

Figura 2.14: Curva típica de tensão-deformação para diferentes temperaturas relativas de transformações (HODGSON,1990).

\subsubsection{Aplicação das ligas com efeito memória de forma}

Grandes variedades de ligas apresentam o efeito memória de forma. Porém, para uso comercial é de interesse apenas as que apresentam quantidade significativa de recuperação da deformação, ou em situações em que é gerada uma força importante durante a mudança de forma. E essas características são observadas nas ligas de Ni-Ti, Cu-Al-Ni, Cu-Al-Zn (NAKATANI et al., 2007).

As ligas Ni-Ti possuem ampla aplicação na medicina por ser biocompatível podendo ser utilizada para diversas finalidades. Um exemplo é a utilização dessa liga para a confecção de filtros para evitar coágulos de sangue (filtro de veia cava), além de sua utilização em implantes e próteses. Na odontologia as ligas de NiTi são utilizadas em aparelhos ortodônticos, para os quais o fenômeno da pseudoeslaticidade é muito importante.

As ligas de CuAlNi por possuírem custo menos elevados que as de NiTi vêm sendo estudadas e aplicadas em sensores, elementos de força de atuadores, luvas de acoplamentos dentre outros. (SILVA, 2007).

Outra aplicação das ligas com efeito memória de forma é seu uso em tubulações onde há a passagem de fluidos aquecidos e é essencial que essas ligas mantenham sua forma neste meio. Além disso, estudos estão sendo desenvolvidos para a utilização dessas ligas na aeronáutica, como por exemplo, em flaps de aviões, estes são estruturas 
móveis que estão inseridas nas asas, que promovem o ganho ou a perda de altitude, ou ainda a mudança em sua direção (ROCHA et al., 2012).

\subsubsection{Ligas CuAINi}

As ligas com base de NiTi possuem boas propriedades de força, ductilidade e resistência à corrosão, além de uma excelente característica de efeito memória de forma. Porém, esse tipo de liga possui custo muito elevado tornando, às vezes, inviável seu uso. Devido a isso, ligas mais viáveis economicamente estão sendo pesquisadas, como é o caso, das ligas com base em cobre, que são mais vantajosas em aplicações de condutividade e deformidade elétricas e térmicas, se comparadas às de NiTi (OTSUKA; WAYMAN,1998).

Neste contexto, estudos utilizando a liga CuAlNi estão sendo realizados com o intuito de observar seus comportamentos e características. A liga binária $\mathrm{CuAl}$ possui memória de forma, porém, torna-se inviável para aplicações práticas pois possui temperatura de transformação austenítica muito elevada. Desta forma, acrescenta-se Ni formando-se a liga CuAlNi a qual possui a temperatura dessa transformação entre $80 \mathrm{e}$ $200{ }^{\circ} \mathrm{C}$, apresentando, assim uma ampla faixa de transformação e pequena histerese, sendo a única liga com memória de forma que pode ser aplicada em temperaturas superiores a $100^{\circ} \mathrm{C}($ MATERIALS, 2013).

Em um sistema binário $\mathrm{CuAl}$, a fase $\beta$ sofre decomposição eutetóide em $\alpha$ (solução sólida primária de $\mathrm{Cu})$ e $\gamma_{2}\left(\mathrm{Cu}_{9} \mathrm{Al}_{4}\right)$ a uma temperatura de $565^{\circ} \mathrm{C}$, porém se a liga for resfriada rapidamente até a temperatura ambiente na região de fase $\beta$, ela terá transformação martensítica. Quando a composição de Al na liga é maior que $11 \% \mathrm{em}$ massa a fase $\beta$ torna-se ordenada antes da transformação martensítica. Para concentrações de aproximadamente $14 \%$ em massa de $\mathrm{Al}$ a temperatura $\mathrm{M}_{\mathrm{s}}$ ainda se encontra acima da temperatura ambiente. Acima de 14\% em massa de Al no sistema $\mathrm{CuAl}$ este fica susceptível a precipitação de $\gamma_{2}$ e assim não sofre transformação martensítica. Quando se adiciona Ni no sistema binário $\mathrm{CuAl}$ a precipitação de $\gamma_{2}$ é suprimida de forma eficaz devido à inibição da difusão do $\mathrm{Cu}$ e do $\mathrm{Al}$ porém, altas concentrações de Ni torna a liga frágil. Percebe-se que a quantidade de cada elemento na liga afeta de forma significativa as propriedades do material (OTSUKA; WAYMAN,1998). A Figura 2.15 exemplifica a influência da quantidade de alumínio na temperatura de transformação de fase da liga $\mathrm{Cu}-\mathrm{xAl}-4 \mathrm{Ni}$. 


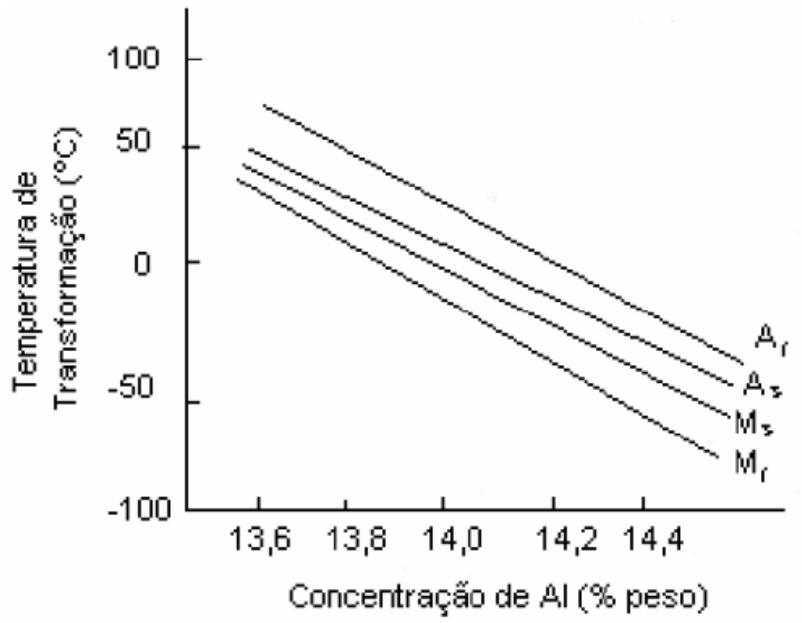

Figura 2.15: Influência da quantidade de $\mathrm{Al}$ na temperatura de mudança de fase (OTSUKA; WAYMAN,1998) (modificado).

As quantidades de cada componente na liga vão variar de acordo com as características finais que se deseja obter, uma vez que, o efeito memória de forma, assim como o comportamento mecânico vão variar dependendo das quantidades de cada elemento na liga. Observa-se na Figura 2.15 que aumentando em pequenas quantidades o teor de $\mathrm{Al}$ na liga, com 4\% de $\mathrm{Ni}$ e base de $\mathrm{Cu}$ ocorre um decréscimo nas temperaturas de transformação. Percebe-se que a quantidade de cada elemento na liga afeta de forma significativa as propriedades do material. Normalmente a composição que se utiliza de cada componente é de $11-14,5 \%$ de alumínio, 3-5\% de Níquel e o restante de cobre (base da liga) (WEE et al., 2015). Os diagramas de fases da liga CuAlNi são apresentados na Figura 2.16 e 2.17. 


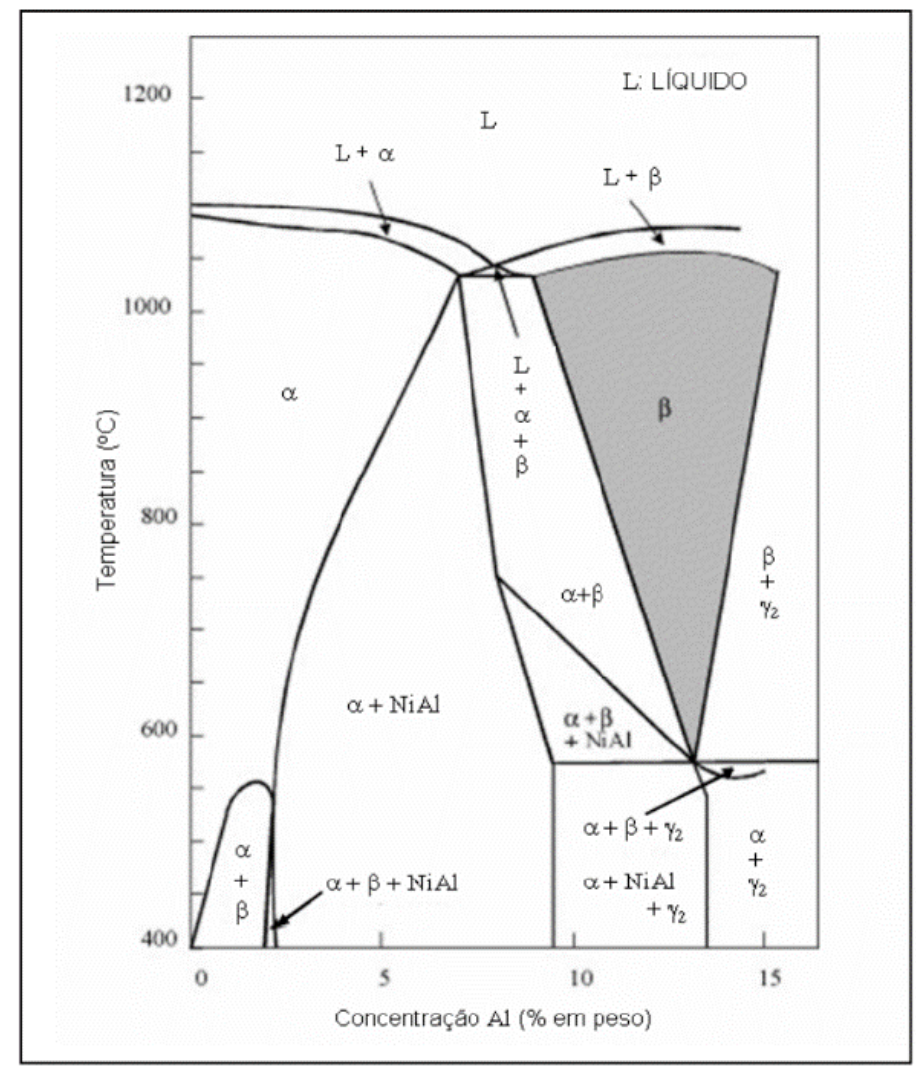

Figura 2.16: Diagramas de fases da liga CuAlNi seção de 3\% de Ni em peso (OTSUKA; WAYMAN,1998) (modificado).

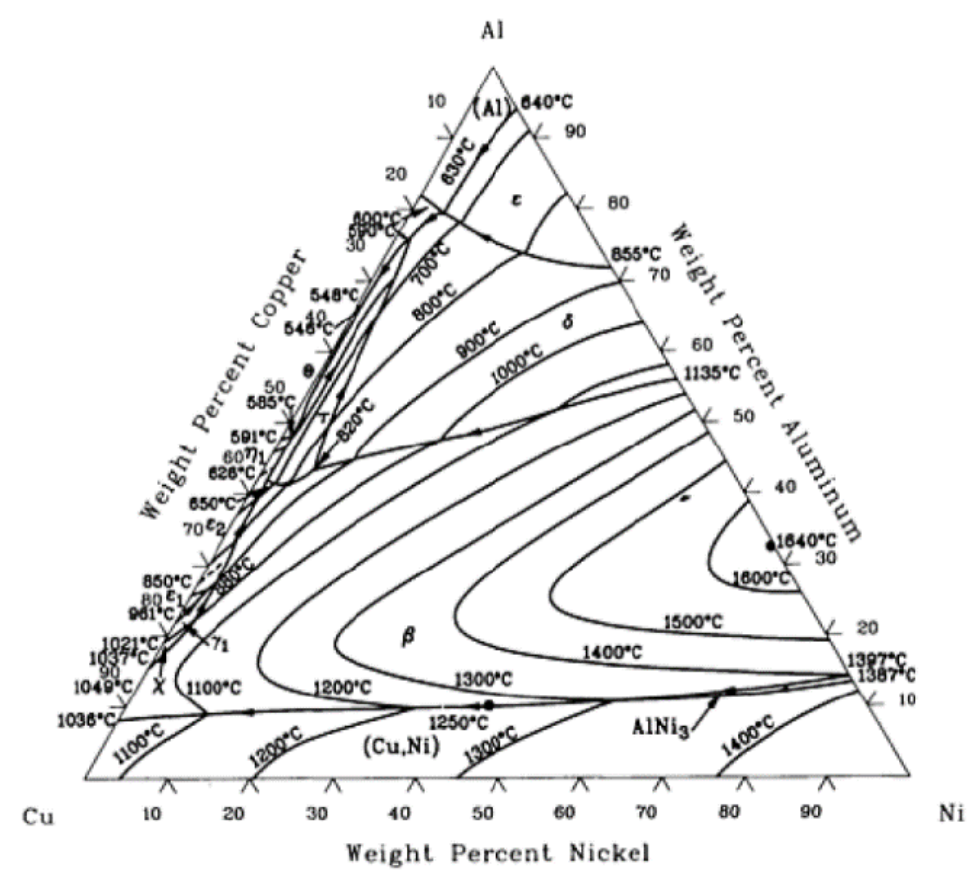

Figura 2.17: Diagramas de fases da liga CuAlNi digrama de fases ternário (ASM, 1992).

É importante salientar que, embora a composição da liga seja o principal fator para o controle das temperaturas de transformações, outros fatores como tratamento térmico, 
taxa de resfriamento, número de ciclos de transformações e tamanho de grão, também afetam o controle das temperaturas de transformações (OTSUKA; WAYMAN,1998).

\subsubsection{Ligas CuAINi fabricadas pelo processo de metalurgia do pó}

A fabricação da liga CuAlNi pelo processo de metalurgia do pó vem sendo estudada a alguns anos. Diversas técnicas de ligação e mistura dos pós elementares, compactação e sinterização são estudadas e as ligas obtidas possuem diferentes características. Tang et al. (1997) propôs a fabricação dessa liga utilizando moagem de alta energia variandoa em diferentes tempos com rotação de $100 \mathrm{rpm}$, compactação a frio e elevados tempos de sinterização (20 horas) com temperatura de $900^{\circ} \mathrm{C}$. Os resultados obtidos mostraram que o tempo ótimo de moagem, no qual as ligas apresentaram melhores propriedades em relação à densificação, microdureza e deformação foi a moagem realizada por 15 horas.

O trabalho proposto por Vajpai et.al (2012) estudou a obtenção da liga CuAlNi pelo processo de metalurgia do pó utilizando moagem de alta energia, compactação a frio, sinterização a $550^{\circ} \mathrm{C}$ por uma hora seguindo de laminação a quente a $1000^{\circ} \mathrm{C}$ e tratamentos térmicos. As ligas apresentaram o efeito memória de forma com histerese de transformação com picos em $40^{\circ} \mathrm{C}$. Já Ibarra et al (2005) estudou a fabricação da liga CuAlNi utilizando pós de $\mathrm{Cu}$, $\mathrm{Al}$ e $\mathrm{Ni}$ pré-ligados através do processo de atomização e compactação isostática quente. As ligas também apresentaram o efeito memória de forma após a realização de têmpera como tratamento térmico.

Observa-se que os trabalhos apresentados anteriormente possuem diferentes parâmetros e diferentes técnicas durante a fabricação da liga CuAlNi. Em cada estudo as ligas obtiveram diferentes características e propriedades. A escolha da técnica e parâmetros a serem utilizados vai depender das características desejadas na aplicação da liga em estudo. 


\section{Materiais e Métodos}

$\mathrm{O}$ presente trabalho teve como intuito fabricar a liga $\mathrm{Cu}-13 \mathrm{Al}-4 \mathrm{Ni}$ via metalurgia do pó, e avaliar a influência do tempo de moagem, nas características finais das ligas obtidas. Para cada etapa do processo foi necessário realizar diferentes testes com o objetivo de determinar parâmetros ideais e de observar a eficácia da etapa garantindo, desta forma, a qualidade final do produto. A Figura 3.1 representa o fluxograma do processo de obtenção e caracterização da liga em estudo.

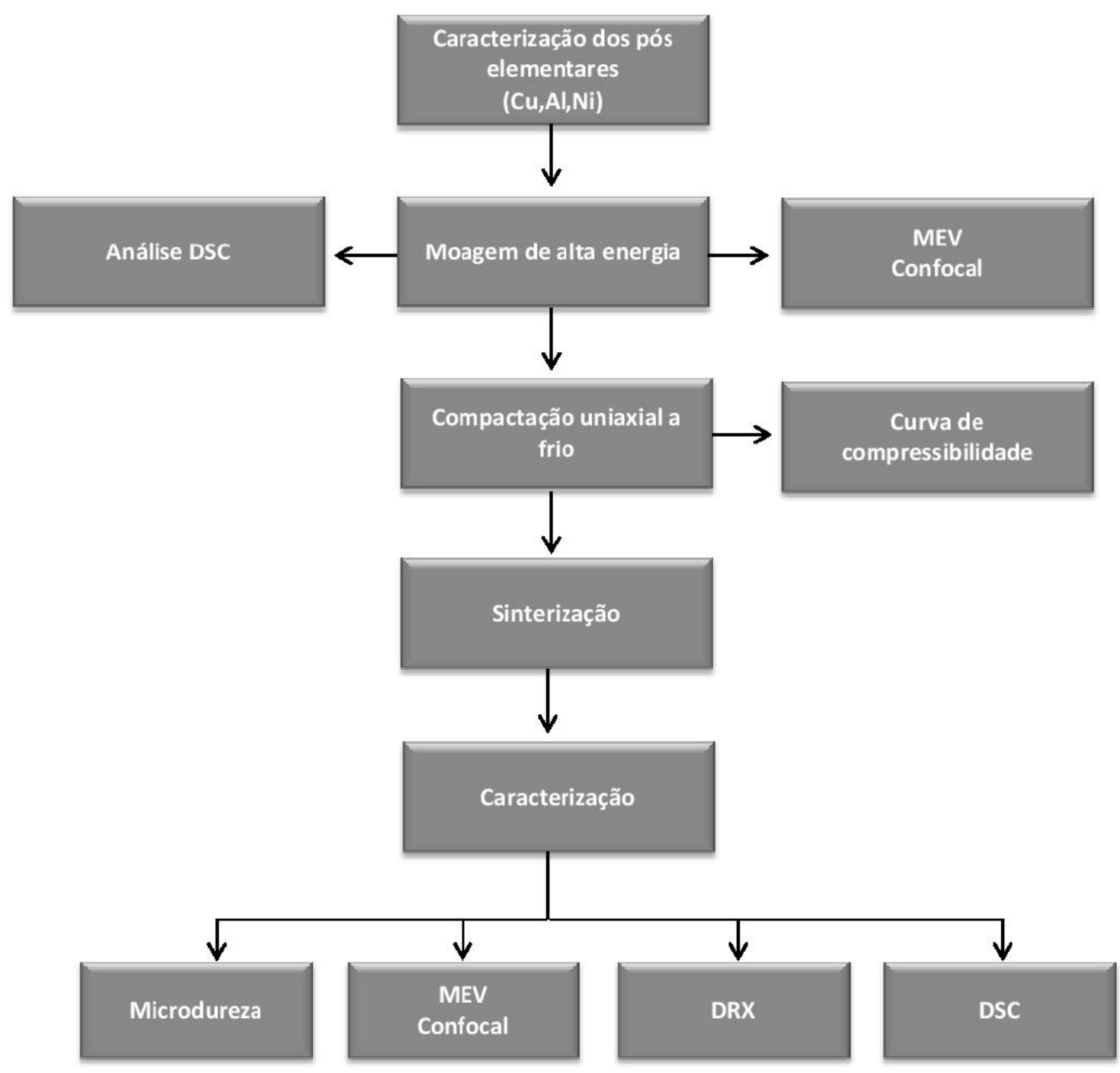

Figura 3.1: Fluxograma das etapas do trabalho.

Vale ressaltar que neste trabalho o parâmetro que sofreu variação foi somente o tempo de moagem. Assim, as diferenças observadas nos resultados que serão apresentados são consequências somente da influência do tempo de moagem. 


\subsection{Caracterização dos pós elementares}

Para a avaliação da morfologia dos pós metálicos de Alumínio $(\mathrm{Al})$, Cobre $(\mathrm{Cu})$ e Níquel (Ni) (estes adquiridos de empresas fabricantes de pós metálicos) utilizou-se o Microscópio Eletrônico de Varredura (MEV) da marca JEOL, modelo JSM-7100F. Para visualização no microscópio as amostras foram depositadas sobre uma fita de carbono dupla face e, então analisadas. Foi aproveitada a espectroscopia de energia dispersiva (EDS) o qual possibilita a determinação da composição qualitativa e semiquantitativa das amostras, a partir da emissão de raios X característicos, e então, comparada com as especificações técnicas fornecidas pelos fabricantes.

Outra etapa foi a realização da análise DSC nos pós elementares, de forma individual, com o intuito de determinar a temperatura de fusão dos mesmos.

\subsection{Moagem}

Para a preparação da liga CuAlNi via metalurgia do pó, inicialmente, foi necessário realizar a mistura e homogeneização dos pós através do moinho de bolas planetário, da marca Retsch modelo PM 100. Escolheu-se como técnica de mistura a moagem de alta energia para que houvesse ligação mecânica entre os elementos envolvidos durante a moagem. A quantidade dos pós foi adicionada respeitando os respectivos teores da composição em peso da liga, ou seja, 83\% de Cobre, 13\% de Alumínio e 4\% de Níquel. Esta composição foi escolhida de acordo com Otsuka, Wayman, 1998, que afirma que estas concentrações (podendo haver pequenas variações como apresentado na revisão bibliográfica) são as concentrações ótimas para a obtenção da liga CuAlNi com efeito memória de forma. Além disso, esta composição já é utilizada em ligas produzidas com fins comerciais. À mistura total adicionou-se $1 \%$ de estearato de zinco, o qual atuou como agente controlador do processo, e também como lubrificante para contribuir na compactação e facilitar o desmolde da peça compactada.

Os parâmetros utilizados na moagem foram a rotação $(250 \mathrm{rpm})$, razão bola-pó (10:1) e variou-se o tempo de moagem em 2, 4, 8 e 16 horas. Para evitar a oxidação dos pós, a moagem foi realizada a vácuo. Com o intuito de evitar superaquecimento na câmera de moagem, foram programadas paradas de quatro minutos a cada dez minutos de moagem. Um esquema simplificado do procedimento de moagem para duas horas esta exemplificado na Figura 3.2. 


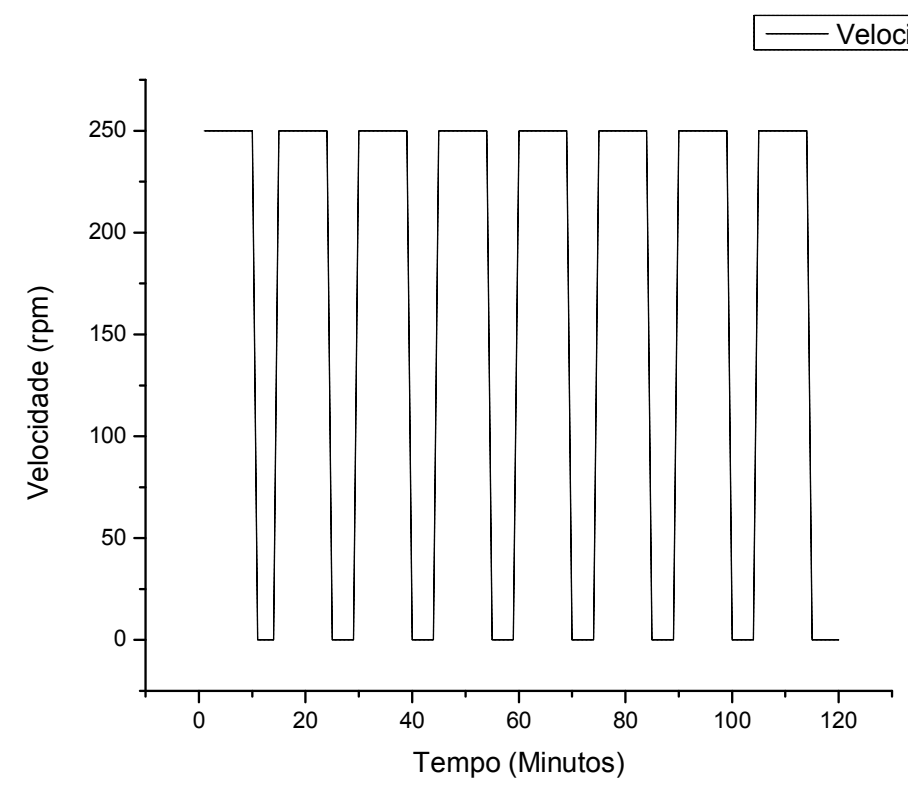

Figura 3.2: Procedimento de moagem.

Após a etapa de moagem, realizou-se a análise DSC nos pós moídos, para a determinação do ponto de fusão da mistura e, posteriormente, utilizá-lo como parâmetro de referência na escolha da temperatura de sinterização. Além disso, observou-se, através do MEV e do microscópio Confocal da marca Olympus modelo LEXT OLS 4100, a diferença morfológica nas misturas após a moagem. Por fim, para a confirmação da formação de ligação mecânica entre os elementos envolvidos na moagem utilizou-se a técnica de eletrón-retroespalhado (BSE-Backscattering electrons) (etapa realizada no MEV).

\subsection{Compactação}

Confeccionou-se a matriz de compactação no formato cilíndrico com as seguintes especificações: altura da matriz: $30 \mathrm{~mm}$, diâmetro externo: $25 \mathrm{~mm}$, diâmetro interno: 15 $\mathrm{mm}$, de acordo com a Figura 3.3.
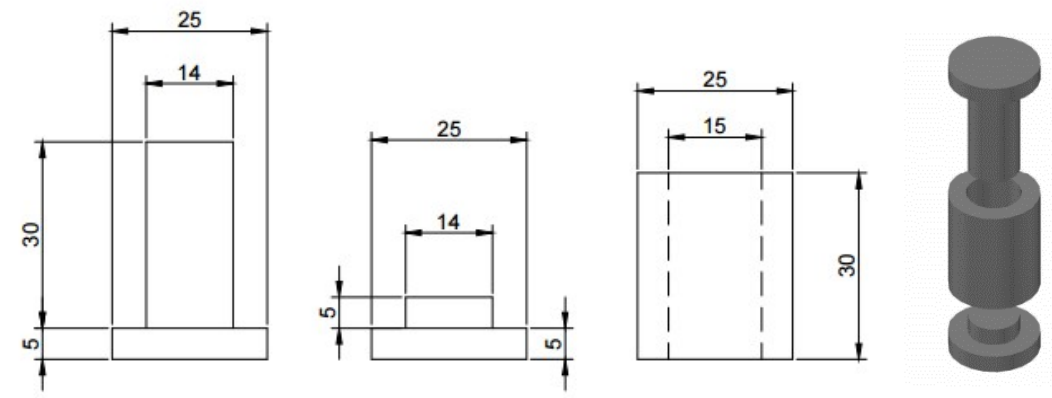

Figura 3.3: Desenho esquemático da matriz de compactação 
Para determinar a pressão ideal de compactação em cada amostra, foram construídas curvas de compressibilidades dos pós moídos por diferentes tempos. Realizou-se essa etapa de acordo com a norma Standard Test Method for Compressibility of Metal Powders in Uniaxial Compaction (ASTM B331-16). O método de compactação escolhido para os testes, assim como para a confecção da curva de compressibilidade foi a compactação uniaxial a frio, realizados em uma prensa hidráulica com capacidade máxima de 10 toneladas. Foram feitos três ciclos de prensagem, com intervalo entre eles de 60 segundos até a pressão ideal para cada amostra.

\subsection{Sinterização}

As sinterizações das peças compactadas foram realizadas em forno tubular da marca Carbolite modelo MTF 12/25/250, com atmosfera controlada de argônio. Como é necessária a retirada do estearato de zinco utilizado como lubrificante realizou-se a sinterização em duas etapas como é apresentado na Figura 3.4. A primeira etapa consistiu no aquecimento da temperatura ambiente até $450^{\circ} \mathrm{C}$, seguido de uma isoterma de 60 minutos, havendo a eliminação do lubrificante. Na segunda etapa da sinterização, continuou-se o aquecimento de $450^{\circ} \mathrm{C}$ até $1000^{\circ} \mathrm{C}$, seguido de uma isoterma de 90 minutos. Posteriormente, as amostras sofreram resfriamento lento no forno.

A taxa de aquecimento utilizada durante o processo de sinterização foi de $5^{\circ} \mathrm{C} / \mathrm{min}$. Essas temperaturas foram definidas baseadas nos valores encontrados para a temperatura de eliminação do estearato de zinco, e de fusão da mistura dos pós metálicos, através da análise DSC que foram, respectivamente, $400^{\circ} \mathrm{C}$ e $1060^{\circ} \mathrm{C}$.

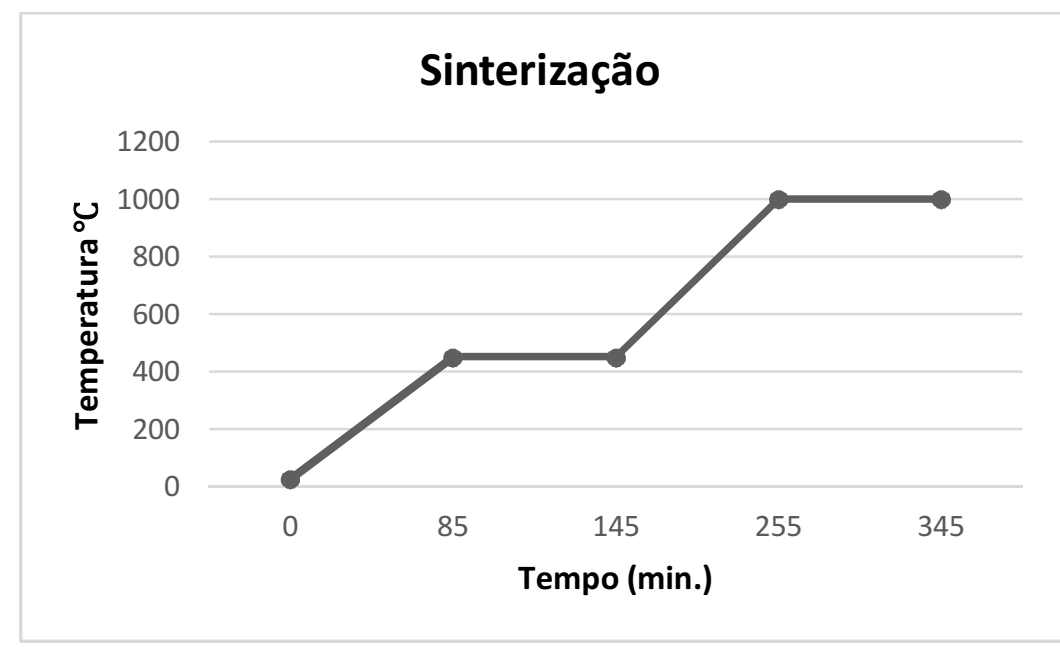

Figura 3.4: Etapas da sinterização. 
Após o cálculo da densidade (como apresentado posteriormente na seção 4.9) as amostras sinterizadas passaram pelo processo de metalografia, de acordo com a norma padrão Standard Guide for Preparation of Metallographic (ASTM E3-11) para que fossem realizadas, em seguida, as microscopias e análises de microdureza do sinterizado. Para a preparação metalografica, as amostras foram cortadas, nos sentidos longitudinais e transversais e, posteriormente embutidas. As peças foram lixadas na sequência de lixas de granulometria de \#220, \#400, \#600, \#800, \#1200 e \#2500 e polidas em alumina dispersa de 1,0 e $0,03 \mu \mathrm{m}$.

\subsection{Densidade aparente}

A densidade aparente considera-se a mistura dos pós metálicos após o processo de moagem. Desta forma, ela é determina calculando a razão entre a massa do pó solto e seu respectivo volume (CHIAVERINI, 2001). As densidades aparentes foram calculadas para os quatro diferentes tempos de moagem de cada teste.

\subsection{Densidade a verde}

Após a compactação calculou-se a densidade a verde da peça compactada através do método geométrico. Para este cálculo considerou-se a massa do compactado e seu respectivo volume, de acordo com a Eq. (1) (CHIAVERINI, 2001). Utilizou-se os pós moídos por 2, 4, 8 e 16 horas.

$$
\rho_{\text {verde }}=\frac{\text { massa do compactado }}{\text { volume do compactado }}
$$

Para o cálculo do volume das peças compactadas, realizaram-se as medidas de suas alturas e diâmetros com o auxílio de um paquímetro digital. O valor da massa foi gerado utilizando uma balança analítica de precisão. Com os valores obtidos calculou-se a média das densidades, os desvios padrão assim como as incertezas associadas a cada medida. 


\subsection{Densidade teórica}

O cálculo da densidade teórica da liga Cu-13Al-4Ni, determinada através da Eq. (2) é importante para determinar a porosidade da peça fabricada via metalurgia do pó (JABUR et. al., 2013).

$$
\rho_{\mathrm{t}}=\frac{\left[\left(\rho_{\mathrm{Cu}} \times \mathrm{w}_{\mathrm{Cu}}\right)+\left(\rho_{\mathrm{Al}} \times \mathrm{w}_{\mathrm{Al}}\right)+\left(\rho_{\mathrm{Ni}} \times \mathrm{w}_{\mathrm{Ni}}\right)\right]}{100}
$$

Em que,

$\rho_{t}:$ densidade teórica da mistura;

$w_{C u}$ : percentual em peso do cobre;

$w_{A l}$ : percentual em peso do alumínio;

$w_{N i}:$ percentual em peso de níquel;

$w_{\text {est }}:$ percentual em peso do estearato de zinco;

$\rho_{C u}$ : densidade teórica do cobre;

$\rho_{A l}$ : densidade teórica do alumínio;

$\rho_{N i}$ : densidade teórica do níquel;

$\rho_{\text {est }}:$ densidade teórica do estearato de zinco.

Para este cálculo considerou-se $\rho_{C u}=8,93 \mathrm{~g} / \mathrm{cm}^{3}, \rho_{A l}=2,70 \mathrm{~g} / \mathrm{cm}^{3}$ e $\rho_{N i}=8,91 \mathrm{~g} / \mathrm{cm}^{3}$, $\rho_{\text {est }}=1,05 \mathrm{~g} / \mathrm{cm}^{3}$.

\subsection{Densidade do sinterizado}

O cálculo da densidade do sinterizado, $\rho_{\text {sint }}$, foi realizado através do método de Arquimedes utilizando água destilada como líquido de imersão. Neste procedimento a massa seca e a massa úmida da peça são consideradas, uma vez que existem poros que não podem ser desprezados na densidade final. Da mesma maneira, com os resultados obtidos foram calculadas as médias com seus respectivos desvios padrão e incertezas associadas.

\subsection{Porosidade}

A porosidade nas peças sinterizadas pode interferir em diversas propriedades do material, como a dureza, módulo de elasticidade, rugosidade, propriedades magnéticas, 
dentre outras. Desta forma, é de grande importância para a caracterização do material produzido determinar sua porosidade $(\varphi)$. Esta pode ser calculada através da Eq. (3), que utiliza a densidade teórica obtida através da Eq. (2) e a da peça sinterizada determinada através do método de Arquimedes (JABUR et. al., 2013).

$$
\varphi=\left[1-\left(\frac{\rho_{\text {sint }}}{\rho_{\mathrm{t}}}\right)\right] \times 100
$$

Com os valores encontrados para as densidades dos sinterizados e a teórica, calculou-se a porosidades de todas as amostras.

\subsection{Análise DSC das peças sinterizadas}

Para entender o comportamento da liga após a sinterização em relação à temperatura, realizaram-se as análises DSC nas amostras nos diferentes tempos de moagem. Para a análise, as amostras sinterizadas foram cortadas até atingirem massa igual ou inferior a $15 \mathrm{mg}$, e tamanhos igual ou inferiores a 2,35 $\mathrm{mm}$ de diâmetro e 3,9 mm de altura (dimensões do cadinho utilizado na análise). Posteriormente, as amostras cortadas foram tratadas em banho de ultrassom por 15 minutos, imersas em acetona para a retirada de impurezas presentes nas mesmas. Assim, as amostras foram levadas para a realização da análise no DSC da marca PerkinElmer, modelo 8500. A faixa de temperatura utilizada na análise foi de 0 a $450^{\circ} \mathrm{C}$ com taxa de $20^{\circ} \mathrm{C} /$ minuto, em atmosfera de nitrogênio.

\subsection{Difratometria de raio- $x$}

Para a determinação das fases formadas na liga após a sinterização realizou-se a DRX das amostras no equipamento da marca Rigaku, modelo Ultima 4. Estas foram cortadas em formatos de lâminas, lixadas e polidas para remover a camada de óxido formada. Posteriormente, foram levadas ao banho de ultrassom por 15 minutos imersas em acetona para remover impurezas evitando erro nas análises. As condições para a análise DRX foram estabelecidas com faixa de $20^{\circ}$ a $70^{\circ}$, com passo de $0,05^{\circ}$ e velocidade de $1 \%$ minuto. Os difratogramas obtidos foram analisados no software Crystallographica Search-Match. 


\subsection{Microdureza}

Após a realização da metalografia, foram efetuados os testes de microdureza Vickers utilizando o microdurômetro da marca Future Tech modelo FM-700. As medições foram realizadas em toda a extensão das amostras, aplicando uma carga de 10 gf. Em cada amostra o valor da microdureza foi obtido em cinco pontos diferentes, sendo calculado a média e, o seu respectivo desvio padrão. 


\section{Resultados e discussões}

A seguir são apresentados os resultados, e suas respectivas discussões para cada etapa do processo de obtenção e caracterização da liga de $\mathrm{Cu}-13 \mathrm{Al}-4 \mathrm{Ni}$ via metalurgia do pó.

\subsection{Caracterização dos pós metálicos}

Nesta seção são apresentados os resultados para as análises de composição química dos pós metálicos de $\mathrm{Cu}, \mathrm{Al}$ e $\mathrm{Ni}$ obtidas pela técnica Espectroscopia por Energia de Raios-X (EDS) e as análises morfológicas ambas realizadas no MEV. Para a determinação da temperatura de fusão de cada elemento envolvido foi realizada a análise DSC dos pós elementares.

\subsubsection{Pó de Cobre (Cu)}

De acordo com o Figura 4.1 observa-se que o cobre apresenta formato irregular caracterizando a fabricação via atomização à água. O pó de cobre, adquirido da empresa BRATS possuiu 99,62\% em massa de $\mathrm{Cu}$, como é apresentado na Figura 4.2, indicando alta pureza e adequação para a técnica de metalurgia do pó.

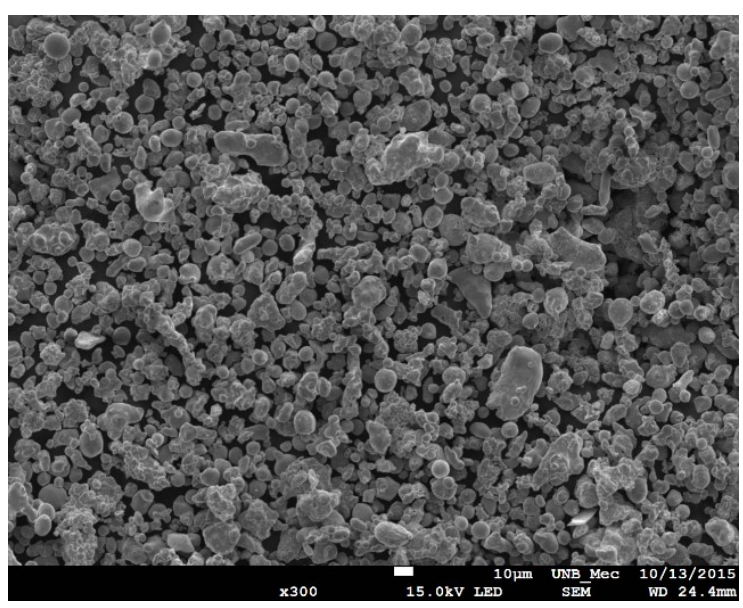

(a)

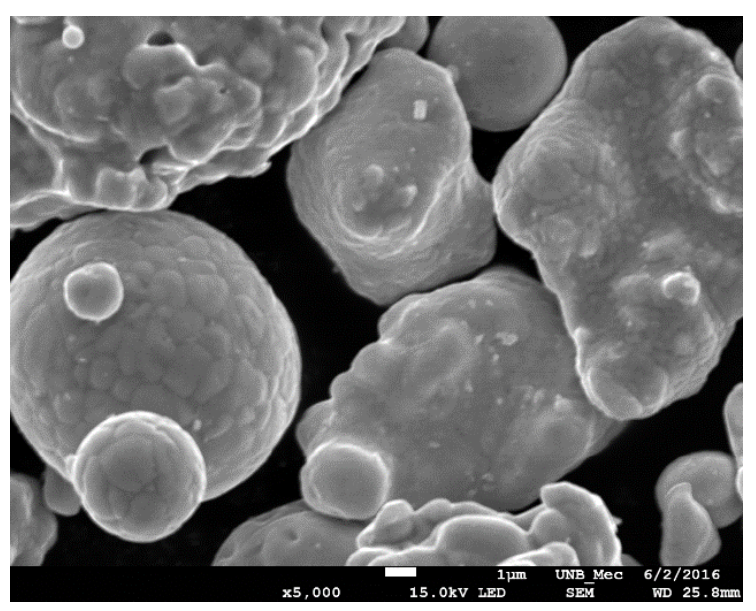

(b)

Figura 4.1: Pó de Cobre (a) aumento de 300x (b) aumento de 5000x. 


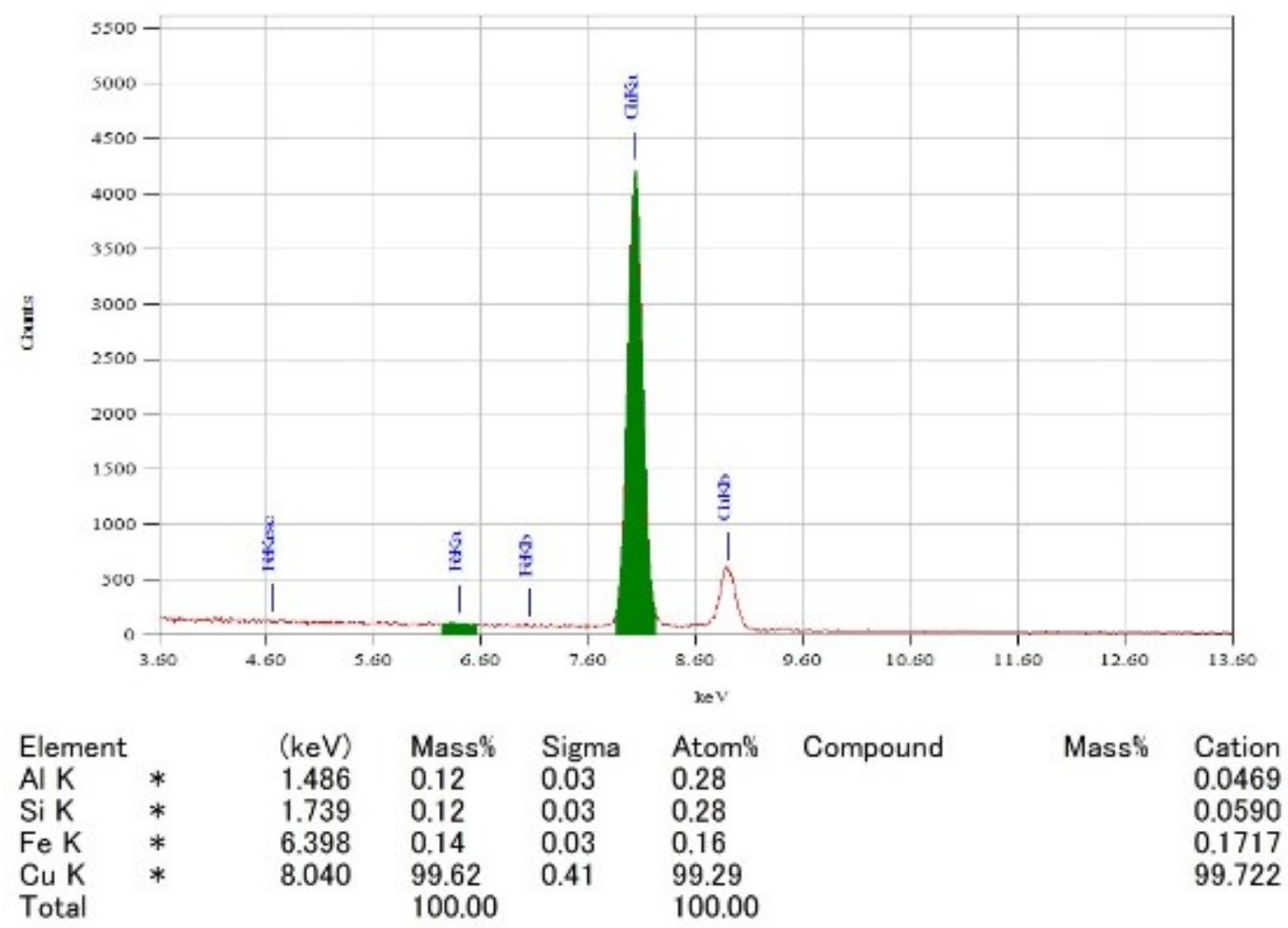

Figura 4.2: Resultado da EDS para o pó de Cobre.

A análise DSC do pó de cobre mostrou que ele apresenta a temperatura de fusão de aproximadamente $1083,78^{\circ} \mathrm{C}$.

\subsubsection{Pó de Níquel (Ni)}

A análise morfológica no MEV mostrou que este possui formato esponjoso, como pode ser visto nas Figuras 4.3. A EDS realizada para o pó de níquel (adquirido na empresa BRATS), de acordo com a Figura 4.4, mostrou que este pó possuía elevada pureza, sendo o percentual em massa de Ni de 99,67\%.

Pelo fato do formato do Ni ser irregular e de aspecto esponjoso, entende-se que o pó deste metal foi fabricado pelo processo Carbonila. A temperatura de fusão para o níquel é de aproximadamente $1445^{\circ} \mathrm{C}$. 


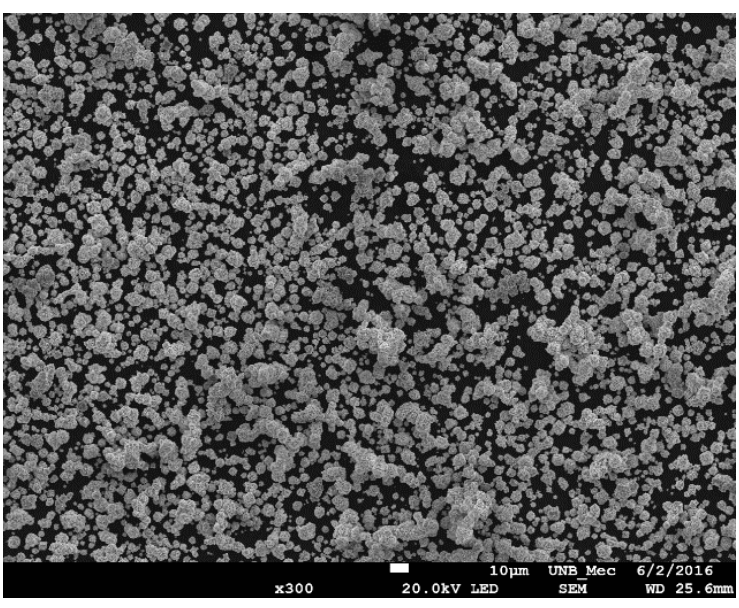

(a)

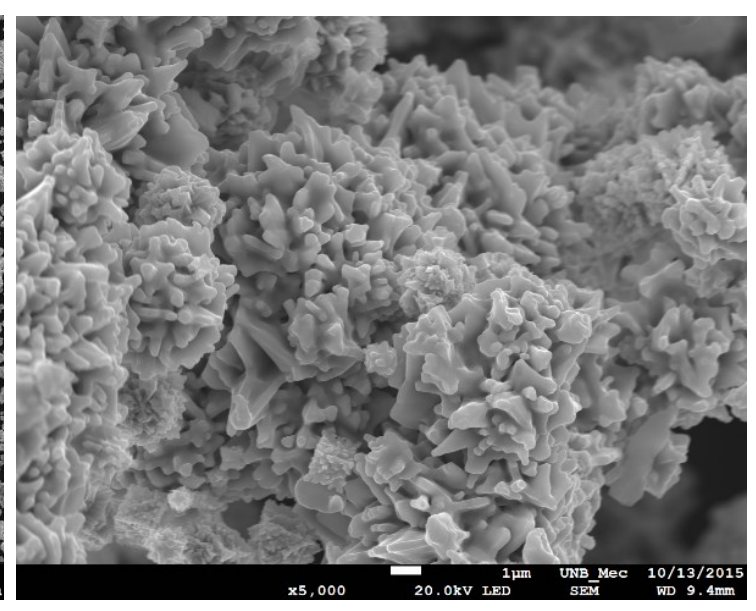

(b)

Figura 4.3: Pó de Níquel (a) aumento de 300x (b) aumento de 5000x

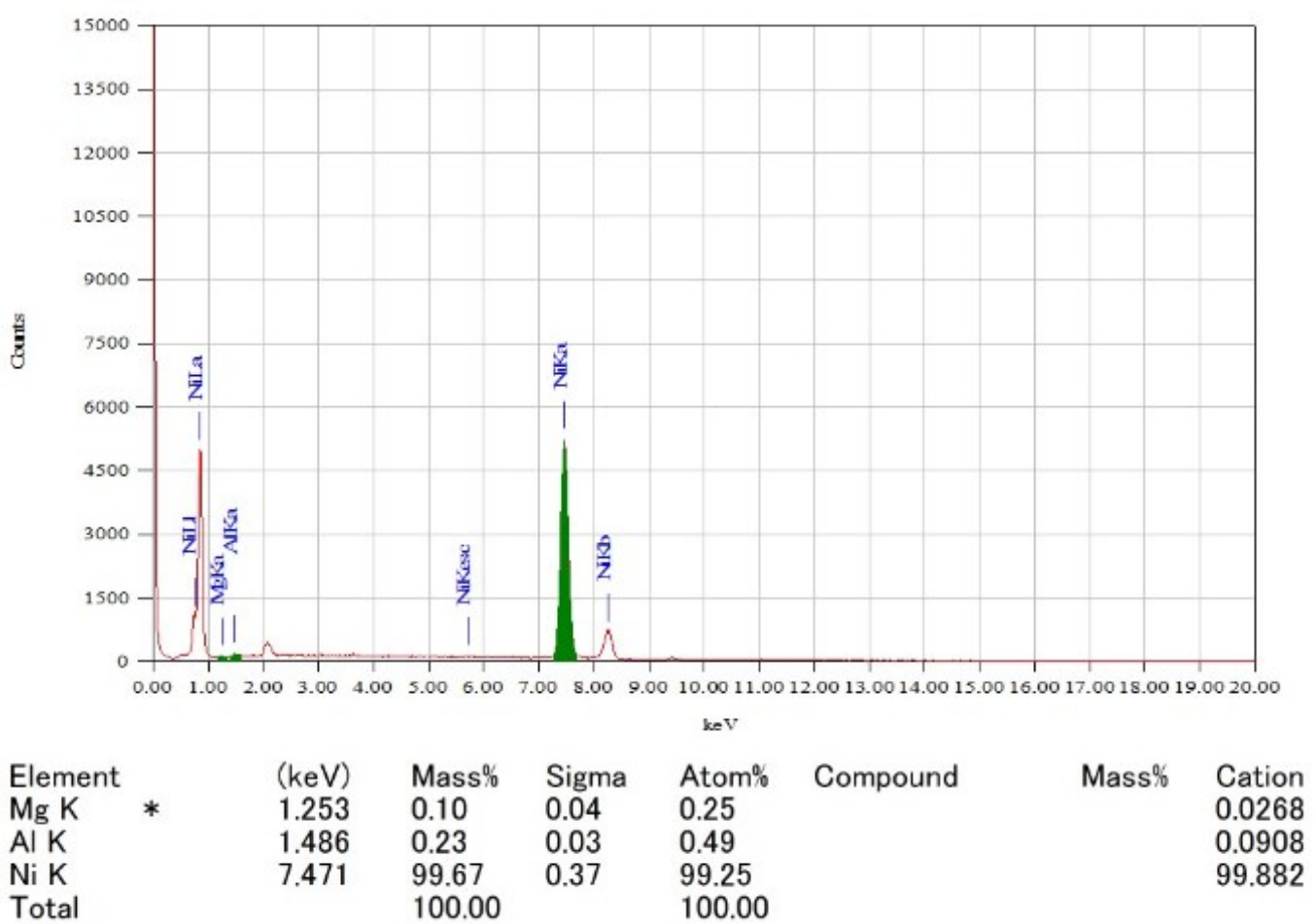

Figura 4.4: Resultado da EDS para o pó de Níquel.

\subsubsection{Pó de Alumínio (Al)}

A análise DSC do pó de alumínio, fornecido pela Alcoa, mostrou que este apresenta temperatura de fusão de aproximadamente $692,33^{\circ} \mathrm{C}$. A Figura 4.5 apresenta as imagens obtidas no MEV para o pó de alumínio, observa-se que sua morfologia é esférica e nodular, caracterização processo de fabricação por atomização a ar. Com a técnica EDS, apresentada na Figura 4.6, afirma-se que o pó de alumínio possui pureza de 99,96\%. 


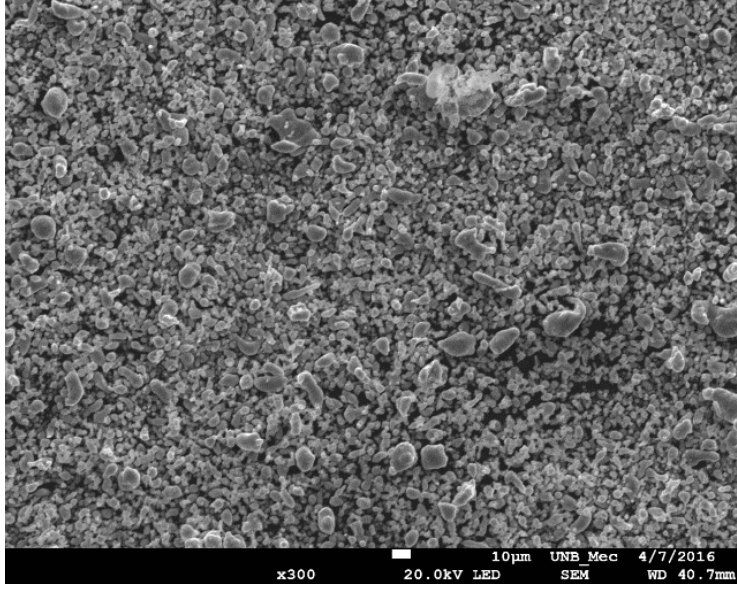

(a)

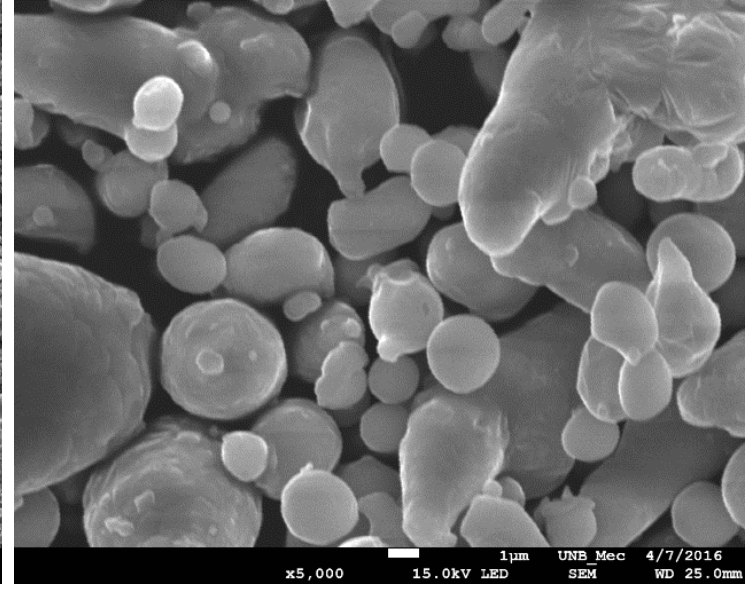

(b)

Figura 4.5: Pó de Alumínio (a) aumento de 300x (b) aumento de 5000x.

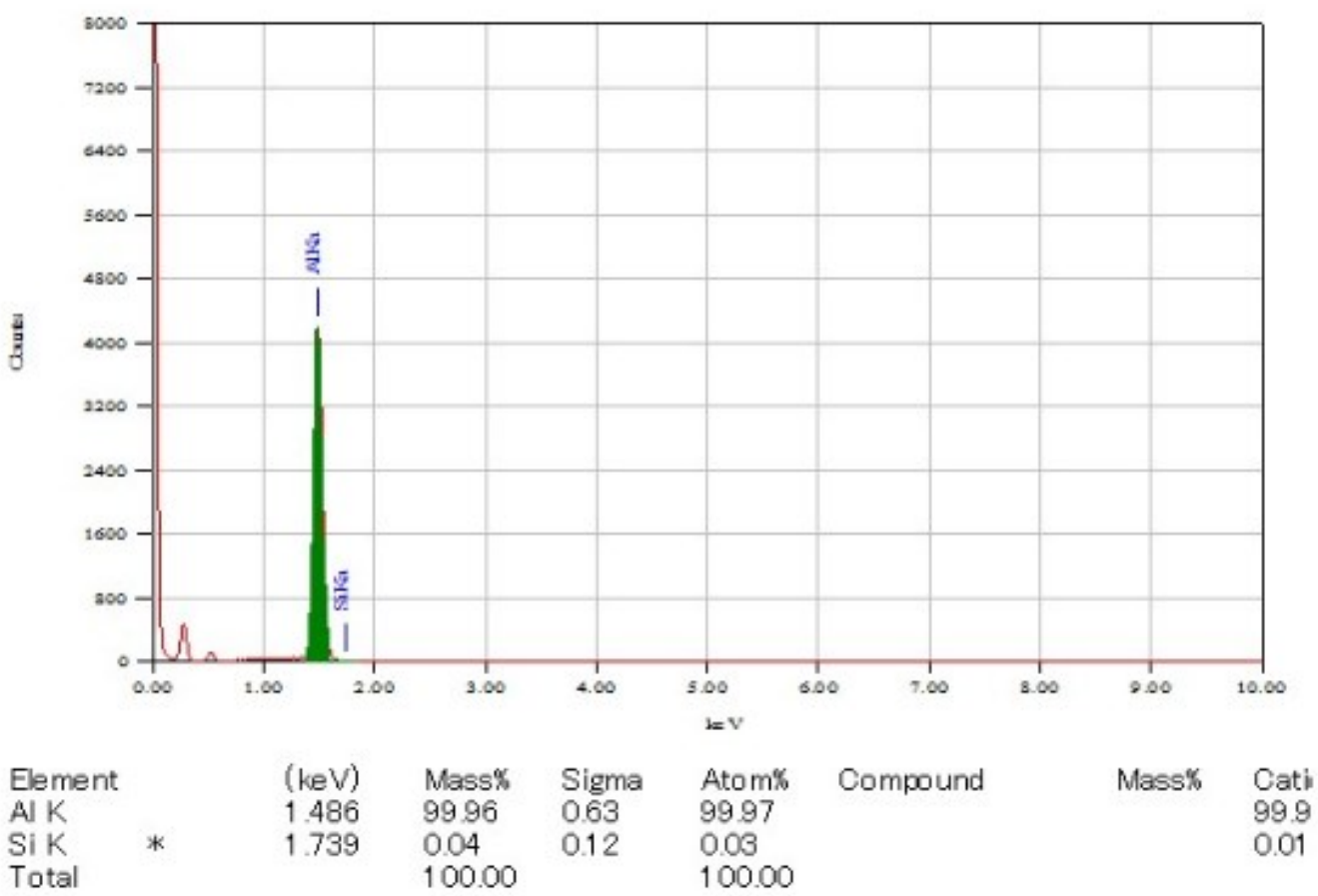

Figura 4.6: Resultado da EDS para o pó de Alumínio.

De acordo com a pureza ideal, acima de $99,5 \%$, para os pós elementares indicada por Ferreira, 2002 pode-se dizer que todos os pós metálicos ( $\mathrm{Cu}, \mathrm{Al}$ e $\mathrm{Ni}$ ) estão adequados para a fabricação da liga CuAlNi via metalurgia do pó.

\subsection{Análise morfológica dos pós após a moagem}

Realizou-se as análises no Confocal e no MEV das misturas dos pós obtidas após a moagem de alta energia para a confirmar se houve ligação mecânica entre eles. Na 
Figura 4.7 são apresentadas as imagens obtidas para as misturas após os diferentes tempos de moagem.

Visualmente, não há diferença morfológica entre as misturas dos pós para os diferentes tempos de moagem. O que se pode dizer é que houve união entre os pós elementares e ligação mecânica entre eles. Este fato é confirmado na mudança de coloração dos elementos e na modificação da morfologia dos pós.

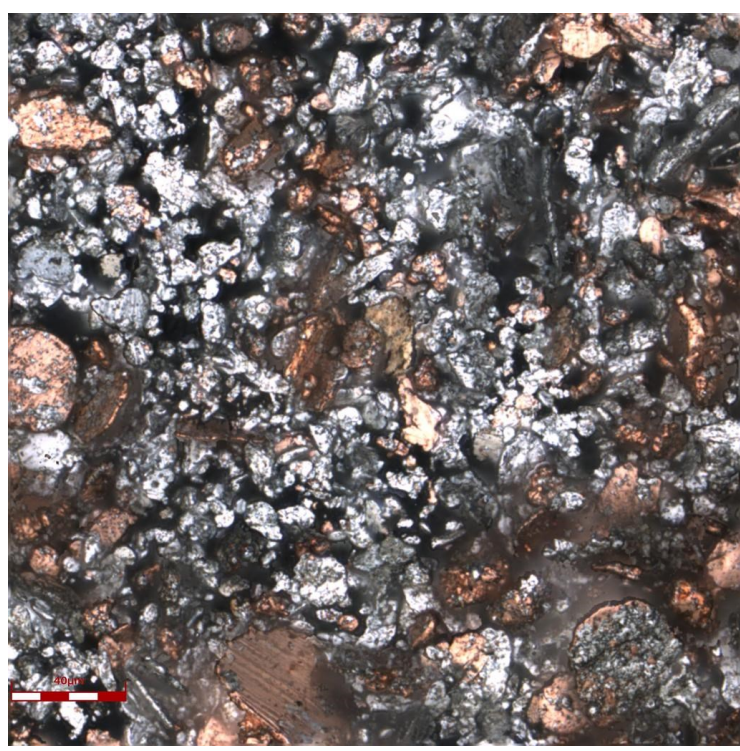

(a)

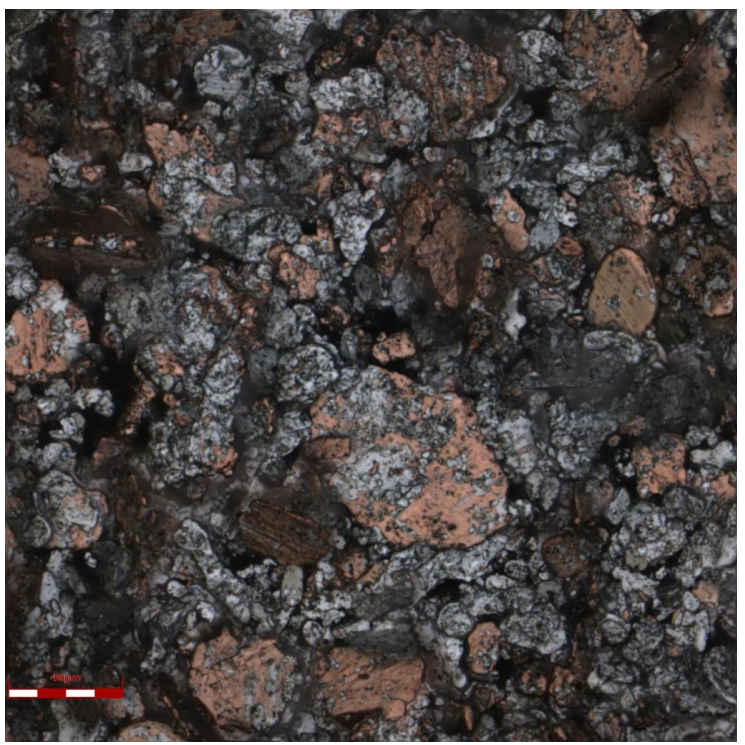

(c)

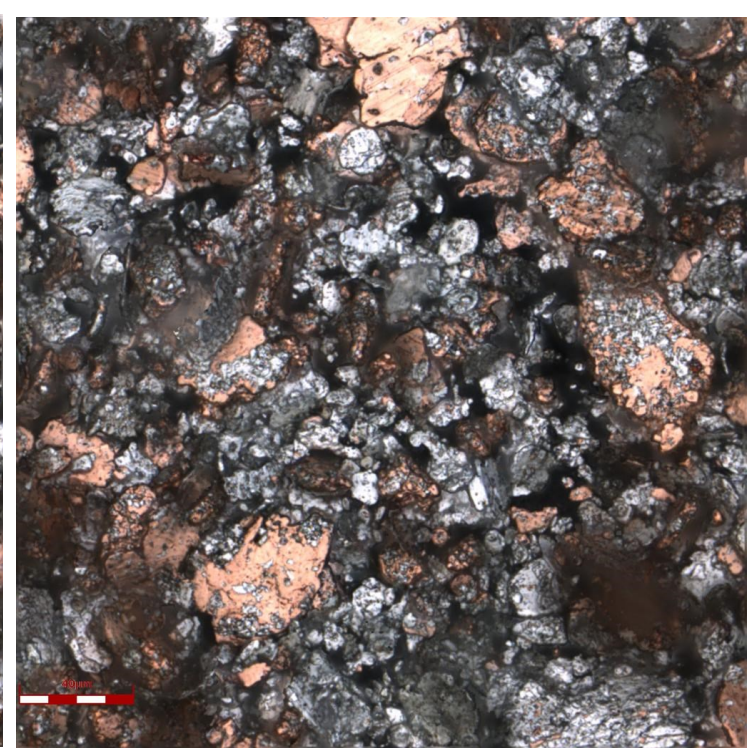

(b)

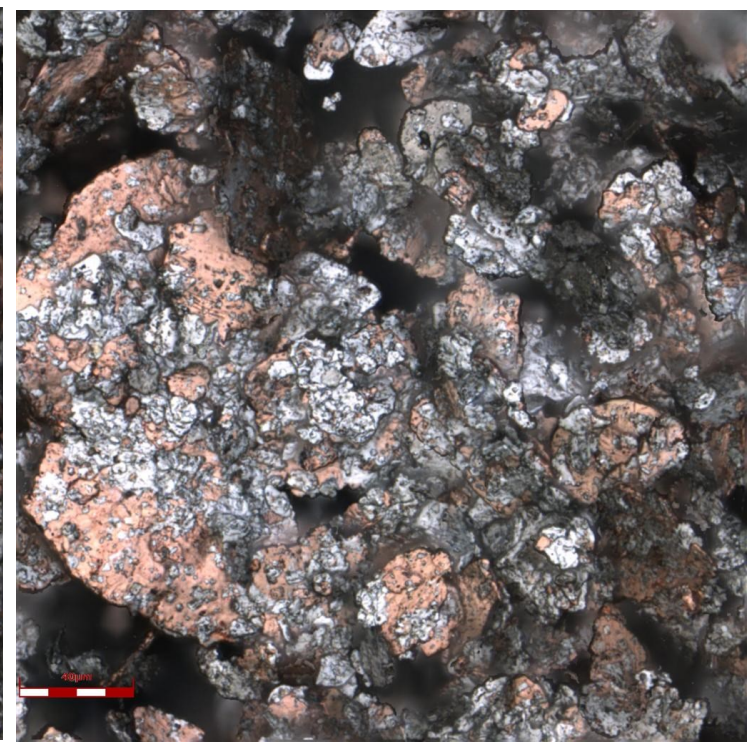

(d)

Figura 4.7: Pós metálicos após diferentes tempos de moagem (aumento 50x). (a) 2h (b) 4h (c) $8 \mathrm{~h}(\mathrm{~d}) 16 \mathrm{~h}$.

Na Figura 4.8, na qual os pós não sofreram moagem de alta energia, a diferença morfológica de todos os elementos envolvidos em relação aos pós que sofreram 
moagem apresentados na Figura 4.7 é bem nítida, sendo possível a identificação individual de cada elemento, diferentemente do que ocorre para os pós após serem moídos por tempos iguais e superiores a 2 horas.

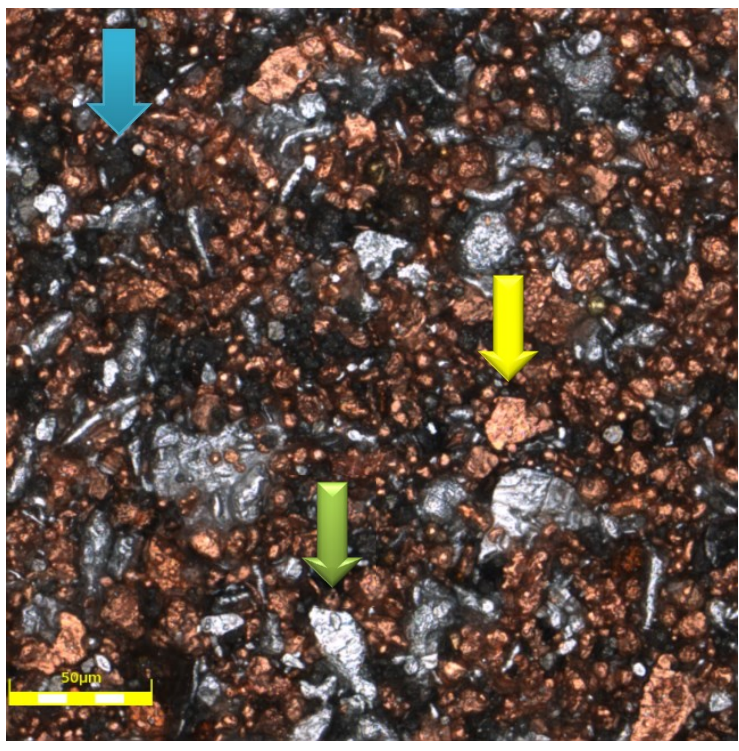

(a)

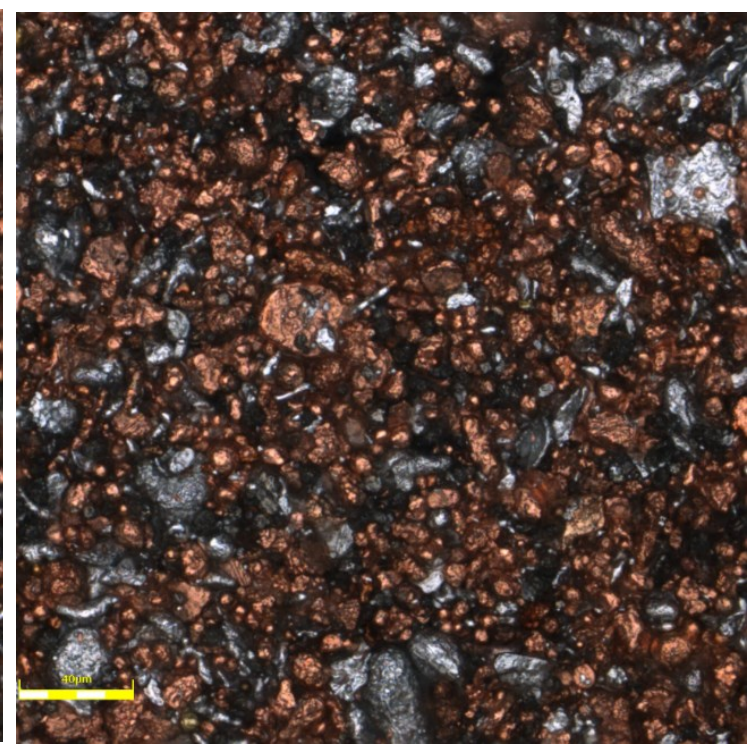

(b)

Figura 4.8: Pós metálicos sem sofrerem moagem de alta energia (aumento 50x).

Nas imagens dos pós que não sofreram moagem é possível identificar separadamente o cobre (seta amarela), que possui coloração característica, o alumínio representado pelo tom prateado (seta verde), e o níquel que é caracterizado pela coloração cinza escuro (seta azul). Já nas imagens da Figura 4.7 essa identificação não é possível, sinal de formação de ligação mecânica e junção dos pós elementares.

As misturas dos pós também foram analisadas no MEV e as imagens obtidas estão apresentadas nas Figuras 4.9, 4.10, 4.11 e 4.12. Da mesma maneira como foi comentado para as imagens obtidas através do Confocal, observa-se que em todas as amostras houve deformação plástica dos elementos metálicos e ligação mecânica entre eles. Este fato pode ser determinado pela modificação da morfologia dos elementos envolvidos, ou seja, as partículas dos pós de $\mathrm{Cu}, \mathrm{Al}$ e $\mathrm{Ni}$ deixaram de possuir o formato específico de cada uma delas e passaram a ter um formato indefinido, havendo a formação de agregados, ou placas, (indicados pelos cículos vermelhos nas Figuras de 4.9 a 4.12) e união entre as partículas.

Visualmente é possível perceber que as partículas dos pós moídos por 2 horas apresentam menor quantidade de agregados e partículas soltas, indicadas pelas setas na Figura 4.9, concluindo que o tempo de moagem de 2 horas não foi suficiente para agregar totalmente as partículas. 
- Mistura dos pós metálicos após moagem de 2 horas

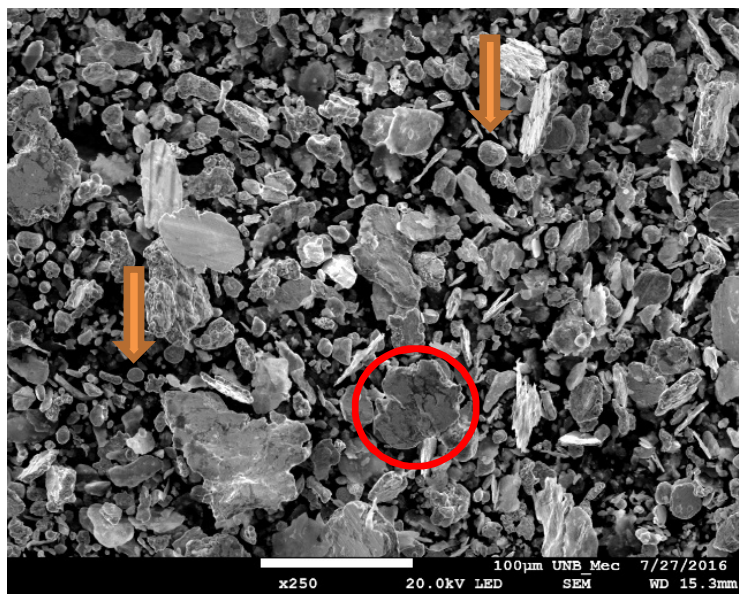

(a)

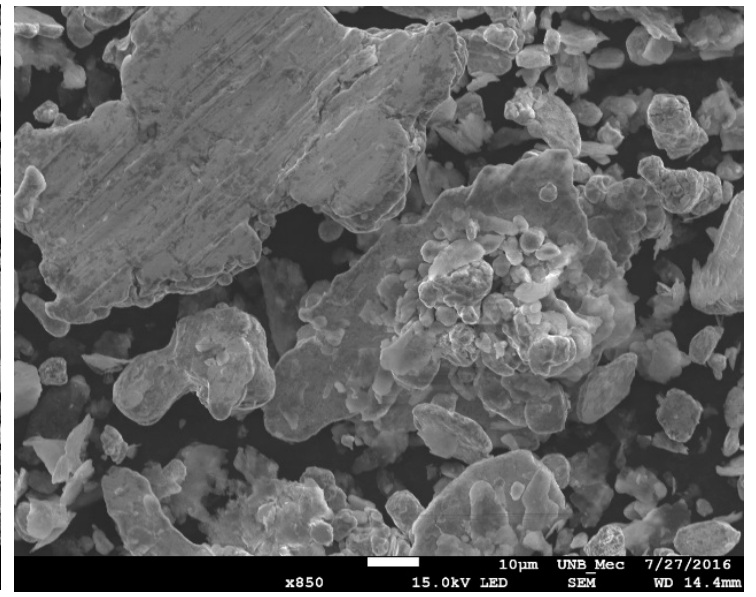

(b)

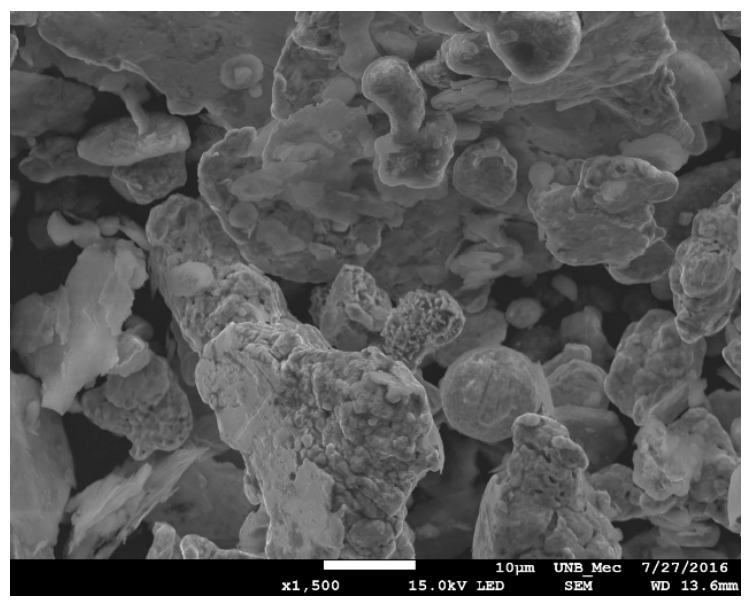

(c)

Figura 4.9: Pós metálicos após moagem de 2h. (a) aumento 250x (b) aumento de 850x (c) aumento de $1500 x$.

A partir de 4 horas de moagem, a identificação de partículas soltas já é mais difícil. Nos pós moídos por 16 horas pode-se observar maiores quantidades de "placas", em relação ao demais tempos que é uma característica de maior deformação plástica entre os pós metálicos envolvidos na moagem. 
- Mistura dos pós metálicos após moagem de 4 horas

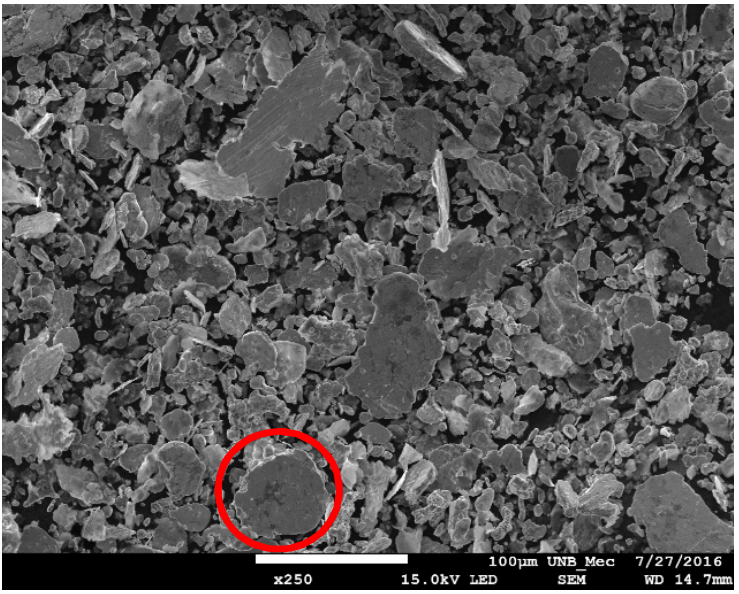

(a)

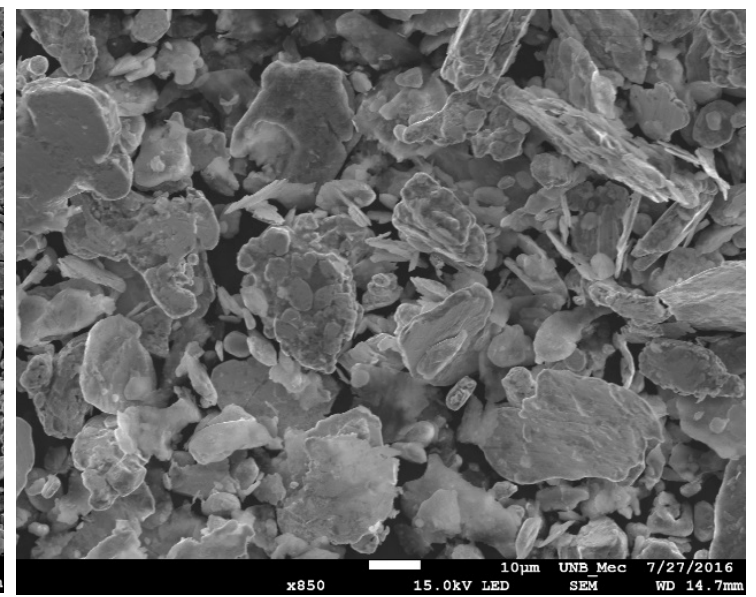

(b)

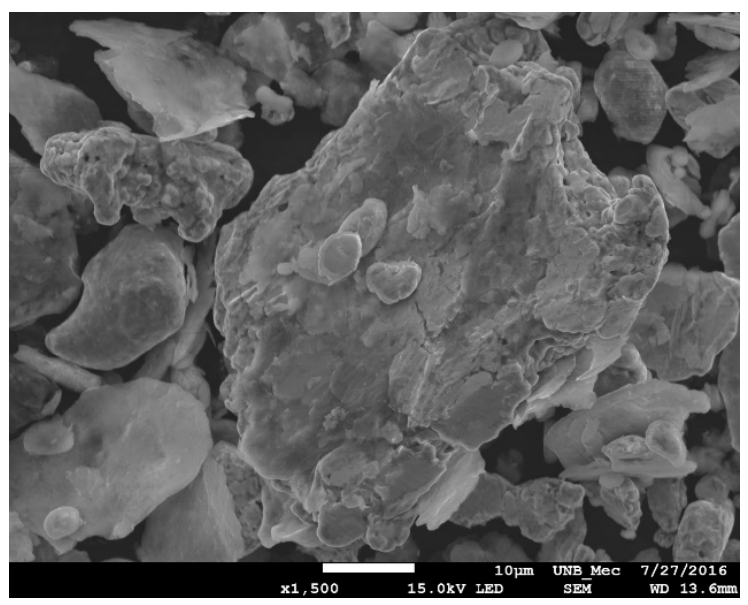

(c)

Figura 4.10: Pós metálicos após moagem de 4h. (a) aumento 250x (b) aumento de 850x (c) aumento de 1500x.

- Mistura dos pós metálicos após moagem de 8 horas

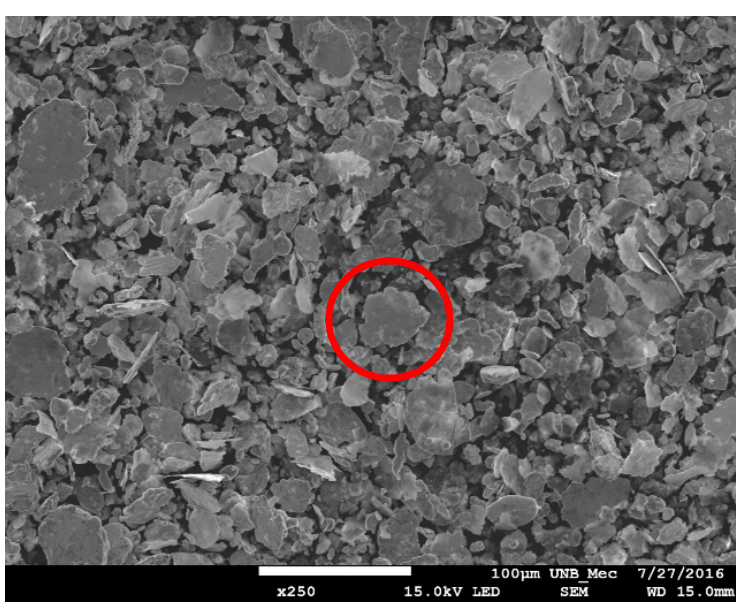

(a)

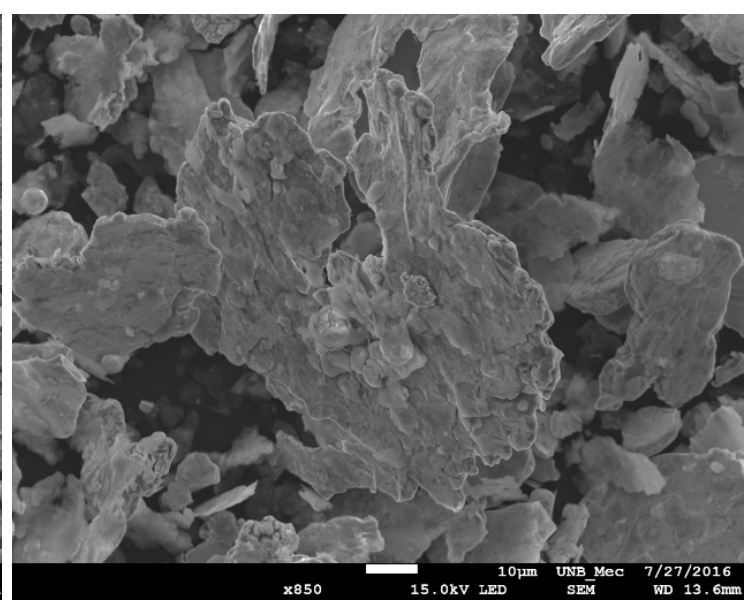

(b) 


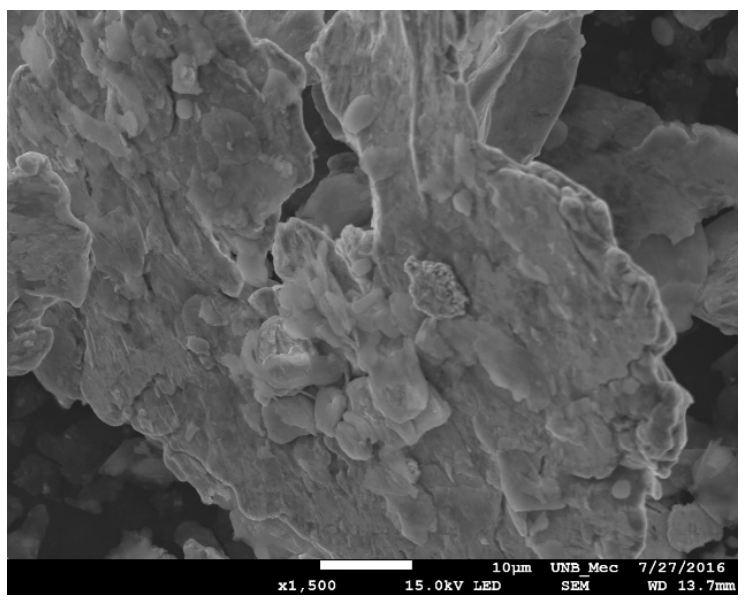

(c)

Figura 4.11: Pós metálicos após moagem de 8h. (a) aumento 250x (b) aumento de 850x (c) aumento de 1500x.

- Mistura dos pós metálicos após moagem de 16 horas

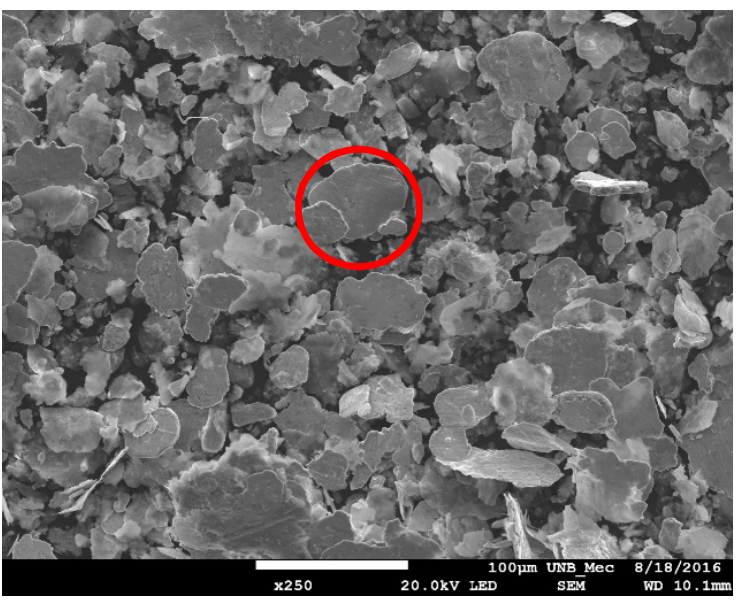

(a)

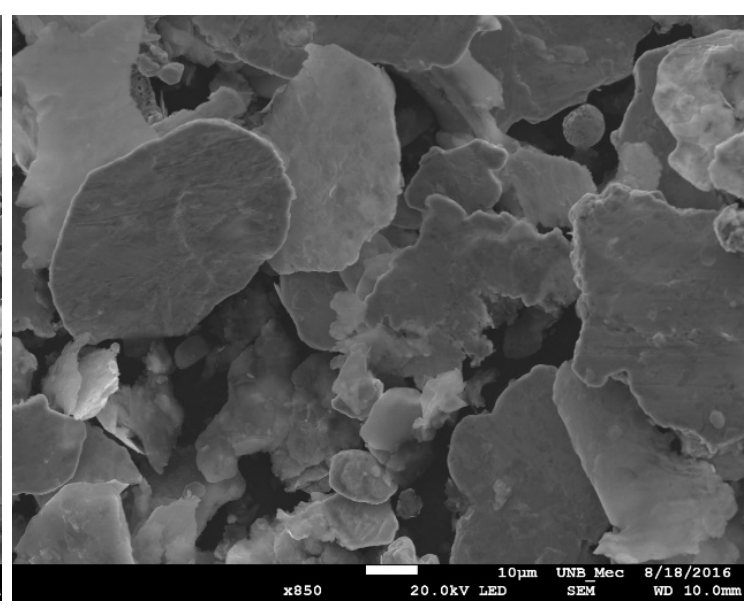

(b)

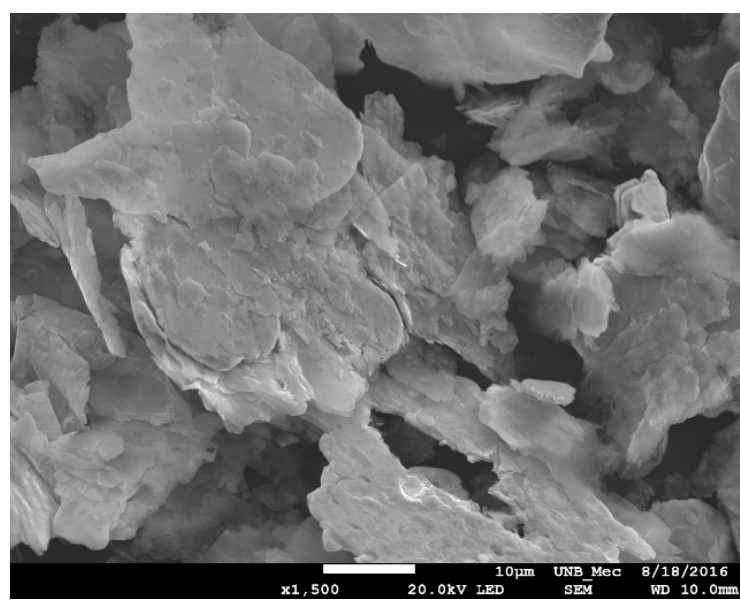

(c)

Figura 4.12: Pós metálicos após moagem de 16h. (a) aumento 250x (b) aumento de 850x (c) aumento de 1500x. 
Após a análise morfológica realizou-se no MEV a análise com a técnica BSE (Figura 4.13) para confirmar a formação de ligação mecânica entre os pós metálicos na mistura.

Com a técnica BSE houve a confirmação de que durante a moagem ocorreu ligação mecânica entre as partículas, uma vez que houve a mescla dos elementos envolvidos como está indicado pelas setas nas Figuras 4.13. Observa-se a diferença de tonalidade nas imagens, indicando elementos diferentes. As partículas mais claras são as de cobre e as mais escuras de alumínio. Como o níquel está presente em pequenas quantidades sua identificação é muito difícil (TANG et al, 1997).

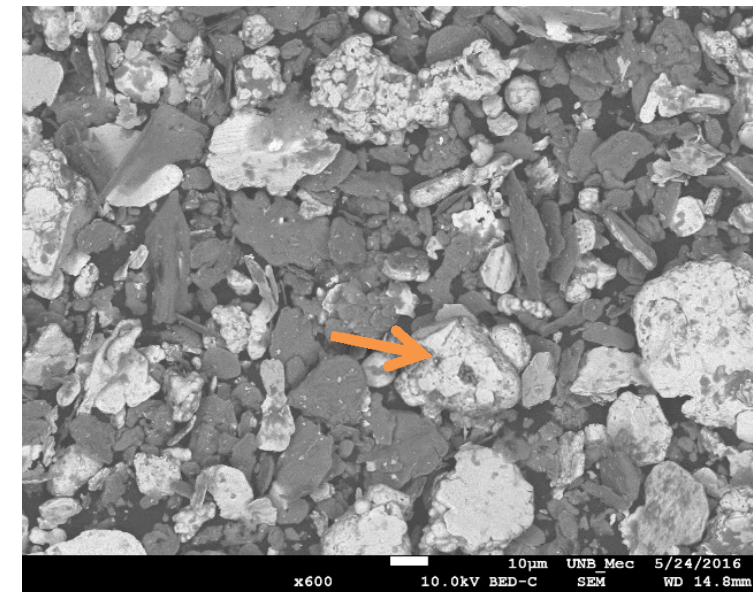

(a)

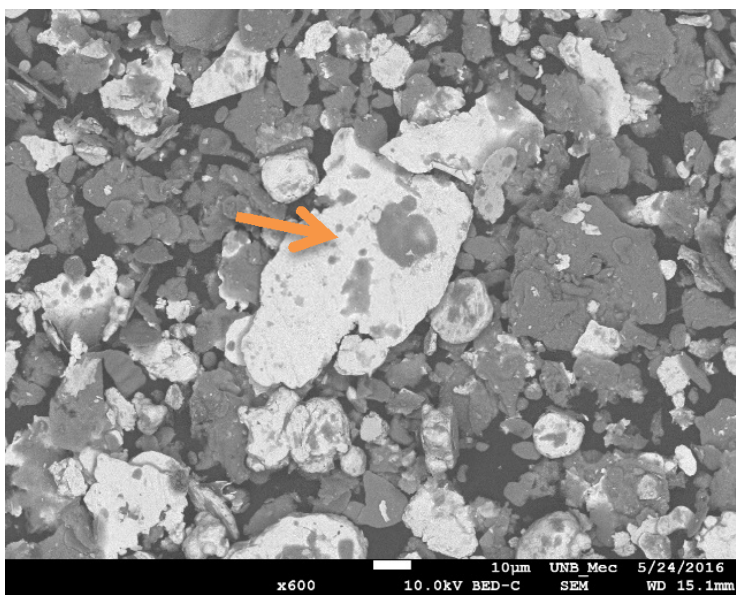

(c)

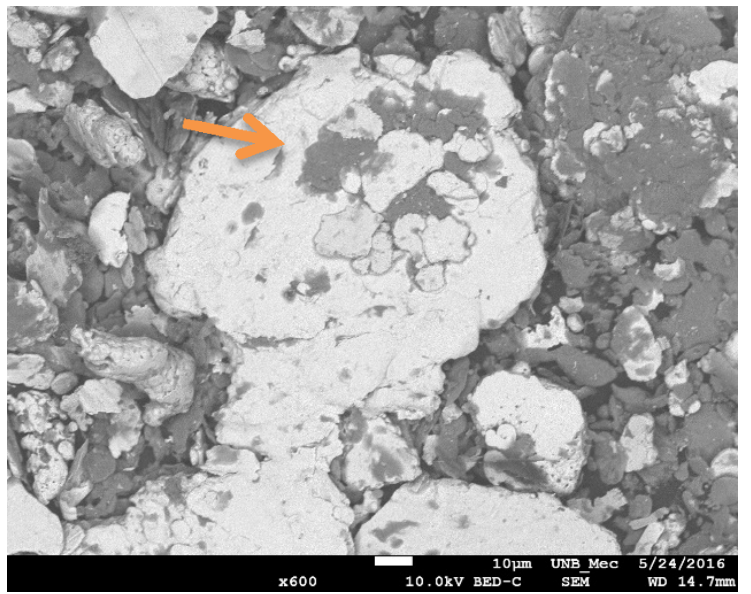

(b)

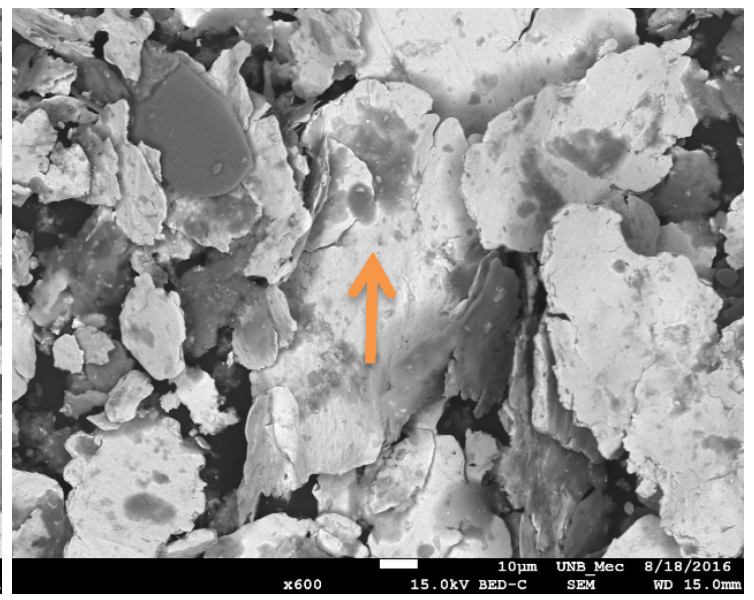

(d)

Figura 4.13: Pós metálicos após diferentes tempos de moagem (aumento 600x). (a) 2h (b) 4h (c) $8 \mathrm{~h}(\mathrm{~d}) 16 \mathrm{~h}$.

A influência direta do tempo de moagem na formação da ligação mecânica não pode ser definida visualmente através das imagens, somente é possível dizer que para 
maiores tempos de moagem, observa-se maiores quantidades de agregados devido à deformação plástica e união das partículas nas misturas. Para determinar de forma quantitativa esta influência calculou-se a densidade aparentes das misturas.

\subsection{Análise DSC dos pós após a moagem}

Com o intuito de determinar a temperatura ideal de sinterização foram realizadas as análises térmicas via DSC (ANEXO II) nas misturas dos pós após sofrerem moagem de alta energia. Os picos exotérmicos dos gráficos gerados durante análise mostraram que a liga funde em aproximadamente $1060^{\circ} \mathrm{C}$, então se determinou que a sinterização fosse realizada até $1000^{\circ} \mathrm{C}$.

Observa-se que a temperatura de fusão da liga é diferente das temperaturas de fusão dos elementos envolvidos separadamente. Este fato está de acordo com o apresentado por Tang et al. (1997), que afirma que no processo de moagem de alta energia há a modificação das características dos elementos e, consequentemente, ocorre a mudança na temperatura de fusão dos mesmos.

Durante a realização das análises também foi realizada a técnica TGA para verificar a perda de massa durante o aquecimento. Assim, foi possível determinar a temperatura na qual o estearato de zinco é eliminado da mistura que é de aproximadamente $400^{\circ} \mathrm{C}$, fator fundamental para a definição dos parâmetros envolvidos na sinterização.

\subsection{Cálculo da densidade aparente dos pós após a moagem}

As densidades aparentes dos pós após moagem de alta energia em diferentes tempos foram calculadas de acordo com a Eq. (1). Os valores obtidos para as densidades estão dispostos na Tabela 1.

Tabela 1: Valores para as densidades aparentes dos pós após a moagem.

\begin{tabular}{|c|c|c|c|c|}
\hline & Moagem 2 h & Moagem 4 h & Moagem 8 h & Moagem 16 h \\
\hline Massa (g) & $4,985 \pm 0,010$ & $4,844 \pm 0,010$ & $4,306 \pm 0,010$ & $3,655 \pm 0,010$ \\
\hline Volume (cm $\mathbf{3})$ & $2,000 \pm 0,500$ & $2,000 \pm 0,500$ & $2,000 \pm 0,500$ & $2,000 \pm 0,500$ \\
\hline Densidade (g/cm $\mathbf{3})$ & $2,492 \pm 0,623$ & $2,422 \pm 0,605$ & $2,221 \pm 0,538$ & $1,828 \pm 0,457$ \\
\hline
\end{tabular}

Com a representação gráfica da Figura 4.14 fica nítido o decrescimento das densidades aparentes dos pós com o aumento do tempo de moagem. 


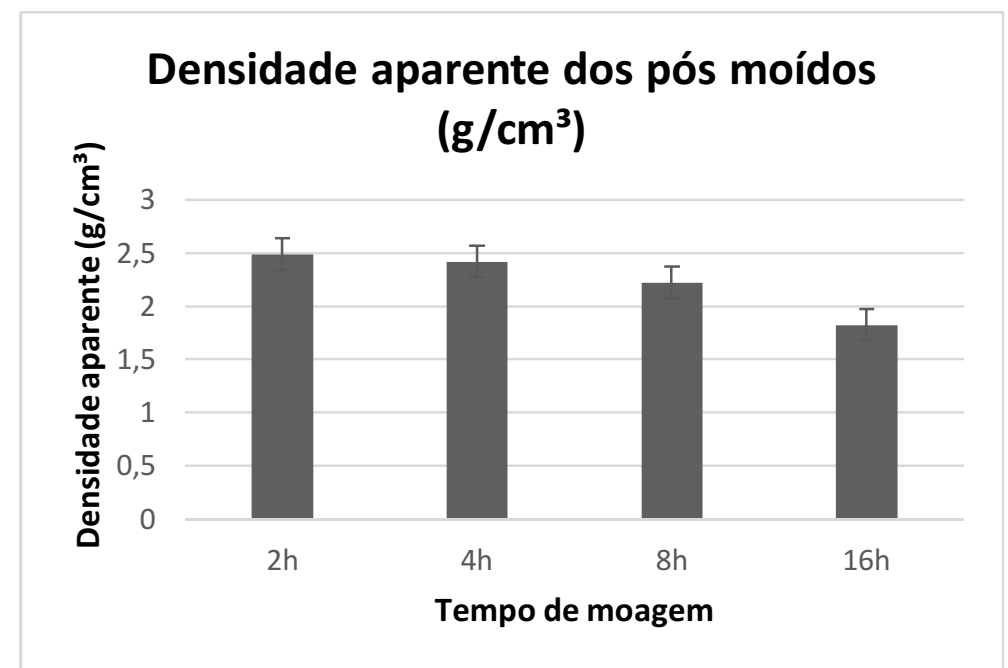

Figura 4.14: Gráfico de barras da densidade aparente em relação ao tempo de moagem.

Observa-se que quanto maior o tempo de moagem menos densa é a mistura, ou seja, a mistura dos pós metálicos com moagem de 16 horas apresenta menor densidade aparente. Este fato está de acordo com Chiaverini (2001), pois, este afirma que quanto mais as partículas se diferirem do formato esférico, menor será a densidade aparente. Neste caso, os pós moídos por 16 horas apresentaram maior deformação plástica fazendo com que a sua morfologia se diferisse muito da esfericidade (formação de agregados), influenciando diretamente na densidade aparente. Assim, pode-se dizer que o tempo de moagem, neste caso, influenciou diretamente a formação de agregados de partículas e no valor da densidade aparente da mistura após a moagem.

\subsection{Cálculo da densidade teórica}

Utilizando a Eq. (2) foi possível obter o valor de $\rho_{t}=8,119 \mathrm{~g} / \mathrm{cm}^{3}$ para a densidade teórica da liga Cu-13Al-4Ni. Este resultado é importante para a comparação dos valores de densidade do sinterizado com o esperado (densidade teórica). Além disso, utilizou-se este valor para o cálculo da porosidade das amostras obtidas.

\subsection{Curvas de compressibilidade}

Para determinar a pressão ideal de compactação, foram geradas as curvas de compressibilidade dos pós moídos durante diferentes tempos. Os gráficos obtidos são importantes, uma vez que nem sempre maiores pressões significam melhores compressibilidades. Vale ressaltar que os ferramentais, bem como as técnicas de compactação influenciam na densificação e na pressão final aplicada dos pós. As 
Figuras 4.15, 4.16, 4.17 e 4.18 apresentam, respectivamente, as curvas de compressibilidade obtidas para os pós moídos por $2 \mathrm{~h}, 4 \mathrm{~h}, 8 \mathrm{~h}$ e $16 \mathrm{~h}$.

Observa-se que os pós moídos por 2 horas apresentaram maior densificação após a aplicação de 2 toneladas $(39,927 \mathrm{MPa})$, uma vez que para quantidades inferiores e superiores a esta o valor da densidade a verde foi inferior.

- Moagem de 2 horas

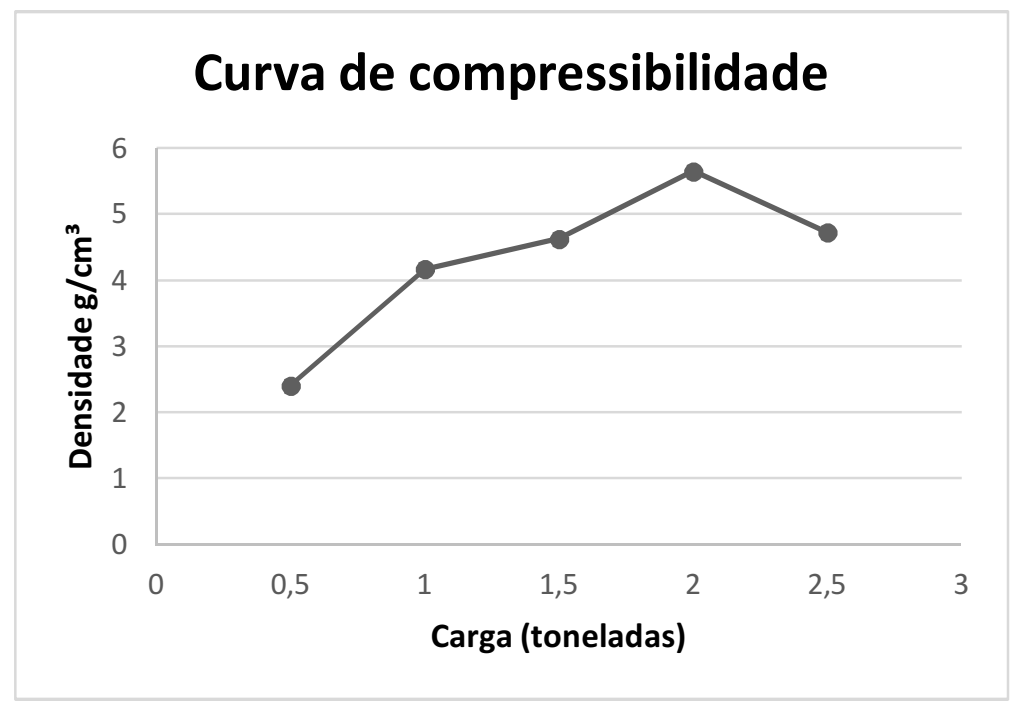

Figura 4.15: Curva de compressibilidade para os pós moídos por 2 horas.

- Moagem de 4 horas

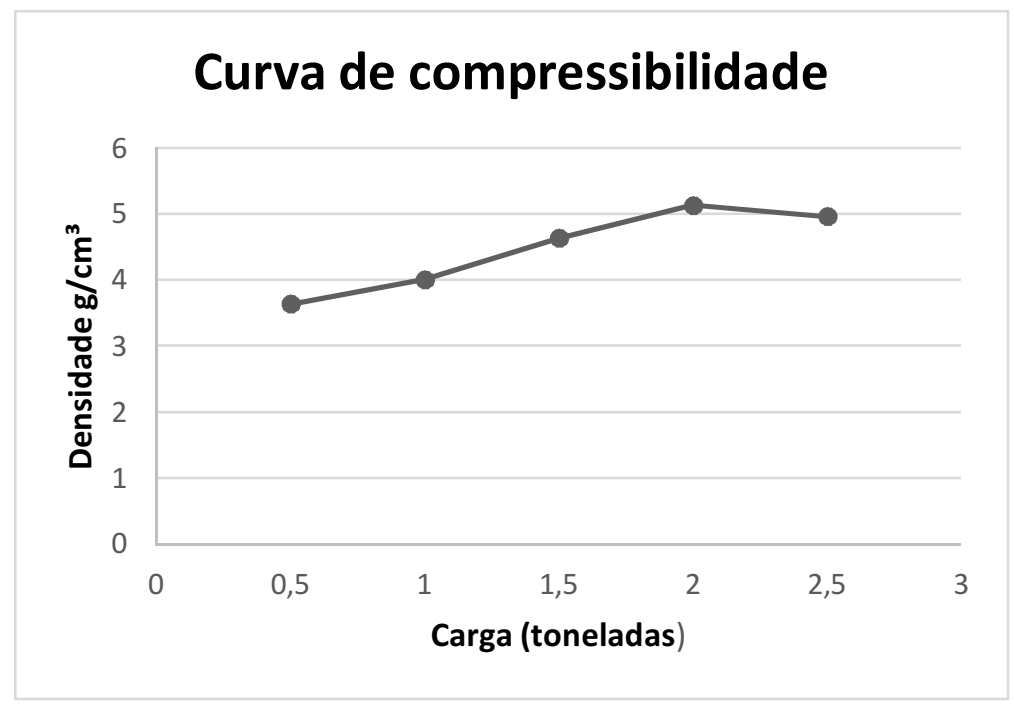

Figura 4.16: Curva de compressibilidade para os pós moídos por 4 horas.

O mesmo comportamento observado na curva de compressibilidade dos pós metálicos moídos por 2 horas foi obtido para os pós moídos por 4 horas. Ou seja, a 
maior densificação foi obtida quando se aplicou duas toneladas. Porém, a densidade ideal (em 2 toneladas) foi menor para a moagem de 4 horas se comparado com a moagem de 2 horas. Este fato também é observado na Figura 4.17 a qual apresenta a curva de compressibilidade para a moagem de 8 horas.

- Moagem de 8 horas

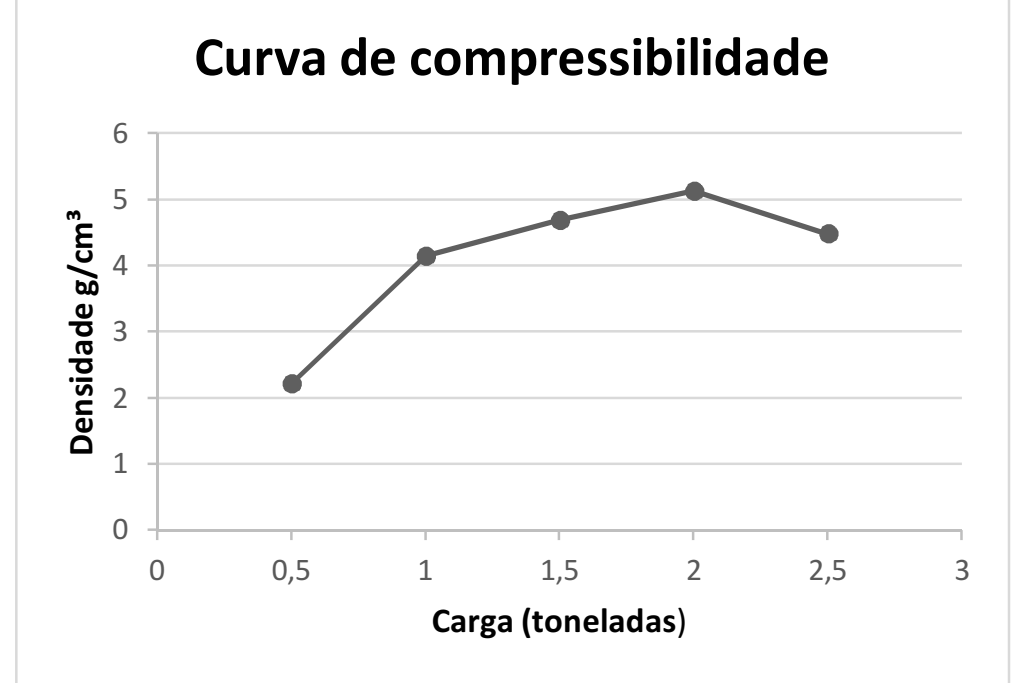

Figura 4.17: Curva de compressibilidade para os pós moídos por 8 horas.

Nos três tempos de moagem apresentados anteriormente, a quantidade de carga ideal aplicada foi de duas toneladas, sendo que, os valores das densidades a verde são inversamente proporcionais ao tempo de moagem.

- Moagem de 16 horas

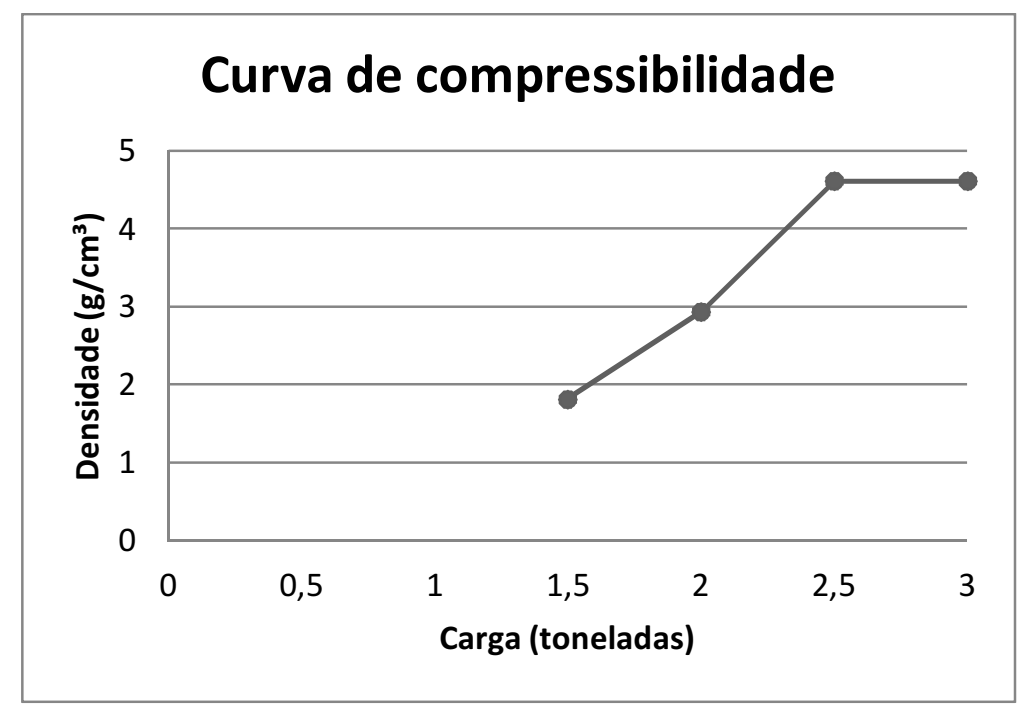

Figura 4.18: Curva de compressibilidade para os pós moídos por 16 horas. 
Para os pós moídos por 16 horas, diferentemente do que ocorreu para as amostras apresentadas anteriormente, cargas inferiores a 1,5 toneladas $(29,945 \mathrm{MPa})$ não foram suficientes para que ocorresse a compactação dos pós, não havendo formação do compactado. A partir de 1,5 toneladas foi possível obter corpos de prova, e a melhor densificação foi obtida aplicando carga de 2,5 toneladas, ou seja, 49,908 MPa. O valor da densidade a verde se manteve constante para 3,0 toneladas aplicadas e cargas superiores a esta não foram possíveis de serem testadas devido ao limite do ferramental. Estes comportamentos assim como os observados anteriormente estão discutidos e analisados na seção 4.7 .

\subsection{Cálculo das densidades a verde}

Calculou-se a densidade a verde dos compactados respeitando os procedimentos descritos na metodologia. Os valores obtidos estão apresentados na Tabela 2.

Tabela 2: Valores para os cálculos das densidades a verde das misturas.

\begin{tabular}{|c|c|c|c|c|}
\hline & Moagem de 2h & Moagem de 4h & Moagem de 8h & Moagem de 16h \\
\hline Massa (g) & $5,782 \pm 0,338$ & $4,272 \pm 0,198$ & $4,017 \pm 0,088$ & $3,100 \pm 0,010$ \\
\hline Volume (cm $\mathbf{3})$ & $1,063 \pm 0,020$ & $0,832 \pm 0,015$ & $0,783 \pm 0,044$ & $0,672 \pm 0,005$ \\
\hline Densidade (g/cm $\mathbf{3})$ & $5,439 \pm 0,365$ & $5,135 \pm 0,257$ & $5,130 \pm 0,327$ & $4,613 \pm 0,180$ \\
\hline
\end{tabular}

A Figura 4.19 apresenta o gráfico de barras para os valores de densidade a verde em função do tempo de moagem. Da mesma maneira como observado para as densidades aparentes, os valores de densidade a verde são inversamente proporcionais ao tempo de moagem.

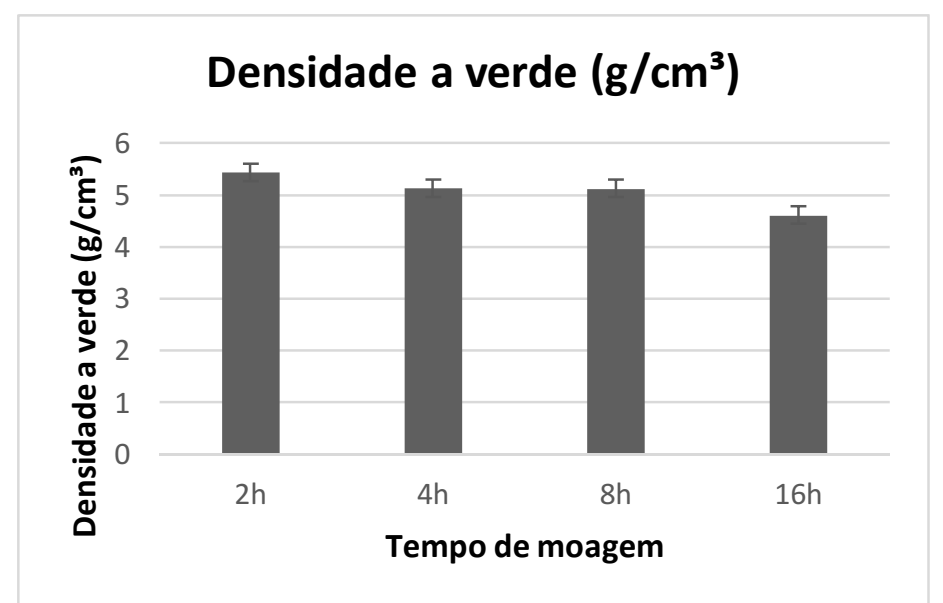

Figura 4.19: Evolução da densidade a verde com o tempo de moagem. 
Com os valores encontrados observam-se que elevando o tempo de moagem, as densidades do compactado diminuem. Esse fato está de acordo com Knewitz (2009). Este afirma que quanto mais irregulares forem as partículas, mais difícil será a compactação e, consequentemente, terá menor densificação. E neste contexto, maiores tempos de moagem tendem a deixarem as partículas mais irregulares devido à deformação plástica, e assim se obtém densidades menores.

Além disso, tempos de moagem longos ( $8 \mathrm{~h}$ e $16 \mathrm{~h}$ ) tornam as partículas mais encruadas e mais incompressíveis. Nos compactados obtidos com os pós moídos por $8 \mathrm{~h}$ e 16h observou-se o surgimento de trincas laterais devido ao alívio de tensão ao ejetálos da matriz de compactação, tendo como consequência a diminuição da densidade a verde do compactado e do sinterizado (COSTA et al., 2010)

\subsection{Densidade dos sinterizados}

As densidades dos sinterizados foram calculadas de acordo com o método de Arquimedes. A Tabela 3 apresenta os valores das densidades dos sinterizados nos diferentes tempos de moagem.

Tabela 3: Densidade dos sinterizados.

\begin{tabular}{|c|c|}
\hline Tempo de moagem & $\boldsymbol{\rho}_{\text {sint. }}\left(\mathbf{g} / \mathbf{c m}^{3}\right)$ \\
\hline $\mathbf{2} \mathbf{~ h}$ & $5,679 \pm 0,370$ \\
\hline $\mathbf{4} \mathbf{~ h}$ & $6,380 \pm 0,448$ \\
\hline $\mathbf{8} \mathbf{~ h}$ & $6,363 \pm 0,202$ \\
\hline $\mathbf{1 6} \mathbf{~ h}$ & $5,661 \pm 0,781$ \\
\hline
\end{tabular}

A Figura 4.20 apresenta o gráfico de barras para os valores das densidades do sinterizado nos quatro tempos de moagem. Diferentemente do que ocorreu para a densidade a verde dos compactados, a densidade do sinterizado aumentou de valor com o aumento do tempo de moagem, porém até um limite. 


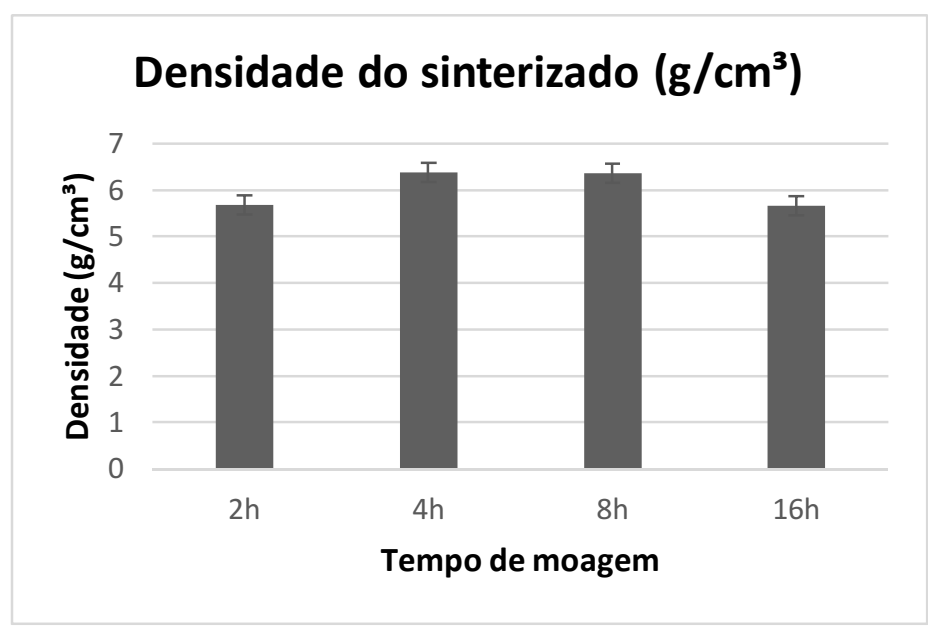

Figura 4.20: Gráfico de barras da densidade do sinterizado em relação ao tempo de moagem.

Com os resultados da Tabela 3, considerando os valores das densidades, assim como suas respectivas incertezas, observa-se que tempos de $4 \mathrm{~h}$ e $8 \mathrm{~h}$ de moagem favoreceram a obtenção de peças com maior densificação. As amostras que tiveram os pós elementares moídos por 16 horas apresentaram menor densidade, e, este fato está relacionado com a alta quantidade de vazios existentes nas amostras. Além disso, as rachaduras geradas nas peças sinterizadas com moagem de 16 horas, devido à tensão residual decorrente da alta deformação plástica e da compactação contribuiu para a diminuição da densidade. Para que haja aumento da densificação é necessário realizar um estudo de métodos mais eficazes de compactação e, avaliar se o tempo de sinterização está adequado para amostras que sofreram moagens por longos tempos, uma vez que houve diminuição na densidade dos sinterizados oriundos de pós moídos por 8 horas e 16 horas, se comparados com os moídos por 4 horas.

Os resultados apresentados para a densidade do sinterizado está de acordo com Tang et.al (1997) pois este afirma que quanto maior o tempo de moagem de alta energia sofrido pelos pós elementares, maior será a densidade do sinterizado. Porém, há um tempo ótimo de moagem, no qual abaixo ou acima deste, as densidades dos sinterizados são inferiores. Para Tang et al. (1997) o tempo ótimo obtido para a moagem de alta energia em uma liga $\mathrm{CuAlNi}$, utilizando rotação de 100 rpm e razão bola-pó de 5:1 foi de 15 horas.

\subsection{Porosidade}

As porosidades das amostras sinterizadas foram calculadas através da Eq. (3). A Tabela 4 apresenta os valores das porosidades das amostras para os diferentes tempos de moagem. 
Tabela 4: Porosidade dos sinterizados

\begin{tabular}{|c|c|}
\hline Tempo de moagem & Porosidade $(\boldsymbol{\varphi})$ \\
\hline $\mathbf{2}$ h & $30,053 \%$ \\
\hline $\mathbf{4} \mathbf{~ h}$ & $21,419 \%$ \\
\hline $\mathbf{8} \mathbf{~ h}$ & $21,628 \%$ \\
\hline $\mathbf{1 6} \mathbf{~ h}$ & $30,275 \%$ \\
\hline
\end{tabular}

O comportamento observado para as densidades do sinterizado é elucidado no cálculo da porosidade. Mesmo as amostras que apresentaram alta quantidade de vazios é possível relacionar o tempo de moagem com a porcentagem de poros do material. $\mathrm{Ou}$ seja, a moagem de alta energia, neste caso, contribuiu para a diminuição da porosidade, também até certo limite, no caso em estudo, as menores porosidades foram obtidas para os tempos de $4 \mathrm{~h}$ e $8 \mathrm{~h}$ de moagem.

Para diminuir a porosidade das ligas fabricadas por metalurgia do pó é necessário estudar todos os fatores envolvidos em sua obtenção como tempo de moagem, quantidade de lubrificante adicionado, técnica utilizada na compactação, temperatura e tempo de sinterização, dentre outros. Neste trabalho, focou-se em estudar como o tempo de moagem interfere na quantidade de poros do material, mas vale ressaltar que a porosidade final da liga é consequência de um conjunto de fatores e parâmetros utilizados.

\subsection{Microscopia dos sinterizados}

As amostras sinterizadas foram analisadas no Confocal e no MEV para verificar a efeito da sinterização e a porosidade do material. A Figura 4.21 apresenta as imagens das amostras em diferentes tempos de moagem.

Analisando as imagens obtidas no Confocal para os sinterizados observa-se que as amostras apresentaram quantidades significativas de vazios confirmando os cálculos de porosidade apresentados na seção 4.8. Outra característica observada é a diferença de coloração existente na liga, uma branca e uma alaranjada, caracterizando que houve difusão dos elementos envolvidos. 


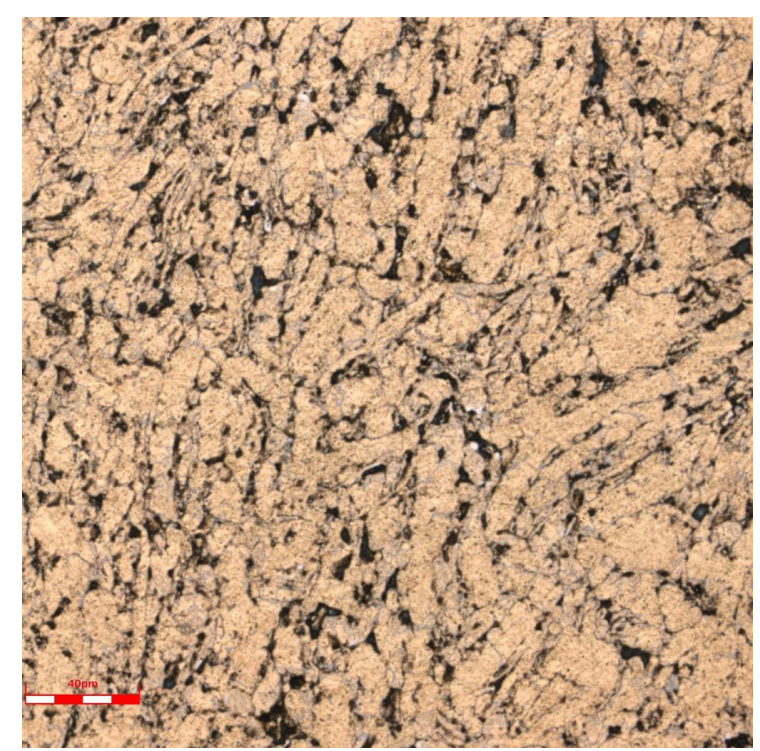

(a)

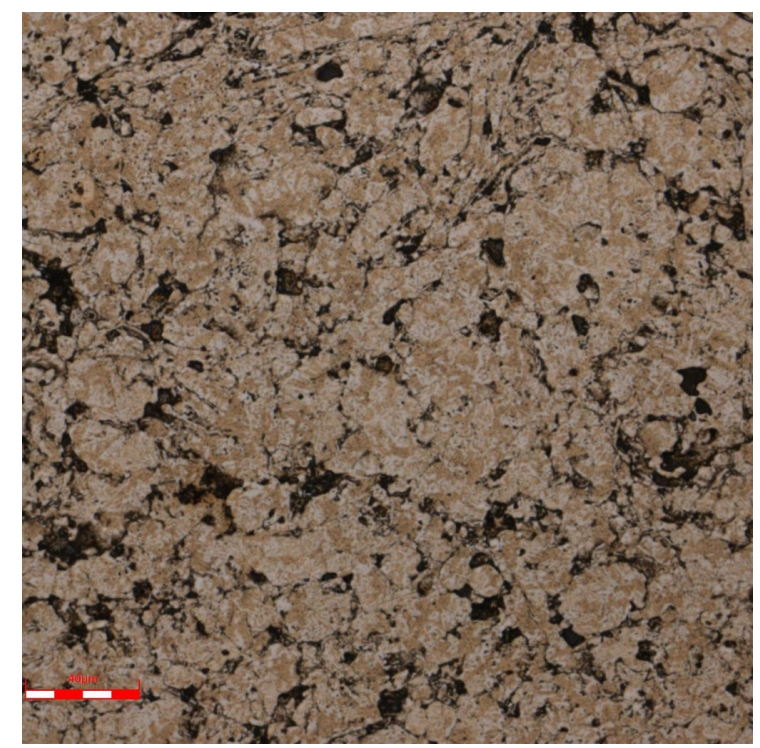

(c)

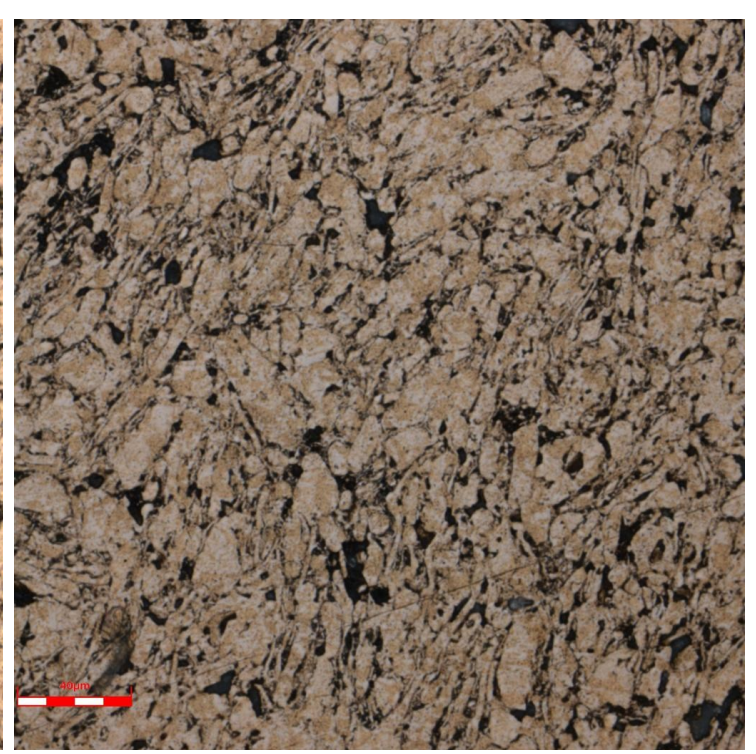

(b)

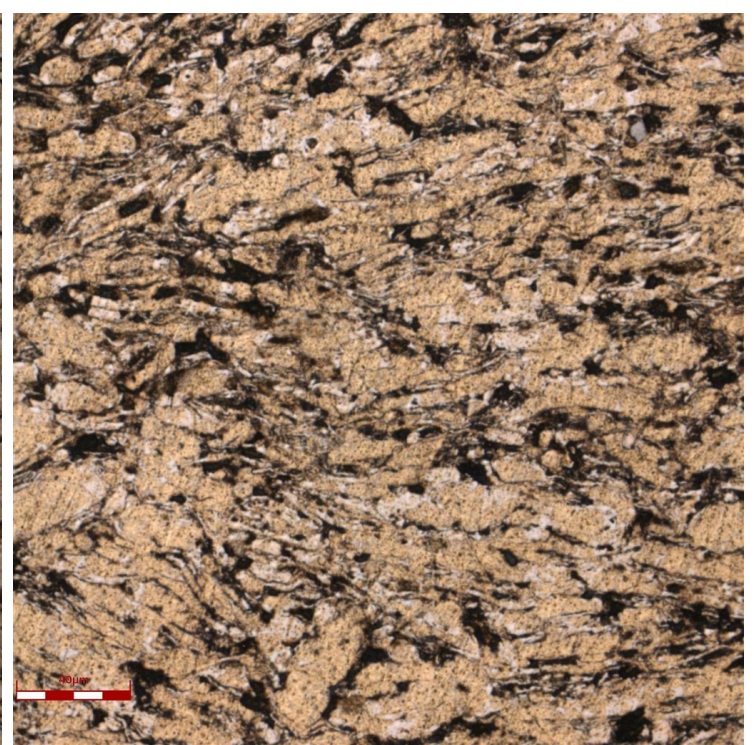

(d)

Figura 4.21: Imagens dos sinterizados em diferentes tempos moagem (aumento de 50x). (a) $2 \mathrm{~h}$ (b) $4 \mathrm{~h}(\mathrm{c}) 8 \mathrm{~h}(\mathrm{~d}) 16 \mathrm{~h}$.

Nas imagens obtidas através do MEV a presença de vazio, alguns indicados pelos círculos amarelos, fica mais nítida. Observa-se que as para o tempo de moagem de 16 horas as partículas não tiveram boa sinterização e junção. Este fato tornou o material quebradiço e houve muita dificuldade para a realização da metalografia, uma vez que as partículas se desintegravam. Assim, pode-se dizer que utilizando as condições e parâmetros deste trabalho, os tempos ótimos de moagem foram de 4 e 8 horas. As imagens obtidas através do MEV das amostras sinterizadas estão apresentadas nas Figuras 4.22, 4.23, 4.24 e 4.25 . 
- Moagem 2 horas

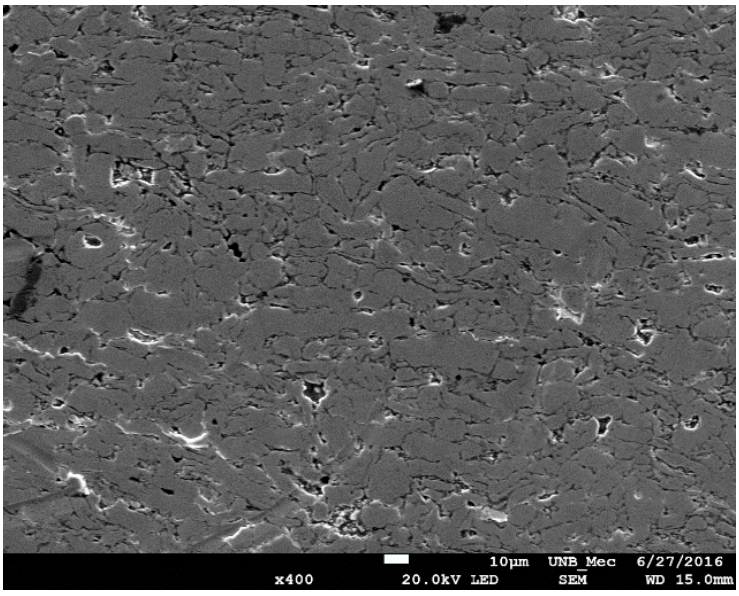

(a)

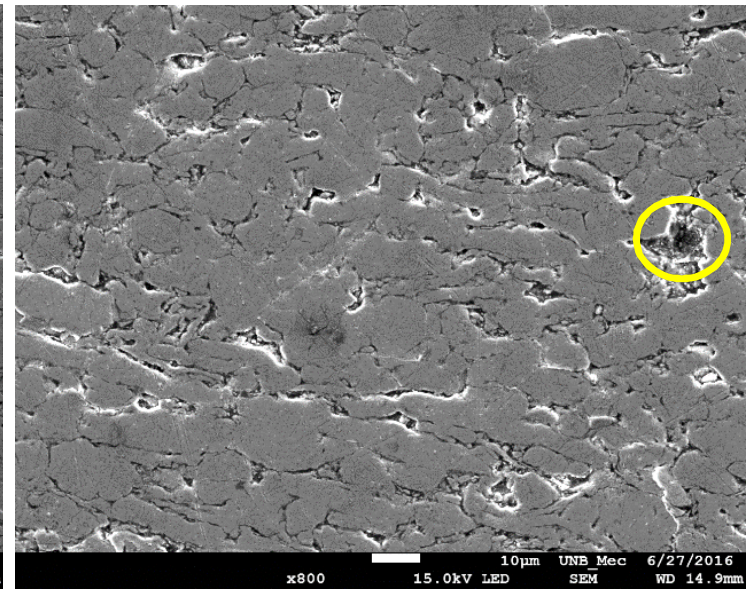

(b)

Figura 4.22: Imagens dos sinterizados com moagem de 2h. (a) aumento 400x (b) aumento 800x.

- Moagem 4 horas

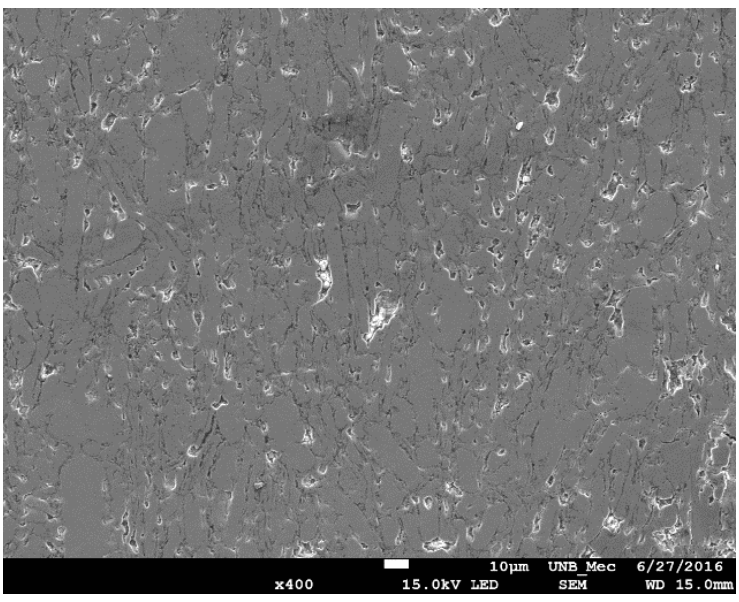

(a)

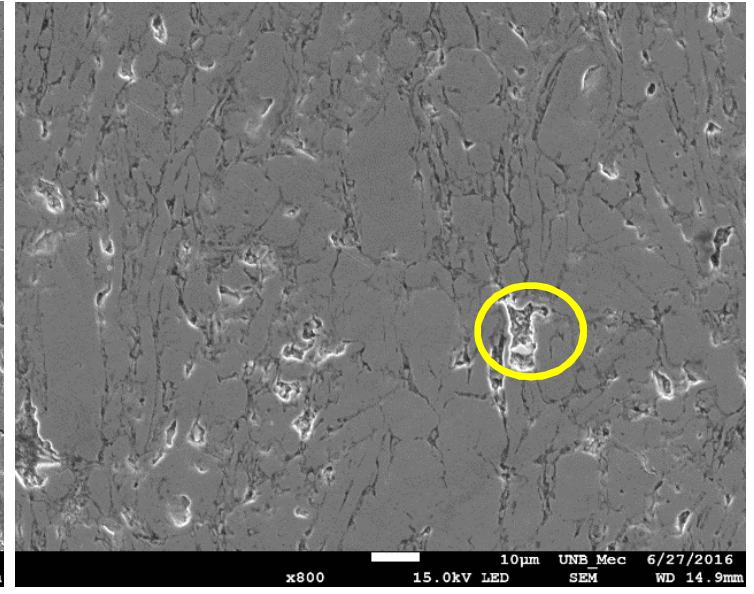

(b)

Figura 4.23: Imagens dos sinterizados com moagem de 4h. (a) aumento 400x (b) aumento 800x. 
- Moagem 8 horas

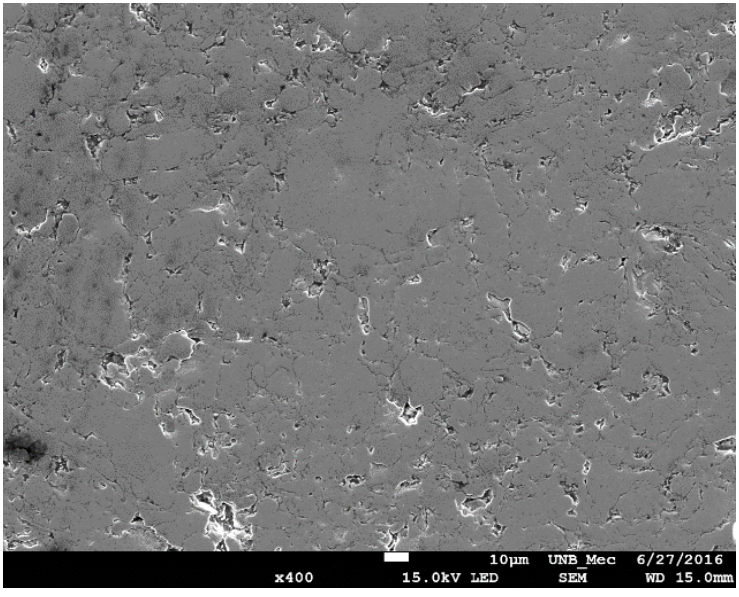

(a)

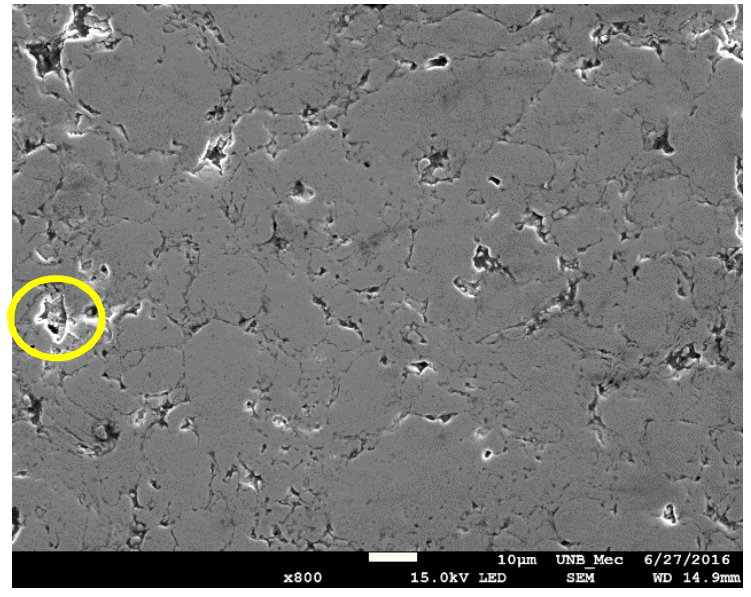

(b)

Figura 4.24: Imagens dos sinterizados com moagem de 8h. (a) aumento 400x (b) aumento 800x.

- Moagem de 16 horas

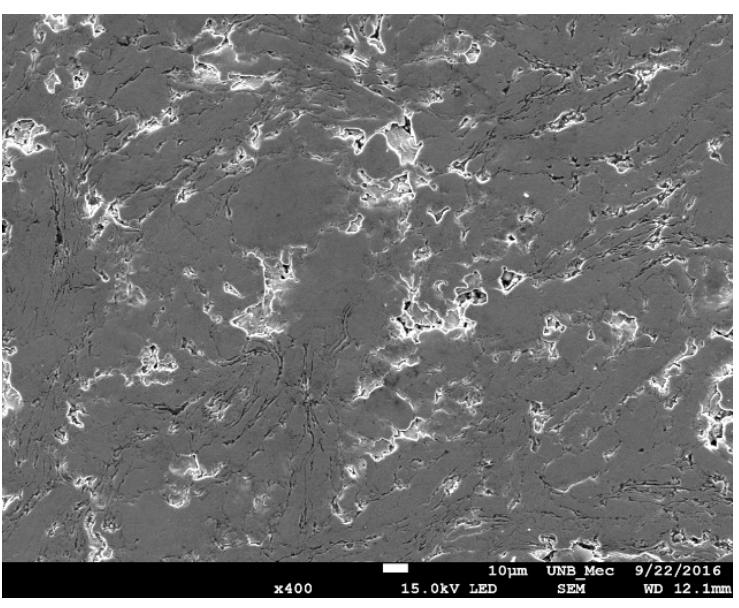

(a)

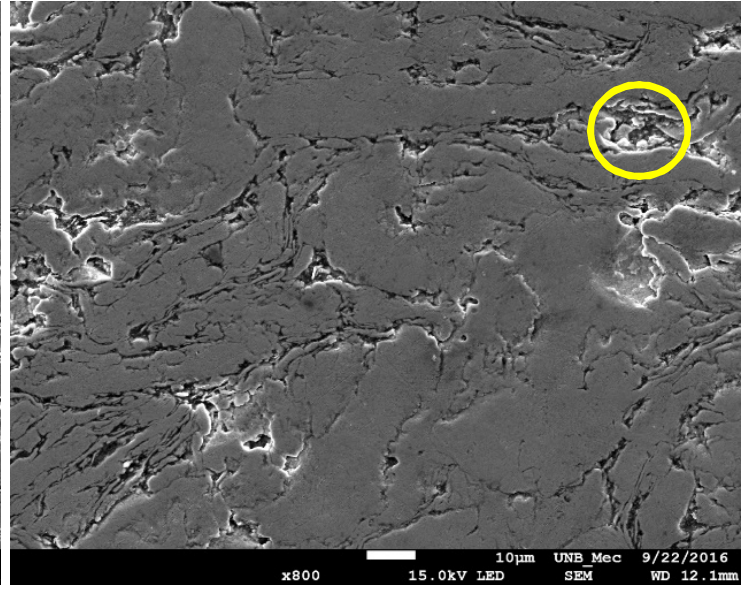

(b)

Figura 4.25: Imagens dos sinterizados com moagem de 16h. (a) aumento 400x (b) aumento $800 x$.

Com o intuito de observar a homogeneidade e dispersão dos elementos $\mathrm{Cu}, \mathrm{Al}$ e $\mathrm{Ni}$ foram realizados no MEV os mapas de raio-x nas amostras sinterizadas, como é apresentado na Figura 4.26. 
- Moagem de 4 horas
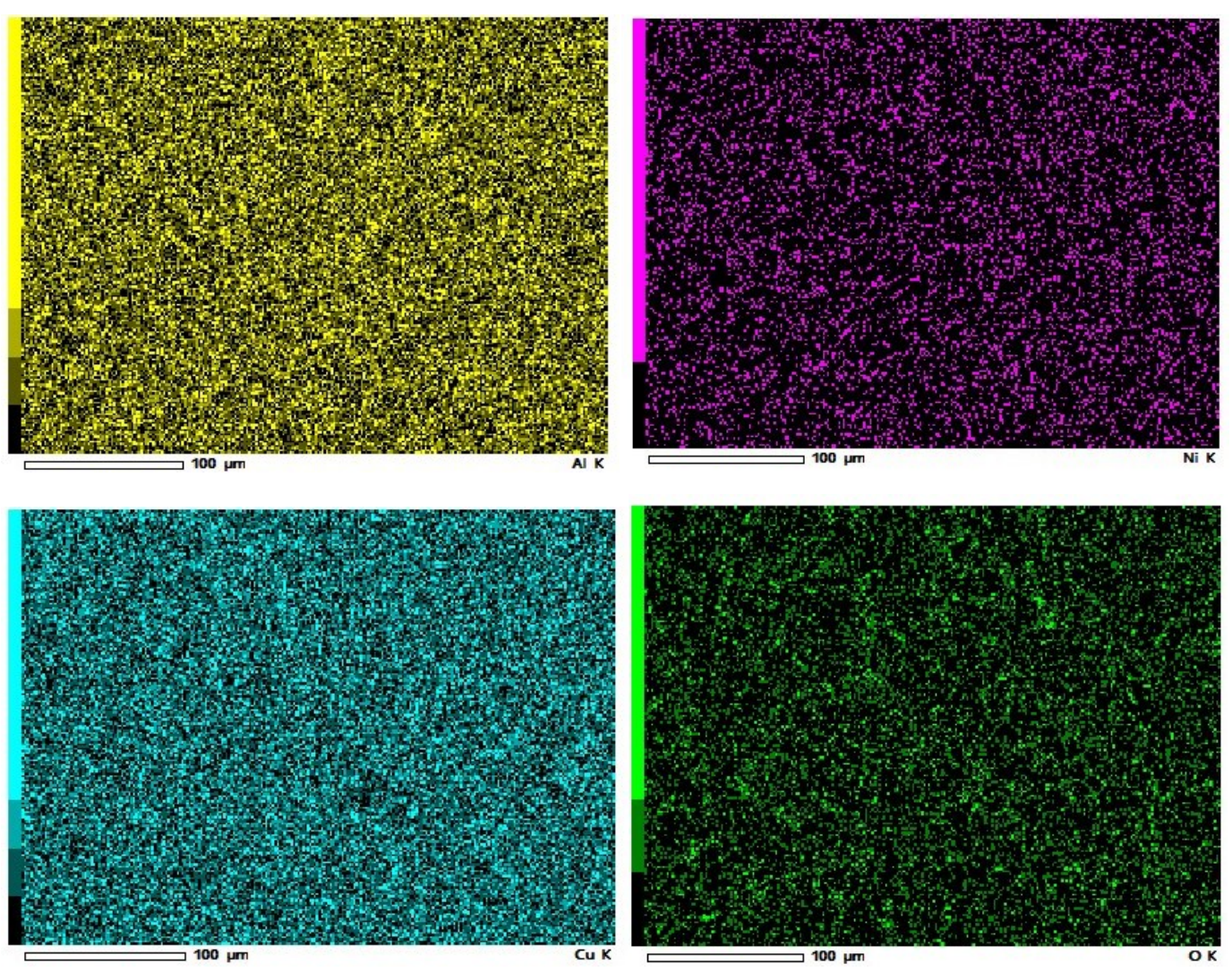

$\begin{array}{llllll}\text { Element } & (\mathrm{keV}) & \text { Mass\% } & \text { Sigma } & \text { Atom\% } & \text { Compound } \\ \text { O K } & 0.525 & 9.90 & 0.08 & 26.90 & \\ \text { Al K } & 1.486 & 12.12 & 0.07 & 19.53 & \\ \text { Ni K } & 7.471 & 3.83 & 0.09 & 2.84 & \\ \text { Cu K } & 8.040 & 74.15 & 0.40 & 50.73 & \\ \text { Total } & & 100.00 & & 100.00 & \end{array}$

Figura 4.26: Mapa de raio-x da amostra sinterizada com moagem de 4 horas.

Segundo Vajpai et al. (2009), uma das características das ligas produzidas através da moagem de alta energia é a homogeneidade. Com o mapa de raio-x observa-se que não há segregação dos elementos envolvidos, sendo que todos eles estão bem dispersos na liga. Assim, é possível dizer que a moagem de alta energia e a sinterização proporcionou boa difusão dos elementos formando uma liga homogênea. Além disso, observa-se a presença do elemento oxigênio devido à alta oxidação que as ligas de CuAlNi sofrem naturalmente. Os mapas para as amostras com os tempos de moagem de 2, 8 e 16 horas encontram-se no ANEXO I. Para todos os tempos de moagem houve uma boa difusividade dos elementos presentes na formação da liga. 


\subsection{Análise DSC das amostras sinterizadas}

As análises DSC das amostras sinterizadas foram realizadas de acordo como descrito na metodologia. Os gráficos gerados estão no ANEXO II. Em nenhuma das amostras, analisadas na faixa de temperatura de 0 a $450^{\circ} \mathrm{C}$ apareceu o efeito memória de forma através das transformações de fase. Esse fato já era esperado uma vez que, para que haja esta característica é necessário que se faça tratamentos térmicos com o objetivo de estabilizar a fase $\beta$ que se forma em temperaturas superiores a $565^{\circ} \mathrm{C}$, proporcionando o aparecimento de transformações martensíticas.

\subsection{Análise DRX}

As Figuras 4.27, 4.28, 4.29 e 4.30 apresentam os difratogramas para os tempos de moagem de $2 \mathrm{~h}, 4 \mathrm{~h}, 8 \mathrm{~h}$ e $16 \mathrm{~h}$. Como as condições de moagem, compactação e sinterização de todas as amostras foram as mesmas, as diferenças encontradas nos difratogramas são consequências dos diferentes tempos de moagem dos pós elementares.

- Moagem de 2 horas

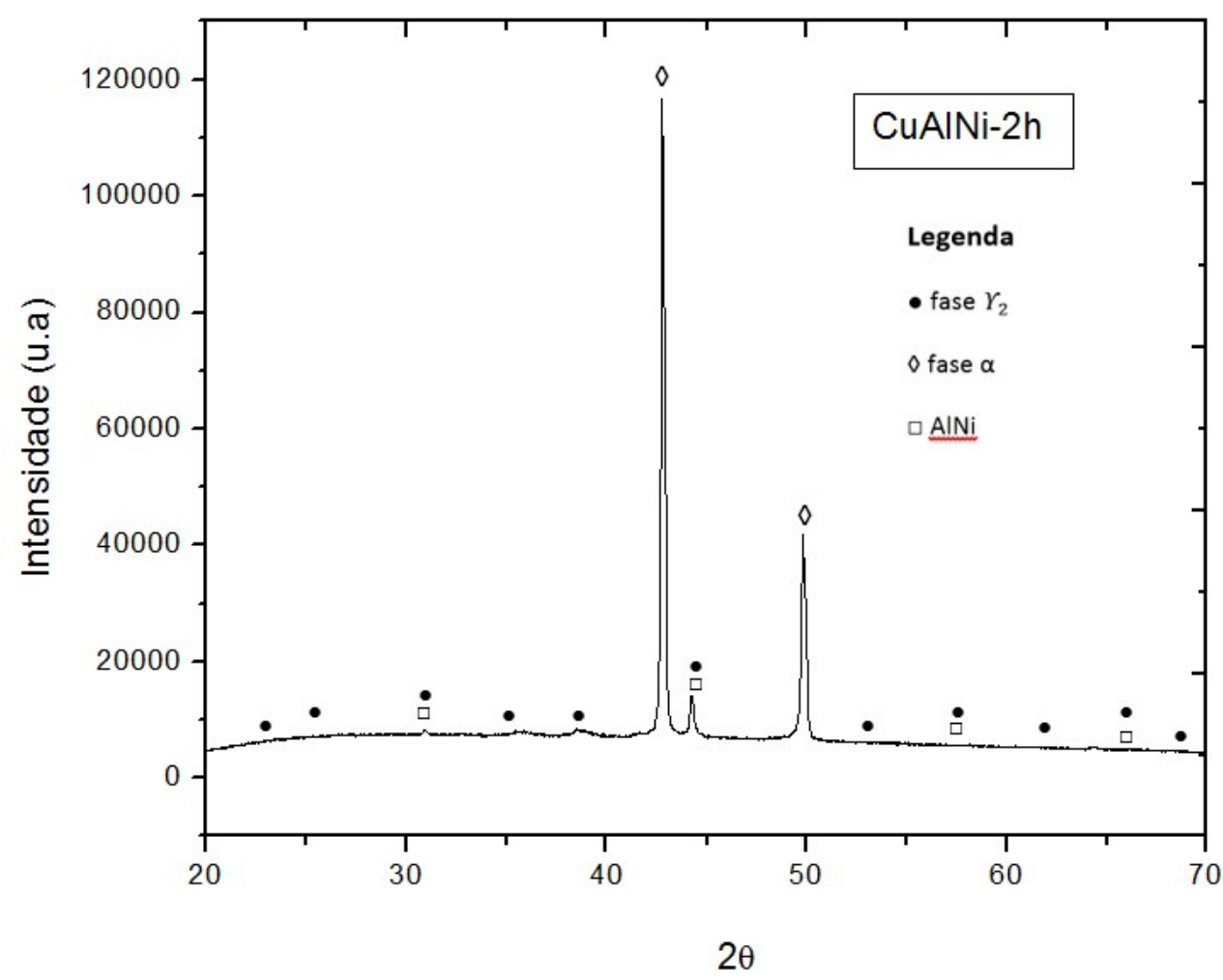

Figura 4.27: DRX para os sinterizados com moagem de 2 horas. 
- Moagem de 4 horas

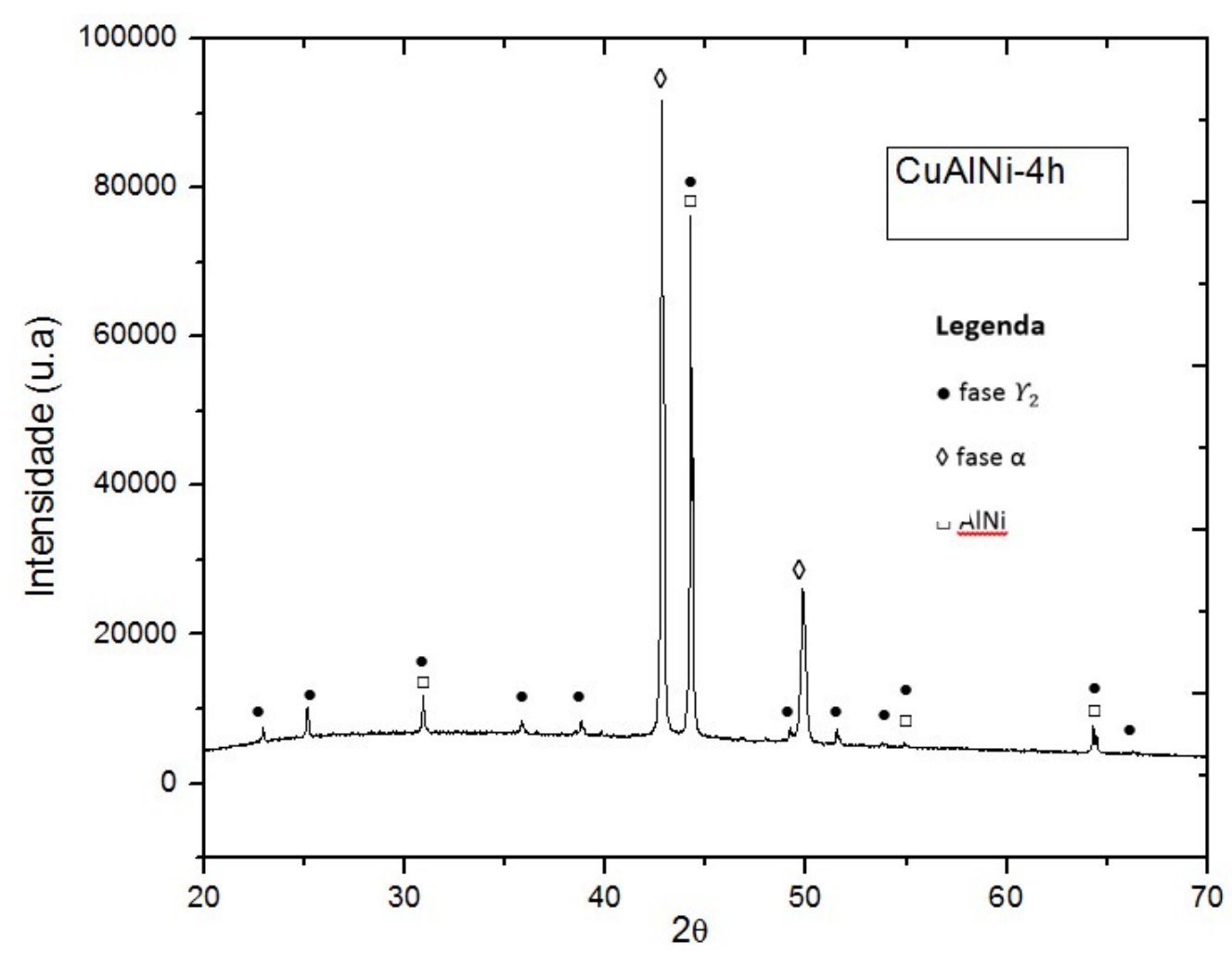

Figura 4.28: DRX para os sinterizados com moagem de 4 horas.

- Moagem de 8 horas

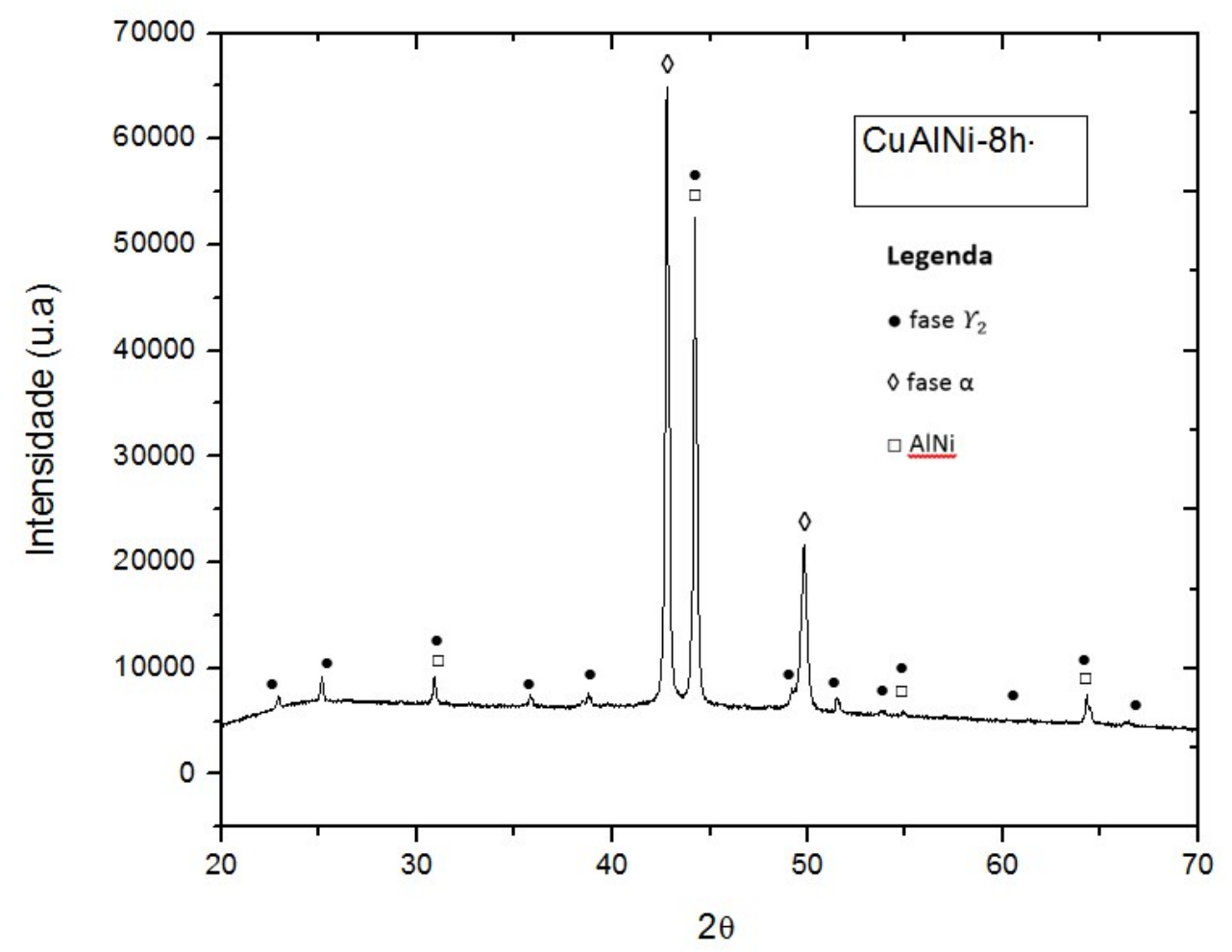

Figura 4.29: DRX para os sinterizados com moagem de 8 horas. 
- Moagem de 16 horas

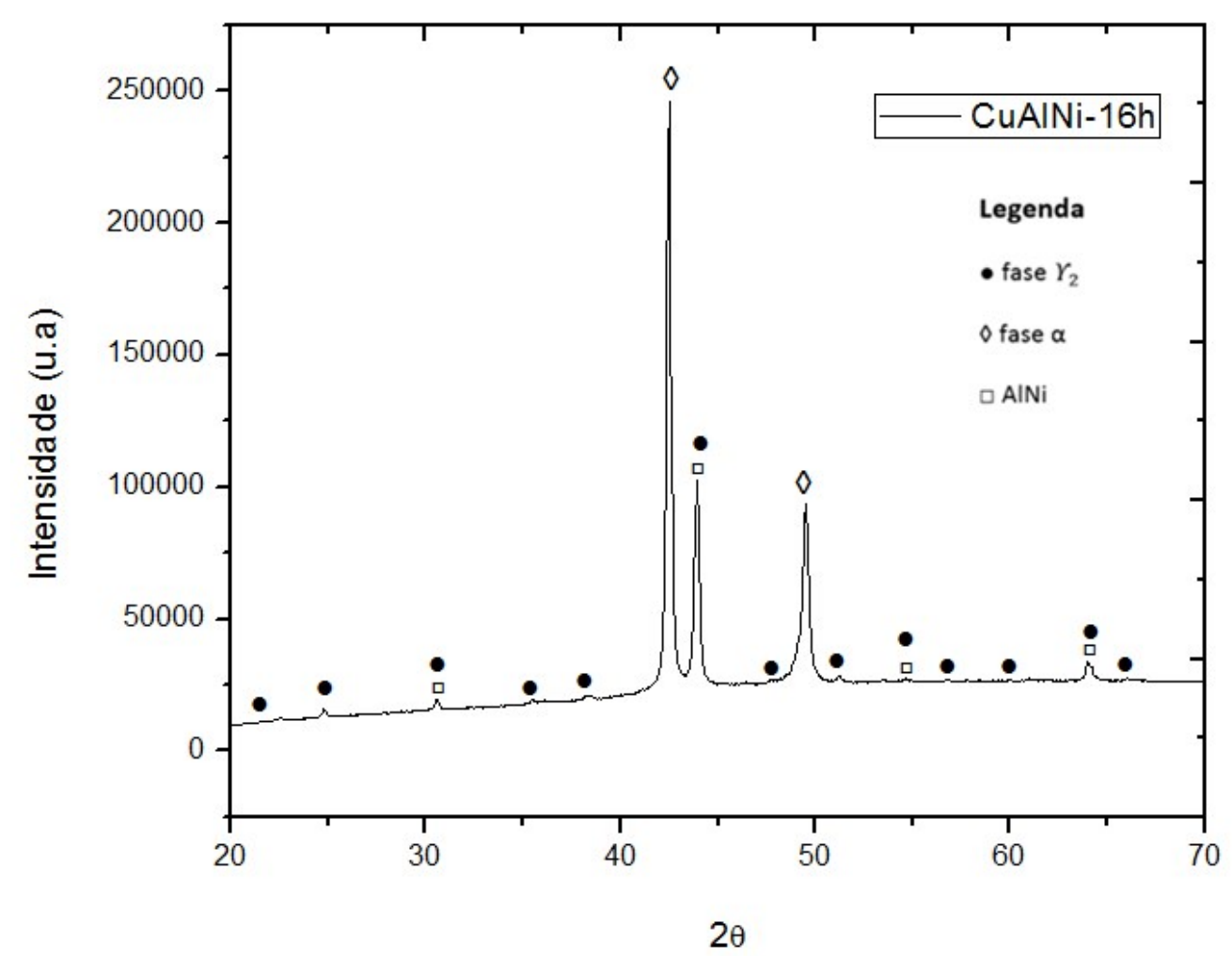

Figura 4.30: DRX para os sinterizados com moagem de 16 horas.

Em todas as amostras para os diferentes tempos de moagem, obteve-se formação das mesmas fases com intensidades diferentes. Como as amostras foram sinterizadas a $1000^{\circ} \mathrm{C}$ e, posteriormente resfriadas lentamente no forno, a fase $\beta$ formada em temperaturas acima de $565^{\circ} \mathrm{C}$ sofreu decomposição eutetoide em fases $\gamma_{2}$, $\alpha$ e $\mathrm{AlNi}$, de acordo com o apresentado por Zeghdane et al. (2010).

$\mathrm{O}$ aumento do tempo de moagem favoreceu a formação da fase $\gamma_{2}$, sendo que as intensidades desta fase com moagens de 4 e 8 horas foram muito próximas. Segundo Gama (2003) o aparecimento da fase AlNi está associado à fase $\gamma_{2}$. Como os picos de AlNi estão sobrepostos nos da fase $\gamma_{2}$, a identificação de sua intensidade só é possível fazendo a decovolução dos picos. A fase $\alpha$, que é uma solução primária de $\mathrm{Cu}$ com estrutura cúbica de face centrada, é a que possui maior intensidade em todas as amostras, sendo inversamente proporcional ao tempo de moagem, com exceção para a amostra de 16 horas. O que se pode observar de forma clara é que o tempo de moagem de alta energia vai influenciar diretamente na formação de fase da liga em estudo. 


\subsection{Microdureza}

Os valores obtidos para a microdureza Vickers estão apresentados na Tabela 5. A dureza mais elevada foi obtida para a moagem de 4 horas. Além disso, comparando as moagens de 2, 4 e 8 horas o surgimento das fases $\gamma 2$ e AlNi nas ligas favoreceu o aumento da microdureza. Como foi apresentado nas imagens do Confocal e do MEV nas amostras com moagem de 16 horas havia grande quantidade de vazios, resultando em uma baixa microdureza.

Tabela 5: Valores obtidos para microdureza de Vickers (carga aplicada de $10 \mathrm{gf}$ ).

\begin{tabular}{|c|c|}
\hline Tempo de moagem & Microdureza (HV-10 gf) \\
\hline $\mathbf{2} \mathbf{~ h}$ & $209,860 \pm 38,389$ \\
\hline $\mathbf{4} \mathbf{~ h}$ & $237,080 \pm 21,487$ \\
\hline $\mathbf{8} \mathbf{~ h}$ & $233,640 \pm 60,369$ \\
\hline $\mathbf{1 6} \mathbf{~ h}$ & $127,160 \pm 19,977$ \\
\hline
\end{tabular}

As ligas CuAlNi fabricadas via metalurgia do pó com moagem de alta energia, utilizando os parâmetros apresentados neste trabalho apresentaram valores de microdureza inferiores aos obtidos por outros processos, consequência, principalmente de sua porosidade. Pela técnica de fusão a plasma seguida de moldagem por injeção Oliveira (2009) obteve a microdureza de 293,7 $\pm 6,8 \mathrm{HV}$, já Silva et al. (2007) fabricando lingotes e pastilha de CuAlNi pelo método de fusão em forno de indução obteve, respectivamente, o valore médio de microdureza de 386,99 $\pm 14,33 \mathrm{HV}$ e $294,06 \pm 8,37 \mathrm{HV}$. Observa-se que as amostras que tiveram seus pós moídos por 4 horas obtiveram valores mais próximos de microdureza se comparada com as técnicas citadas anteriormente. 


\section{Conclusões e sugestões para trabalhos futuros}

\subsection{Conclusões}

O presente trabalho avaliou a influência do tempo de moagem de alta energia nas características finais da liga $\mathrm{Cu}-13 \mathrm{Al}-4 \mathrm{Ni}$ fabricadas pelo processo de metalurgia do pó. As conclusões obtidas são:

- Para cada tempo de moagem de alta energia são necessários a mudança e o controle das variáveis do processo. Para diferentes tempos de moagem deve-se fazer o estudo da pressão ideal de compactação, assim como da técnica utilizada e também do tempo e temperatura de sinterização. Ou seja, diferentes tempos de moagem vão influenciar de maneira diferente o comportamento da liga, necessitando de estudos individuais de cada parâmetro para cada tempo de moagem.

- O processo de metalurgia do pó é uma técnica viável de obtenção da liga $\mathrm{Cu}$ $13 \mathrm{Al}-4 \mathrm{Ni}$;

- A moagem de alta energia proporcionou a ligação mecânica entre os elementos envolvidos na fabricação da liga, favorecendo a obtenção de ligas com alta homogeneidade;

- O tempo de moagem de alta energia dos pós elementares envolvidos na fabricação da liga influenciou diretamente em suas propriedades. Para os parâmetros de moagem utilizados neste trabalho, observou-se que as densidades aparentes da mistura após a moagem, assim como, as densidades a verde diminuíram com o aumento do tempo de moagem, devido à modificação da morfologia e tamanho das partículas envolvidas. Este fato ocorre devido a moagem de alta energia deformar plasticamente as partículas dos pós elementares.

- Observou-se que o tempo de moagem mais adequado em relação à densificação da liga, utilizando as técnicas e parâmetros deste trabalho, foi o de 4 horas, apresentado densificação $12,344 \%$ maior que a de 2 horas, $0,267 \%$ maior que a de 8 horas e 12, 700\% maior que a de 16 horas. Percebeu-se que o aumento do tempo de moagem contribui para a maior densidade do sinterizado até certo limite, no caso em estudo, os melhores resultados, de forma geral, foram com moagens durante 4 e 8 horas. 
- Com as imagens obtidas através de MEV e Confocal, observou-se que amostras com moagem de 16 horas apresentaram baixa união entre as partículas, sendo difícil até de realizar a metalografia, pois as partículas se desintegravam. Para que haja melhor densificação da liga obtida à partir da moagem de 16 horas, estudos de melhoria das técnicas de compactação e sinterização devem ser realizados.

- As análises DSC revelaram que as ligas obtidas utilizando os parâmetros descrito neste trabalho não apresentaram memória de forma. Este fato já era esperado, uma vez que, é necessária a realização de um tratamento térmico, para que a fase $\beta$, seja estabilizada;

- As análises de DRX mostraram a presença de fase $\gamma_{2}, \alpha$ e AlNi, resultante da decomposição eutetoide da fase $\beta$, uma vez que as amostras sofreram resfriamento lento no forno. As moagens de 4 e 8 horas favoreceram o aparecimento das fases $\gamma_{2}$ e AlNi se comparadas com as moagens de 2 e 16 horas.

- Os valores de microdureza obtidos para as amostras fabricadas via metalurgia mostraram que a moagem de 4 horas favoreceu a obtenção de ligas com dureza mais elevada se comparada aos demais tempos de moagem. A microdureza de para a moagem de 4 horas foi 12,971\% maior que a de 2 horas, 1, 472\% maior que a de 8 horas e $86,442 \%$ maior que a de 16 horas. O surgimento das fases $\gamma_{2} \mathrm{e}$ AlNi nas moagens de 4 e 8 horas favoreceram o aumento da microdureza das ligas;

- Em relação a outros processe de fabricação da liga $\mathrm{CuAlNi}$, com a técnica utilizada neste trabalho foram obtidas ligas com microdurezas inferiores. Por exemplo, a técnica de fusão a plasma proposta por Silva et al (2007) apresentou microdureza $23,88 \%$ maior que a liga fabricada com moagem de 4 horas;

\subsection{Sugestões para trabalhos futuros}

- Estudar outras técnicas de compactação para a obtenção de melhores valores de densidade a verde, e consequentemente, ligas menos porosas;

- Estudar a influência do tempo e a temperatura de sinterização em cada tempo de moagem, encontrando os parâmetros adequados para cada situação; 
- Realizar um estudo específico à respeito da temperatura ideal de sinterização e tratamentos térmicos nas ligas obtidas pelo procedimento apresentado neste trabalho, com o intuito de verificar a existência do efeito memória de forma e compará-los com os obtidos neste trabalho;

- Realizar análises de DRX em amostras obtidas pelo mesmo método descrito neste trabalho, porém após passarem por tratamentos térmicos e compará-los com os resultados apresentados para as ligas sem tratamento térmico;

- Avaliar como o tratamento térmico vai influenciar na microdureza da liga CuAlNi obtida pelo processo apresentado. 


\section{Referências Bibliográficas}

ASM Handbook. 1992 Alloy Phase Diagrams Vol. 3, ASM International.

AMERICAN SOCIETY FOR TESTING AND MATERIALS. ASTM E3-11: Standard Guide for Preparation of Metallographic Specimens. West Conshohocken: Copyright, 2011.

AMERICAN SOCIETY FOR TESTING AND MATERIALS. ASTM B331-16: Standard Test Method of Compressibility of Metal Powders in Uniaxial Compaction. West Conshohocken: Copyright, 2016.

BENJAMIM, J.S.; VOLIN. T.E. Mechanisms of mechanical alloying. Metal Trans; v.5, p. 1929-1934, 1974.

CALUÊTE, R. E. , Estudo das propriedades termomecânicas da liga Cu78,3\%- A19,8\%Mn11,9\%., Dissertação de Mestrado, Departamento de Engenharia Mecânica UFPBCT, João Pessoa, 2012.

CASTAGNET, Mariano. Avaliação da compressibilidade de mistura de pós de Nióbio e Alumínio ativadas mecanicamente. 2008. 76 f. Dissertação (Mestrado) Curso de Tecnologia Nuclear, Materiais, Instituto de Pesquisas Energéticas e Nucleares, São Paulo, 2008.

CHIAVERINI, Vicente. Metalurgia do pó. 4. ed. São Paulo: Associação Brasileira de Metalurgia e Metariais, 2001. 313 p.

Copper / Aluminium / Nickel Shape Memory Alloys, Azom.com, USA. Disponível em: $<$ http://www.azom.com/article.aspx?ArticleID=1368 >. Acesso em: 05 de abril de 2016

COSTA, Thaiane Karoline. ESTUDO DE TEMPOS E TEMPERATURAS DE SINTERIZAÇÃO NA OBTENÇÃO DA LIGA NiTi POR METALURGIA DO PÓ. 2014. 47 f. TCC (Graduação) - Curso de Engenharia Mecânica, Faculdade de Engenharia do Campus de Guaratinguetá,, Universidade Estadual Paulista, Guaratingueta, 2014.

COSTA, F. A, G. Melchiors, U. U. Gomes, A. G. P. da Silva, A. S. Silva. EFEITO DA MOAGEM DE ALTA ENERGIA E DA PRESSÃO DE COMPACTAÇÃO NA DENSIFICAÇÃO DE UM PÓ COMPÓSITO Nb-20\%Cu. In: CONGRESSO BRASILEIRO DE ENGENHARIA E CIÊNCIAS DOS MATERIAIS, 19., 2010, Campos do Jordão. Anais... . Campos do Jordão: Cbecimat, 2010. p. 3487 - 3494.

CREMONEZI, Alcides et al. A Metalurgia do Pó: alternativa econômica com menor impacto ambiental. São Paulo: Metallum Eventos Técnicos, 2009. 320 p.

DIAS, Maria Cely Freitas. Sinterização, microestrutura e condutividade elétrica com adições de SrO,TiO2 e SrTiO3.2013. 66 f. Dissertação (Mestrado) - Curso de Tecnologia Nuclear-materiais, Ipen, São Paulo, 2013. 
DIAS, Rogério Fonseca. EFEITO DA DEFORMAÇÃO CÍCLICA NAS PROPRIEDADES MECÂNICAS DE UMA LIGA NÍQUEL-TITÂNIO SUPERELÁSTICA. 2005. 157 f. Tese (Doutorado) - Curso de Pós-graduação em Engenharia Metalúrgica e de Minas, Metalurgia Física, Universidade Federal de Minas Gerais, Belo Horizonte, 2005.

FERNANDES, Maria Roseana de Pontes. Compósitos de matriz metálica a base níquel com adição de TaC e NbC produzidas via metalurgia do pó. $2014.114 \mathrm{f}$. Tese (Doutorado) - Curso de Pós Graduação em Ciências e Engenharia de Materiais, Universidade Federal do Rio Grande do Norte, Natal, 2014.

GAMA, Jorge Luis Lauriano. TRANSFORMAÇÃO DE FASE EM LIGAS DE COBRE COM MEMÓRIA DE FORMA. 2003. 117 f. Tese (Doutorado) - Curso de Programa de Pós-graduação em Tecnologias Energéticas e Nucleares, Departamento de Energia Nuclear, Universidade Federal de Pernambuco, Recife, 2003.

GERMAN, R. M. Powder Metallurgy of Iron and Steel, New York, N.Y.: John Wiley \&Son s Inc, 1st Ed., 1998.

GERMAN, R.M Sintering Theory and Practice, Wiley, New York, 1996, p 1-22

JABUR, Adnan S.; AL-HAIDARY, Jafar T.; AL-HASANI, Emad S.. Characterization of Ni-Ti shape memory alloys prepared by powder metallurgy. Journal Of Alloys And Compounds. Amsterda, p. 136-142. jan. 2013.

JESUS FILHO, Edson Souza de. PROCESSAMENTO, USINAGEM E DESGASTE DE LIGAS SINTERIZADAS PARA APLICAÇÕES AUTOMOTIVAS. 2006. 152 f. Tese (Doutorado) - Curso de Tecnologia Nuclear, Instituto de Pesquisas EnergÉticas e Nucleares, São Paulo, 2006.

KNEWITZ, Fabio Luiz. Estudo comparativo de amostras de NiTi produzidas por metalurgia do pó. 2009. 56 f. Dissertação (Mestrado) - Curso de Engenharia Metalurgica, Universidade Federal do Rio Grande do Sul, Porto Alegre, 2009.

MARTIN, C. L. Unloading of powder compacts and their resulting tensile strength. Acta Mater., v. 51 , n. 15, p. 4589-4602, 2003.

MATERIALS, Azom. Copper / Aluminium / Nickel Shape Memory Alloys. 2013. Disponível em: $<$ http://www.azom.com/article.aspx?ArticleID=1368\#_Advantages_of_CuAlNi $>$. Acesso em: 30 maio 2016.

MUTERLLE, Palloma Vieira. Introdução a Metalurgia do Pó. Brasília: Visual, 2016. 21 slides, color.

METALPÓ. Pós metálicos e peças sinterizadas. Disponível em: $<$ http://www.combustol.com.br/uploads/image/Catalogo/metalpo.pdf $>$. Acesso em: 16 ago. 2016.

NAKATANI, Cristiano C. et al. INFLUÊNCIA DO SUPER-RESFRIAMENTO NAS LIGAS Cu-Al-Ni COM EFEITO DE MEMÓRIA DE FORMA. Revistas Científicas de 
América Latina, El Caribe, España y Portugal, Pereira, v. 13, n. 36, p.393-395, set. 2007.

NEVES, Maurício David Martins das. SINTERIZAÇÃO DE MISTURAS DE PÓS DE LIGAS DE FERRO PARA APLICAÇÕES AUTOMOTIVAS. 2005. 104 f. Tese (Doutorado) - Curso de Tecnologia Nuclear-materiais, Ipen, São Paulo, 2005.

OLIVEIRA, Elaine Cristina Pereira e. ESTUDO DA ESTABILIDADE ESTRUTURAL E PROPRIEDADES DE LIGAS À BASE DE Cu-Al-Ni SOLICITADAS A TRATAMENTOS TERMO-CÍCLICOS. 2009. $221 \mathrm{f}$. Tese (Doutorado) - Curso de Engenharia e Ciência dos Materiais, Universidade Estadual do Norte Fluminense Darcy Ribeiro, Campos dos Goytacazes, 2009.

OTSUKA, K.; WAYMAN, C.m.. Shape Memory Materials. Cambridge: University Press, 1998.

PORTUGAL. Faculdade de Tecnologia. Universidade Nova de Lisboa. Calorimetria Diferencial de Varrimento. Disponível em: <http:/www.dq.fct.unl.pt/servicosexternos/calorimetria-diferencial-de-varrimento>. Acesso em: 12 fev. 2016.

RODRIGUES, Daniel. Processamento de pós metálicos e cerâmicos. São Paulo: Escola Politécnica Universidade de São Paulo, 2004.

SALGADO, Lucio. PROCESSAMENTO DA LIGA FERRO-NÍQUEL-COBREMOLIBDÊNIO POR MOAGEM DE ALTA ENERGIA. 2002. 84 f. Tese (Doutorado) - Curso de Tecnologia Nuclear, Instituto de Pesquisas EnergÉticas e Nucleares, São Paulo, 2012.

VAN VLACK, Lawrence Hall. Princípios de ciências e tecnologia dos materias. 4. ed. Rio de Janeiro: Elsevier, 2003. 567 p. Tradução de: Edson Monteiro.

VAJPAI, S. K, DUBE, R.K, SHARMA, M.. Studies on the mechanism of the structural evolution in $\mathrm{Cu}-\mathrm{Al}-\mathrm{Ni}$ elemental powder mixture during high energy ball milling. Springer Science. Uttar Pradesh, p. 4334-4341. 10 jun. 2009.

VJAPAI, S. K, DUBE R.K, CHATTERJEE, P., SANGAL, S. A novel powder metallurgy processing approach to prepare fine-grained $\mathrm{Cu}-\mathrm{Al}-\mathrm{Ni}$ shape-memory alloy strips from elemental powders. Metalurgical And Materials Transactions. Uttar Pradesh, p. 2484-2499. jul. 2012.

SALIM, Verônica Abrahão. DESENVOLVIMENTO DE UMA METODOLOGIA USANDO A TERMOGRAVIMETRIA PARA AVALIAÇÃO DA RETENÇÃO DE CO 2 EM SUBSTRATO SÓLIDO. 2005. 97 f. Dissertação (Mestrado) - Curso de Química, Química Analítica, Universidade Federal Fluminense, Niterói, 2005.

SCHWARTZ, M., 2009, Smart Materials, $1^{\circ}$ Bocca Raton, CRC Press.

SILVA, M.M, SILVA, N.J., SANTOS, M.A, ARAÚJO, C.J. Influência do Reprocessamento por Plasma nas Propriedades de uma Liga Cu-Al-Ni com Memória de 
Forma. Revista Eletrônica de Materiais e Processos, Campina Grande, v. 2, p.18-26, jan. 2007.

SUN, K. X.; CHEN, J.C.; XU, J. Z.; ZHEN, D. L.; KIM, K. T.; Analysis of cold compaction densification behavior metal powders. Mat. Sci. and Eng. A 267, p. 43-49, 1999.

SURYANARAYANA, C. Does a disordered gamma-TiAl phase exist in mechanicaUy aUoyed Ti-Al powders. Intermetallics., v. 3, p. 153-60, 1995.

TANG, S.M.; CHUNG, C.Y; LIU, W.G. Preparation of Cu-AI-Ni-based Shape Memory Alloys by Mechanical Alloying and Powder Metallurgy Method. Journal Of Materials Processing Technology. p. 307-308. jan. 1997.

TAUBENBLAT, P.W. Production and Properties of High Conductivity Copper P/M Parts, New Perspectives in Powder Metallurgy: Vol. 7, Metal Powder Industries Federation, 1980, p 123-134.

ZEGHDANE, S.; NECIB, N.; BRITAH, A.. Structural Characterization of Cu$13.58 \% \mathrm{Al}-3.94 \% \mathrm{Ni}$ (wt.\%) shape memory alloy elaborated by fusion. Edp Science, Alger, v. 6, n. 29001, p.1-9, out. 2010.

WEE, Y.C; ABUBAKAR, T.; HAMZAH, E.; SAUD, S.W. PHASE TRANSFORMATION AND MICROSTRUCTURE BEHAVIOUR OF CU-AL-NI SHAPE MEMORY ALLOYS INCORPORATED WITH COBALT ADDITION. Jurnal Teknologi. Johor, p. 53-56. 15 março. 2015.

Yildiz, K. and M. Kok. 2013. Study of Martensite Transformation and Microstructural Evolution of $\mathrm{Cu}-\mathrm{Al}-\mathrm{Ni}-\mathrm{Fe}$ Shape Memory Alloys. Journal of Thermal Analysis and Calorimetry. 1-6. 


\section{ANEXO I}

Moagem 2 horas
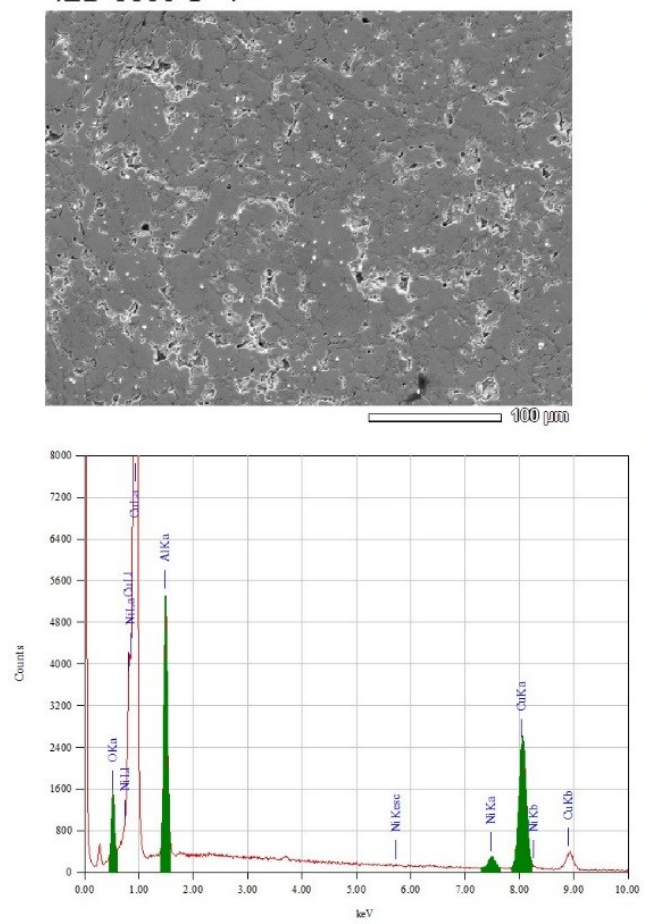

Moagem 8 horas
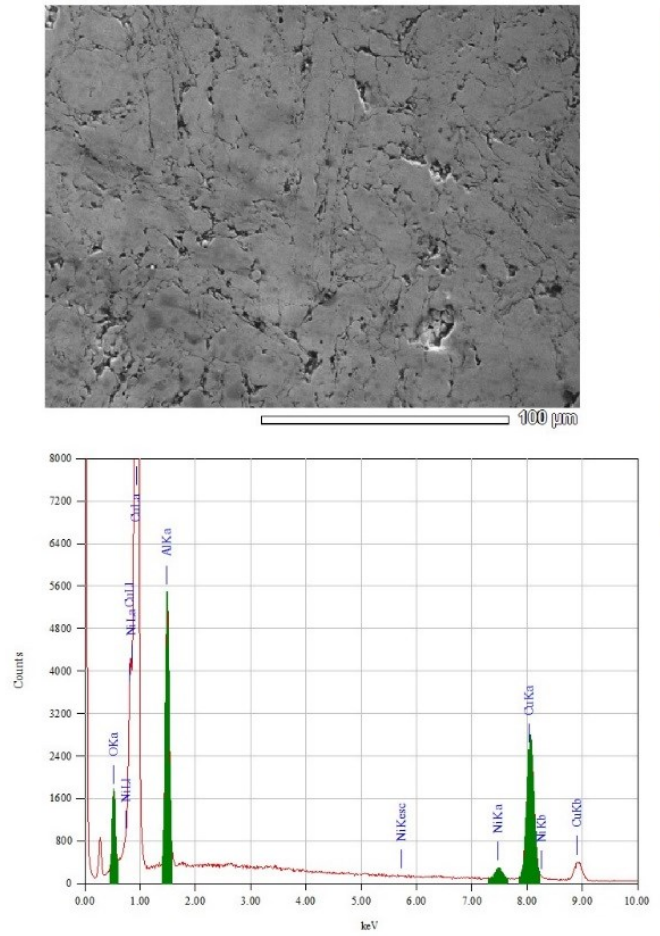

JEOL
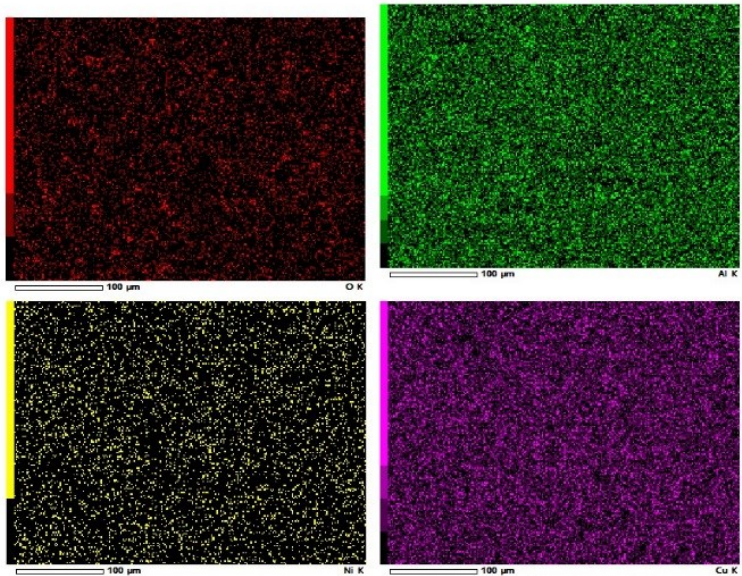

$\begin{array}{llllll}\text { Element } & (\mathrm{keV}) & \text { Mass\% } & \text { Sigma } & \text { Atom\% } & \text { Compound } \\ \text { O K } & 0.525 & 7.10 & 0.07 & 20.43 & \\ \text { Al K } & 1.486 & 12.26 & 0.07 & 20.92 & \\ \text { Ni K } & 7.471 & 4.20 & 0.09 & 3.29 & \\ \text { Cu K } & 8.040 & 76.43 & 0.41 & 55.35 & \\ \text { Total } & & 100.00 & & 100.00 & \end{array}$

JEOL
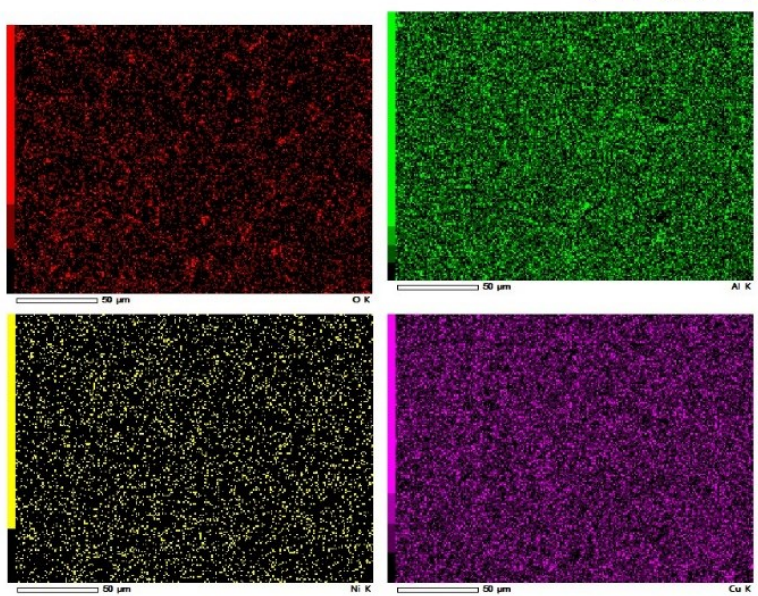

$\begin{array}{llllll}\text { Element } & (\mathrm{keV}) & \text { Mass\% } & \text { Sigma } & \text { Atom\% } & \text { Compound } \\ \text { O K } & 0.525 & 8.02 & 0.07 & 22.66 & \\ \text { Al K } & 1.486 & 12.04 & 0.07 & 20.19 & \\ \text { Ni K } & 7.471 & 4.10 & 0.09 & 3.16 & \\ \text { Cu K } & 8.040 & 75.84 & 0.39 & 53.99 & \\ \text { Total } & & 100.00 & & 100.00 & \end{array}$ 
Moagem 16 horas
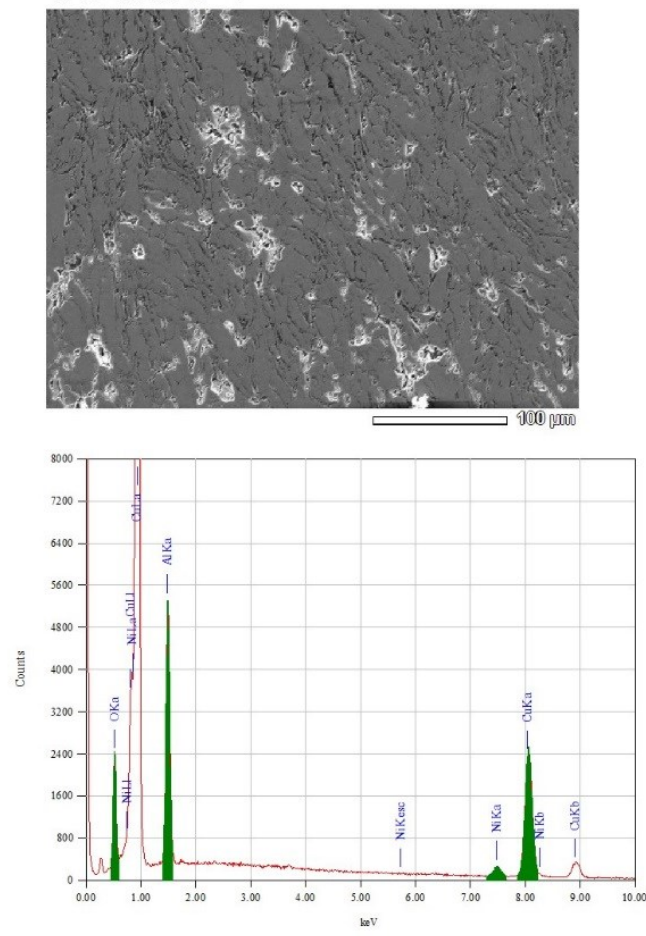

JEOL
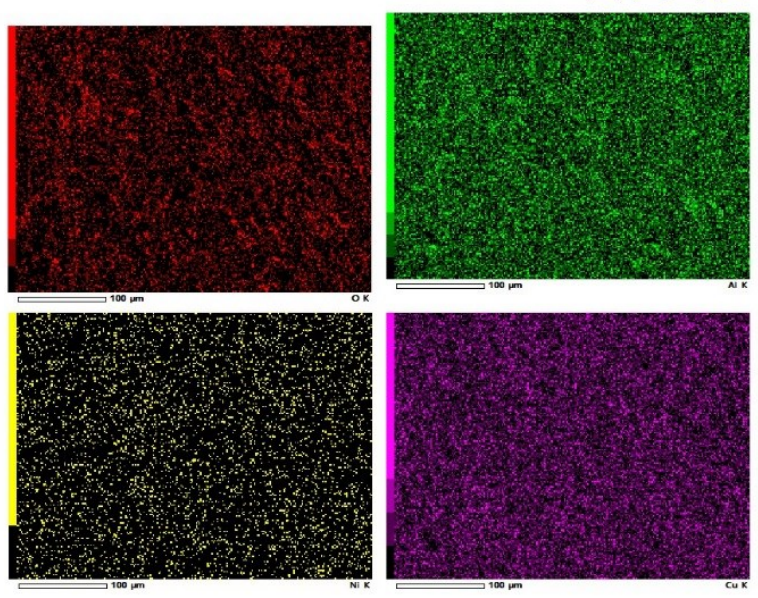

$\begin{array}{llllll}\text { Element } & (\mathrm{keV}) & \text { Mass\% } & \text { Sigma } & \text { Atom\% } & \text { Compound } \\ \text { O K } & 0.525 & 12.00 & 0.08 & 31.28 & \\ \text { Al K } & 1.486 & 12.12 & 0.07 & 18.74 & \\ \text { Ni K } & 7.471 & 3.49 & 0.09 & 2.48 & \\ \text { Cu K } & 8.040 & 72.39 & 0.40 & 47.51 & \\ \text { Total } & & 100.00 & & 100.00 & \end{array}$

\section{ANEXO II}

Sample: mistura 1 Size: $94.7720 \mathrm{mg}$

Method: Lara

DSC-TGA

File: C. ISDTL ara Prof Pallomalmistura1.001 Operator: Vitor Magalini

Run Date: 26-Feb-2016 10:56

Comment: N2 $50 \mathrm{~mL} / \mathrm{min} 100 \mathrm{Gc} / \mathrm{min}$ ate $1400 \mathrm{gC}$

Instrument: SDT Q600 V20.9 Build 20

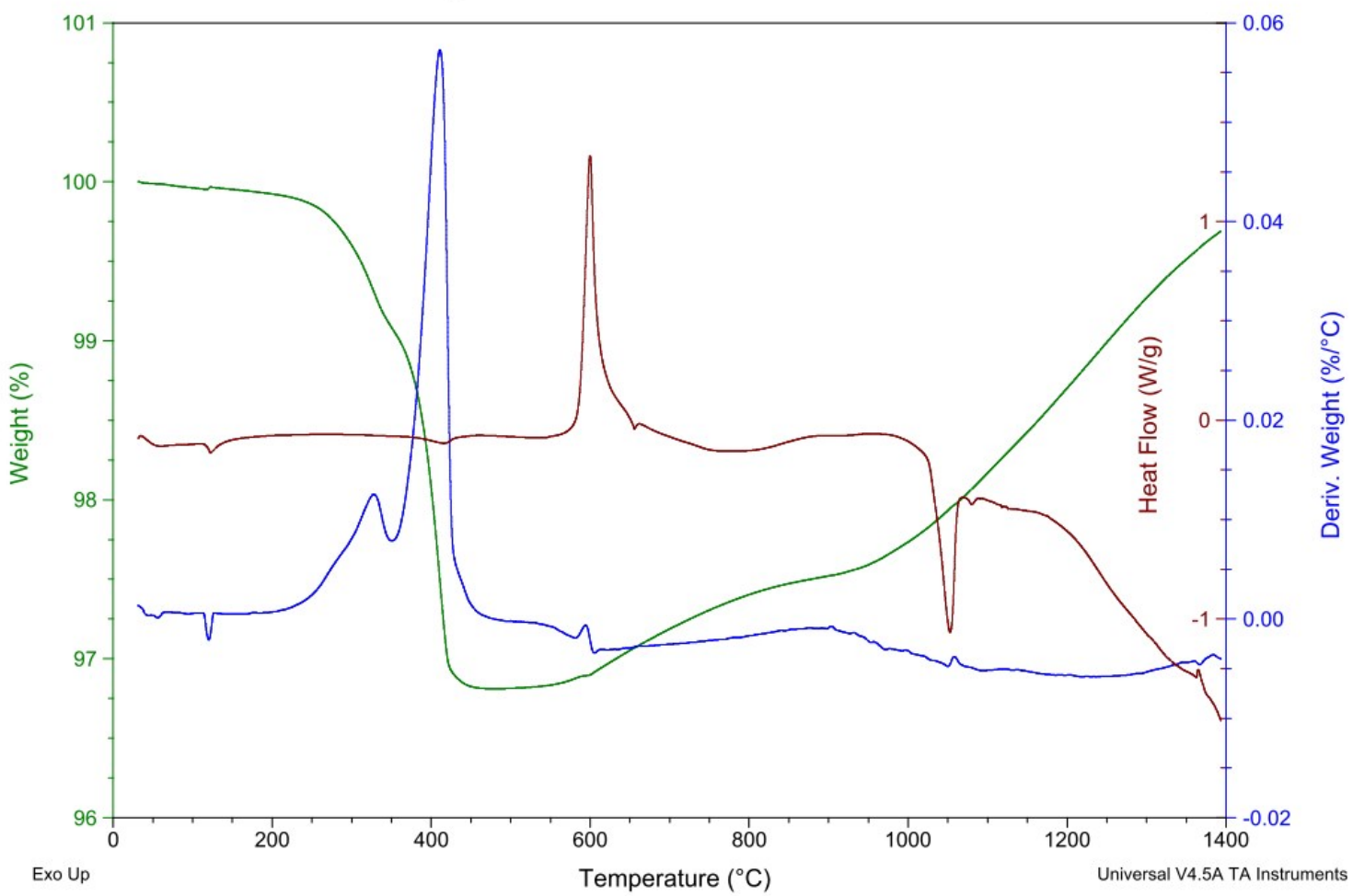


- Moagem de 2 horas

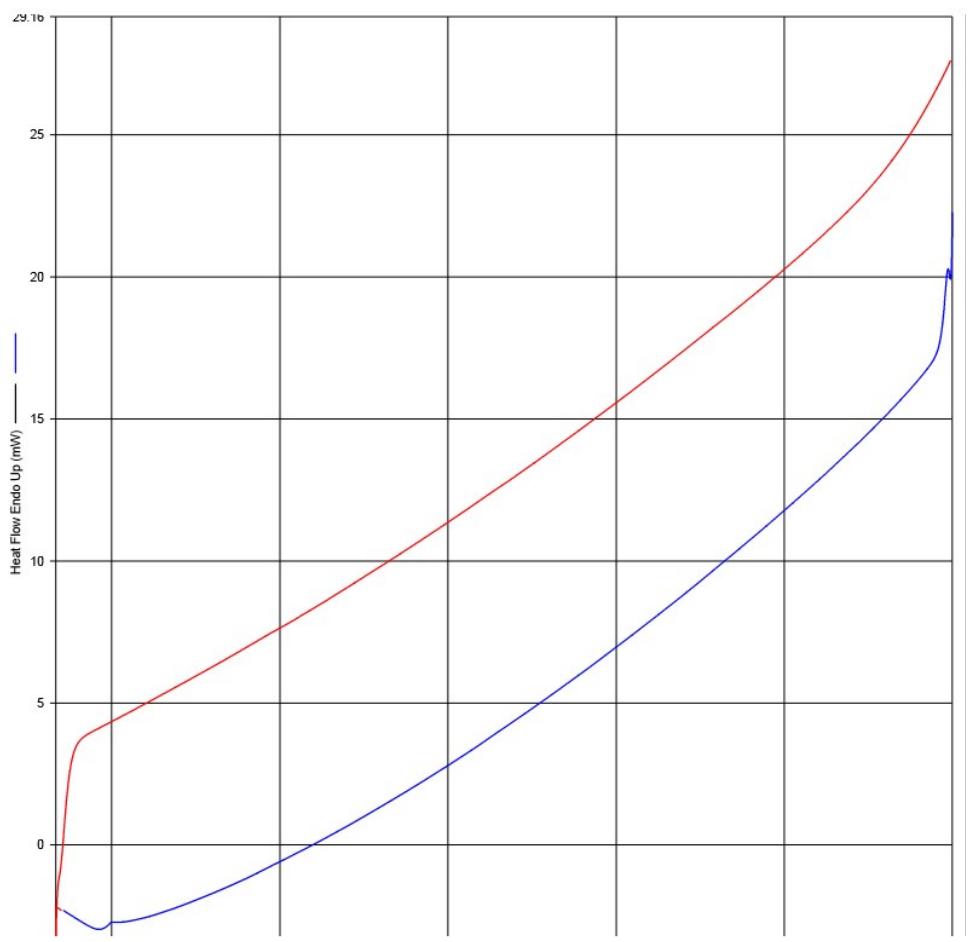

- Moagem de 4 horas

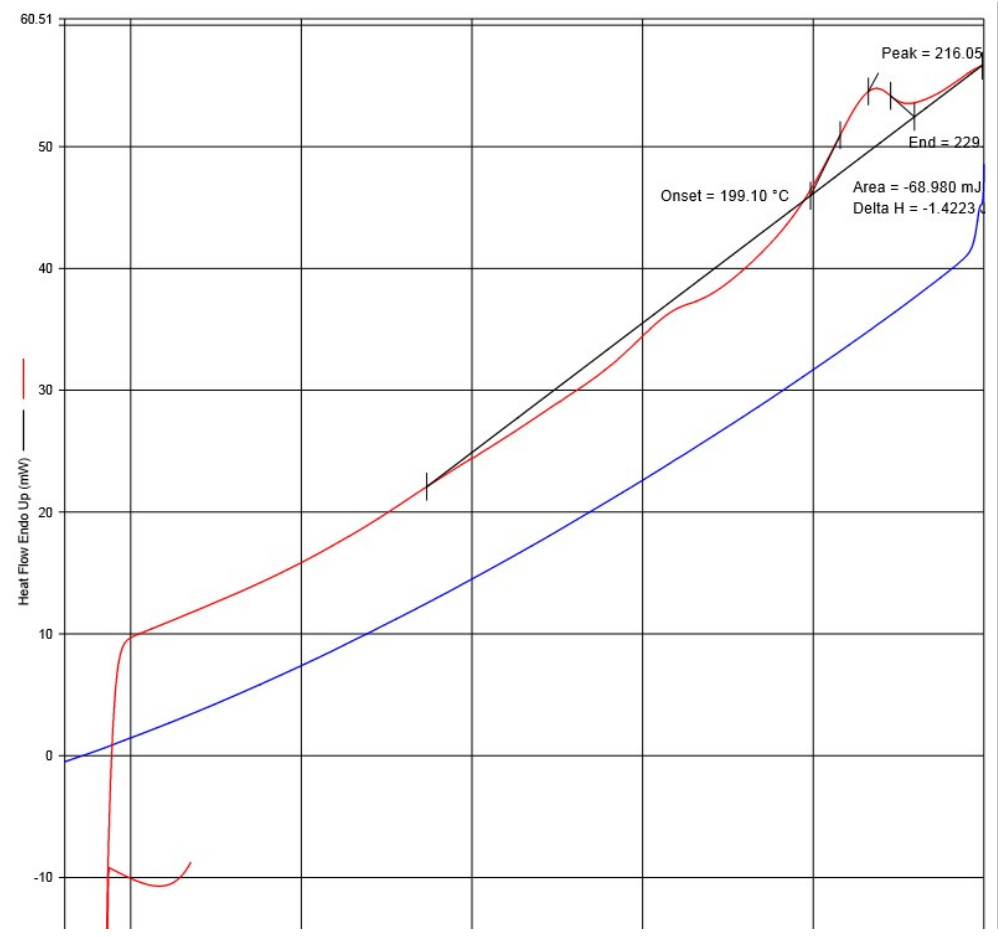


- Moagem de 8 horas

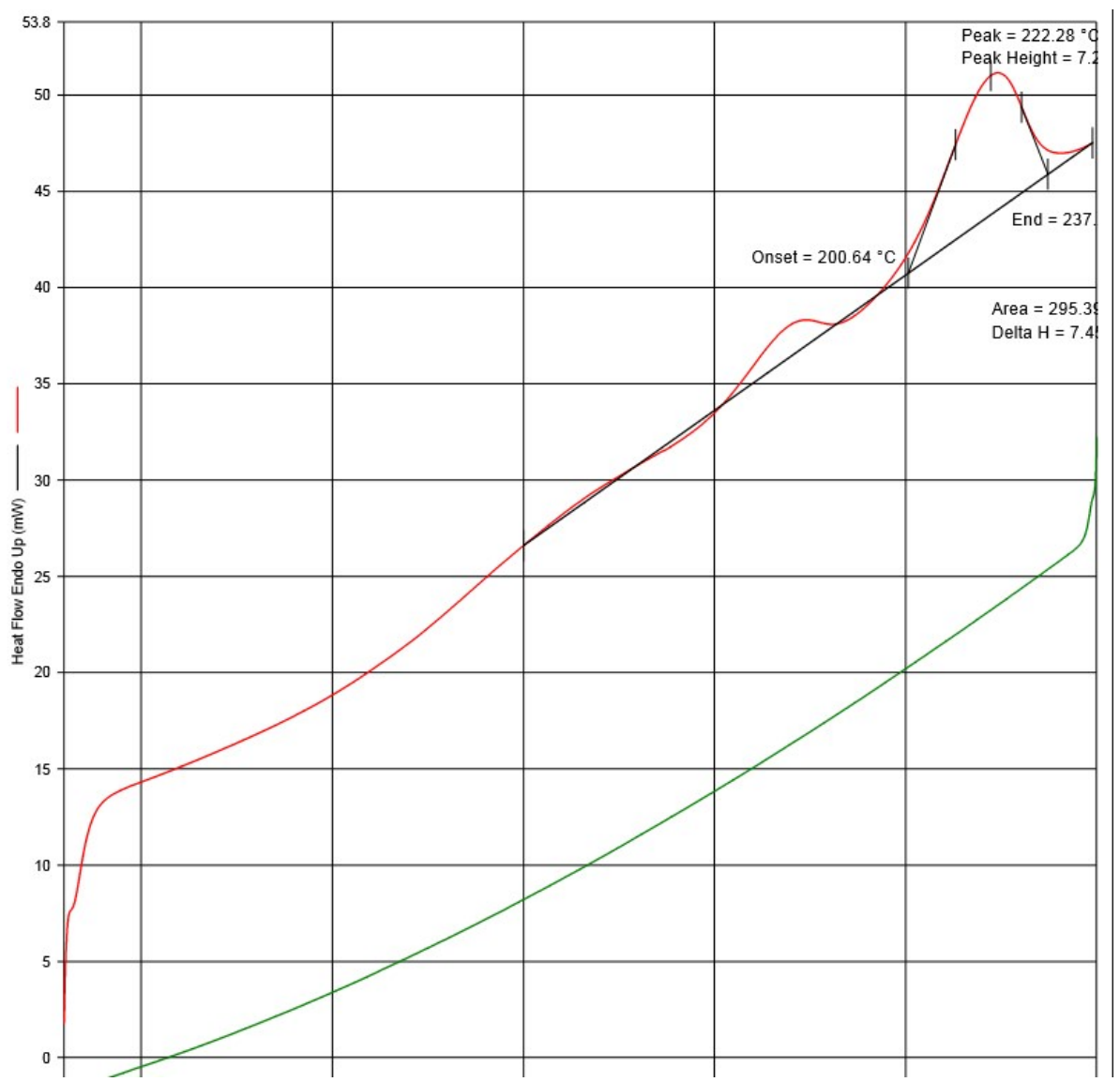

- Moagem de 16 horas

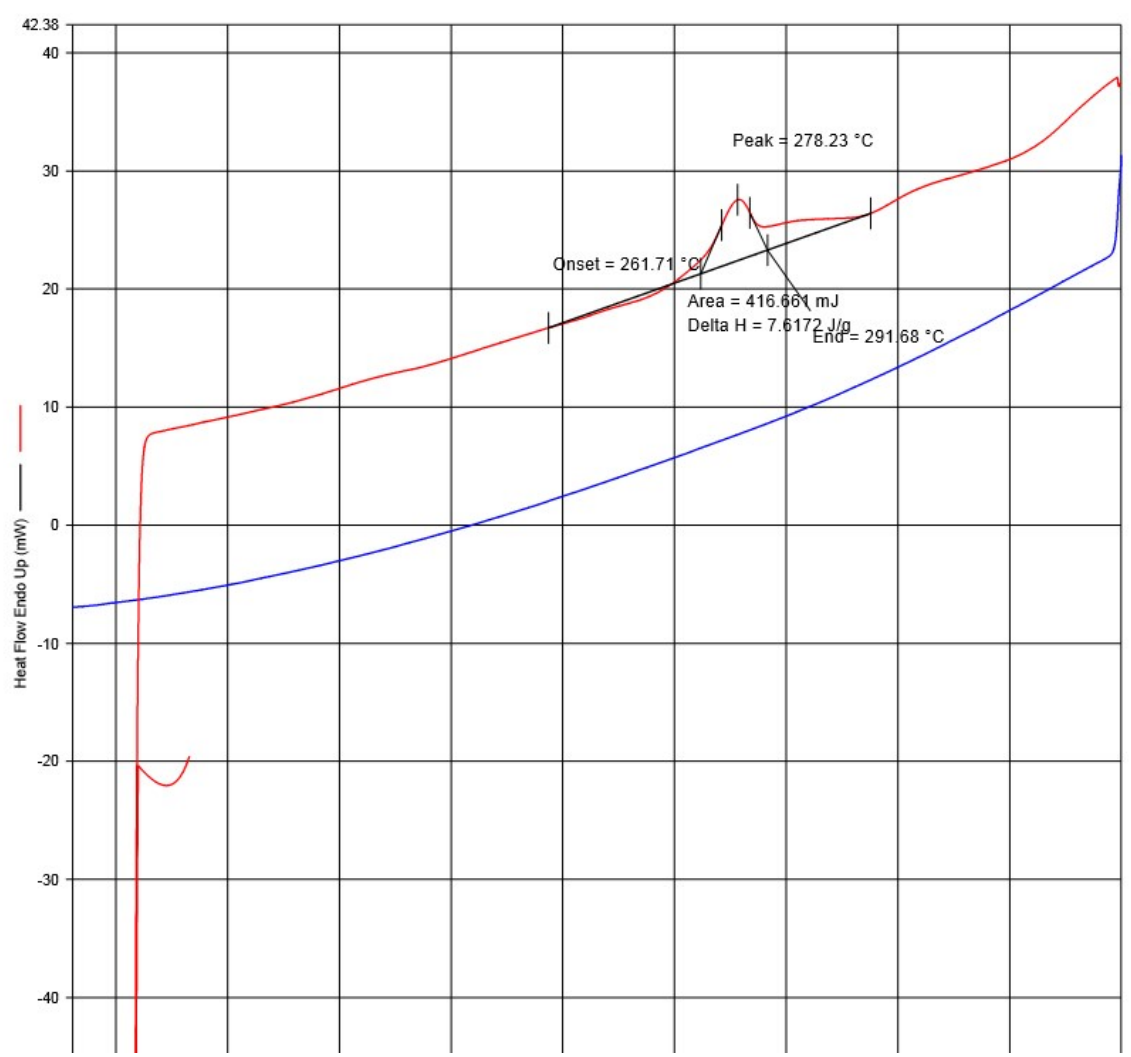


This document was created with Win2PDF available at http://www.win2pdf.com. The unregistered version of Win2PDF is for evaluation or non-commercial use only. This page will not be added after purchasing Win2PDF. 